The Effect of Credit Rationing on the Shape of the Competition-Innovation Relationship

Jan Bena

DISCUSSION PAPER NO 629

DISCUSSION PAPER SERIES

March 2009

Jan Bena joined the FMG as a visiting research assistant in 2004. He gained his PhD in Economics from the Centre for Economic Research and Graduate Education of Charles University (CERGE-EI) in Prague in 2006 and he joined the LSE PhD programme in Finance in the same year. Since 2004, Jan has been a junior researcher at the Economics Institute of the Academy of Sciences of the Czech Republic, and since 2005 he has been working as a tutorial fellow in the Department of Finance at the LSE. Jan's main research interest lies in the area of corporate finance and his current research analyses how limited access to external finance alters corporate investment decisions. 


\title{
The Effect of Credit Rationing on the Shape of the Competition-Innovation Relationship
}

\author{
Jan Bena \\ LSE/FMG
}

November 2008

\begin{abstract}
Using a dynamic model of a step-by-step innovation race between financially constrained firms, I study how financial constraints affect innovation activity. The novel theoretical results derive from an analysis of the interaction between the incentive effect of competition on innovation and the effect competition has on the degree of credit rationing. I find that the negative effect of financial constraints on firm- and aggregate-level R\&D investment is most pronounced at both high and low levels of competition. These predictions are supported by empirical evidence: The competition-innovation relationship has an inverted-U shape in less financially developed systems relative to the benchmark pattern observed in countries with highly developed financial systems. Innovation-enhancing policies implemented through competition reforms ought to be complemented by promoting financial development.
\end{abstract}

Keywords: Innovation, R\&D, Competition, Financial constraints, Credit rationing JEL classification: G15, G31, L13, O31

Acknowledgments: I would like to thank Ron Anderson, Patrick Bolton, Antoine Faure-Grimaud, Denis Gromb, Vassilis Hajivassiliou, Jan Hanousek, Štěpán Jurajda, Sergey Slobodyan, Dimitri Vayanos, David Webb, and Kathy Yuan, as well as the participants in seminars at the Financial Markets Group at LSE for their comments and suggestions.

Address: The Financial Markets Group (FMG), London School of Economics and Political Science, Houghton Street, London WC2A 2AE, United Kingdom. E-mail: j.bena@lse.ac.uk, Web: www.janbena.info, Tel : +44 (0) 207955 6270 . 


\section{Introduction}

Product market competition is the driving force of innovation. Competing firms invest in R\&D in order to innovate and achieve higher market shares or higher total factor productivity growth. ${ }^{1}$ The competition-to-productivity argument guided reforms ranging from the EU's 'Single-Market Programme' and product market reforms in other developed countries to the economic transition of many emerging economies in Central and Eastern Europe or Asia. ${ }^{2}$ However, competition pressure may not be sufficient for reaching high innovation levels and therefore innovation-enhancing policies implemented through an increase in competition may fail.

The three most frequently cited obstacles to innovation by firms in the European Community Innovation Surveys are high cost of innovation, lack of financing, and economic risk. ${ }^{3}$ According to the surveys, large firms are more innovative than small firms by a factor of three to four when innovativeness is measured by $\mathrm{R} \& \mathrm{D}$ spending. A smaller proportion of large firms also reports lack of financing among the most significant obstacles to innovation. These survey findings are consistent with small firms finding it more difficult to raise external finance, ${ }^{4}$ fund R\&D projects, and therefore innovating less. Access to external finance may be one of the key determinants of innovation success. As innovation activities typically involve intangible assets, are complex, and carry high risk, the quality of the financial system is likely to be important for securing outside

\footnotetext{
${ }^{1}$ See Aghion, Harris, Howitt, and Vickers (2001); Blundell, Griffith, and Van Reenen (1999); Nickell (1996); or, more recently, Griffith, Harrison, and Simpson (2006).

${ }^{2}$ See Buigues, Ilzkovitz, and Lebrun (1990) for the EU; Nicoletti and Scarpetta (2005) for OECD countries; Bolton and Roland (1992), Boubakri, Cosset, and Guedhami (2004), Djankov and Murrell (2002), Li (1999), or Roland (2001) for emerging economies.

${ }^{3}$ See Jaumotte and Pain (2005a, 2005b).

${ }^{4}$ See Beck and Demirgüç-Kunt (2006) and Beck, Demirgüç-Kunt, and Maksimovic (2005) for evidence that the effect financial development has on a firm's growth is strongest for the smallest companies. Berger and Udell (2006) devise a framework to study the financing of small and medium enterprises.
} 
financing for high-technology companies, especially in their early stage, and therefore for achieving high innovation levels. ${ }^{5}$

To understand what role external finance plays in $R \& D$, I develop a theory of innovation that examines how the interaction between competition and financial constraints determines R\&D activity and test the predictions of my theory empirically. Specifically, I extend the dynamic model of the step-by-step innovation race of Aghion, Bloom, Blundell, Griffith, and Howitt (2005), who analyze how competition affects aggregate innovation activity. In Aghion et al. (2005), firms innovate by spending effort that is unbounded, and they incur no financial cost while innovating. Their analysis thus omits finance, potentially a very important element in a theory of innovation. The novel feature I add to the current theory of competition and innovation is that firms innovate by investing cash in $R \& D$ and, due to financial frictions, face financial constraints limiting their ability to raise external finance and therefore to invest.

In the model of the step-by-step innovation race, competition drives incentives to innovate by technology leaders and followers. Specifically, the innovation incentives of technology leaders and followers depend upon the difference between post- and pre-innovation rents. If competition reduces pre-innovation rents, it increases the incremental payoff from innovating and encourages R\&D investments aimed at 'escaping competition'. In contrast, if competition reduces post-innovation rents, it discourages innovation (this is the so-called Schumpeterian effect). When I introduce financial constraints into this framework, competition interacts with financial constraints so that two new ways in which competition affects innovation activity emerge: the 'lack-of-internal funds effect' and the 'strategic effect'. Intuitively, the two effects work as follows.

First, competition - through altering profits and hence internal funds - limits the amount firms

\footnotetext{
${ }^{5}$ In their analysis of the Alternative Investment Market (AIM) of the London Stock Exchange, Arcot, Black, and Owen (2007) show that AIM has become an important source of funding for early-stage high-technology companies internationally. They argue that the key driver behind AIM's success and growth is the fact that AIM is embedded in the cluster of skills, experience, and resources which has been built up in the City over many years.
} 
can invest in R\&D on their own. Therefore, in the absence of frictionless financial market, firms may not invest optimally, i.e., according to the difference between post- and pre-innovation rents determined by competition, as their internal funds may be insufficient. The non-trivial dual effect of competition on innovation incentives through rents and, at the same time, internal funds and the degree of credit rationing has not been explored to date. I develop this idea into a structural model of the wedge between the optimal unconstrained and constrained-feasible R\&D investment in which the fundamental parameter is competition.

Second, competition - by affecting how much firms can invest in R\&D as well as how much they would like to invest - determines which firms are constrained and which are not. In industry equilibrium, firms choose their $R \& D$ strategies depending on whether their competitors are constrained or not. Constrained competitors are forced to invest less in R\&D, which increases the post-innovation rents of unconstrained firms, and hence gives them extra innovation incentives. In other words, unconstrained firms react strategically to the fact that their competitors are constrained by increasing their R\&D investment. As a result, there is a new channel through which competition sets incentives to innovate; in addition to the direct effect through rents, there is an indirect strategic effect.

I show that the effect of competition on aggregate innovation intensity differs depending on whether firms have frictionless access to external finance or are subject to financial constraints. In the presence of constraints, the wedge between the first-best and financially-constrained aggregate innovation intensity is positive at both intense and very relaxed levels of competition. When I compare the steady state equilibria of industries with very intense and extremely intense (very relaxed and extremely relaxed) competition levels, the wedge is larger in industries with more extreme competition levels. The intuition behind these results is as follows. When intensely competing firms employ the same technology, they aim at high R\&D investments in order to 'escape competition' by innovating and securing monopoly rents as technology leaders. At the same time, the intensely 
competing firms have low internal funds so the wedge between the preferred and feasible R\&D investment is large when external finance is not available. A different intuition explains the surprising positive wedge when competition is relaxed. Technology laggards have stronger incentives to invest in $\mathrm{R} \& \mathrm{D}$ when their post-innovation rents, i.e., the rents achieved after matching current technology leaders, is high. This is when competition between firms operating the same technology is relaxed. Without frictionless access to external finance, the laggards' profits might be too low to allow high $R \& D$ investment induced by relaxed competition and the positive wedge arises. These results are consistent with the interpretation provided by Fazzari, Hubbard, and Petersen (1988, 2000) and contested by Kaplan and Zingales $(1997,2000)$ for a positive correlation between cash flow and investment. ${ }^{6}$ More interestingly, my model can be used to guide empirical tests in this area: R\&D-cash flow sensitivity is particularly strong when competition is very intense and very relaxed.

The theory of innovation closest to my model is that of Aghion, Dewatripont, and Rey (1999) who analyze the incentive effects of competition and financial market discipline on growth when firms are non profit-maximizing. They model the finance-incentive channel as a corporate governance mechanism of financial markets that elicits innovation activity from slacking managers by enforcing financial contracts and denying renegotiation. ${ }^{7} \quad$ However, their analysis leaves out the effect of competition on the degree of credit rationing, the central argument of my model. In contrast to Aghion, Dewatripont, and Rey (1999), I show that finance has real consequences for innovation even if firms are profit-maximizing. In another related study, Povel and Raith (2004) build on

\footnotetext{
${ }^{6}$ Cleary, Povel, and Raith (2007) conduct an extensive theoretical and empirical analysis of the investment-cash flow sensitivity problem and explain why the two literatures arrive at opposite results. Riddick and Whited (2008) document how difficult it is to assess the cost of external finance based on a firm's saving behavior.

${ }^{7}$ Köke and Renneboog (2005) investigate the effect of corporate governance and competition on productivity growth empirically. Giroud and Mueller $(2007,2008)$ verify that firms in non-competitive industries benefit relatively more from good corporate governance.
} 
an extensive industrial organization literature ${ }^{8}$ to analyze the interaction of financing and output market decisions in a static duopoly framework in which one firm is financially constrained and can borrow to finance production costs. They derive debt as an optimal contract and find that, compared with a situation in which both firms are unconstrained, the financially constrained firm produces less while its unconstrained rival produces more. The mechanism of my model is different from Povel and Raith (2004) in that I use a dynamic model of innovation race in which competition drives R\&D investments of individual firms, the firms' investments determine the aggregate industry structure, and the industry structure feeds back into firms' individual decisions. ${ }^{9}$ The focus of my analysis is to compare steady state equilibria when competing firms have frictionless access to external finance with those when firms are financially constrained.

To empirically test the predictions of my theory, I examine whether the competition-innovation pattern varies across countries with different levels of financial development. ${ }^{10}$ Financial development plays a key role in overcoming market frictions, which represent a fundamental source of external finance cost and give rise to financial constraints. ${ }^{11}$ Financial development proxies the presence of financial constraints at the country level. Applying a difference-in-differences methodology on cross-industry, cross-country European data from the period 1995-2004, I ask whether, for example, Italian financial institutions differ significantly from those of the UK in their ability to provide external finance to firms in industries with very intense and very relaxed competition

\footnotetext{
${ }^{8}$ The effect of exogenously imposed debt on product market decisions is studied in, e.g., Brander and Lewis (1986) or Chevalier and Scharfstein (1996). More recently, Faure-Grimaud (2000) and Maurer (1999) use models where financial contracting is optimally determined together with product market decisions.

${ }^{9}$ Akdoğu and MacKay (2008) empirically investigate how industry structure affects firms' investment decisions by changing the value of the real options they face.

${ }^{10}$ Aghion et al. (2005) investigate the shape of the relationship between competition and innovation and find an inverted-U pattern using a two-digit SIC industry panel of 354 industry-year observations based on an unbalanced panel of 311 UK firms.

${ }^{11}$ See the survey by Levine (1997).
} 
levels relative to their ability to provide external finance to firms in industries with intermediate competition levels.

Using industries with intermediate competition levels as the benchmark group, there is strong evidence of a disproportionate positive effect of financial development on R\&D investment in industries where competition is very intense. The corresponding evidence for industries where competition is relaxed is weaker, but I still find that $R \& D$ investment is disproportionately lower in countries with low financial development compared to countries with highly developed financial systems. In other words, the competition-innovation relationship has an inverted-U shape in less financially developed systems relative to the benchmark pattern observed in countries with highly developed financial systems.

These findings add to an extensive literature on the finance-growth nexus ${ }^{12}$ and suggest a new mechanism for how financial development promotes growth. Financial development helps corporate growth as better financial systems allow financing of firms that invest in R\&D projects independently of their industry's current profitability determined by competition.

The paper proceeds as follows. The next section develops the theory of innovation based on competition and financial constraints and derives testable predictions. Section 3 explains the empirical model and presents results. Section 4 concludes. Proofs are in the Appendix.

\section{A Theory of Innovation Based on Competition and Financial Constraints}

\section{$2.1 \quad$ Model}

Using a dynamic model of a step-by-step innovation race between financially constrained firms, I analyze how product market competition affects innovation activity. The economy has a continuum

\footnotetext{
${ }^{12}$ See King and Levine (1993), Rajan and Zingales (1998), Fisman and Love (2004), or Bena and Jurajda (2007).
} 
of industries indexed by $i \in[0,1]$. Each industry is a duopoly with respect to production and innovation. The duopolists participate in an innovation race and maximize the expected discounted sum of profits from supplying their goods to consumers over an infinite horizon. Time is continuous and the unit mass of identical and infinitely-lived consumers have preferences

$$
U \equiv \int_{0}^{\infty}\left\{\int_{0}^{1} \ln Y_{i}(t) d i-L(t)\right\} e^{-r t} d t
$$

where $Y_{i}(t)$ is the output of industry $i$ at date $t, L(t)$ is labor supplied at date $t$, and $1>r>0$ is the rate of time preference. The micro-model of the interaction between duopolists is analogous to that of Aghion, Bloom, Blundell, Griffith, and Howitt (2002). The logarithmic preferences imply that, in equilibrium, consumers spend a constant proportion of income on the output of each industry $i$ at all dates $t$. The demand functions facing the two firms in any industry $i$ depend on the degree of substitutability between the two goods duopolists produce. Each firm takes the wage as given and produces output using labor as the only input according to a constant-returns-to-scale production function. The unit costs of production of the two firms are independent of the quantities produced.

There is an infinite sequence of technology levels $k=0,1,2, \ldots$. Each firm engages in $\mathrm{R} \& \mathrm{D}$ in order to acquire the next technology level. The technological advantage decreases the firm's unit cost of production relative to its competitor. The state of an industry is described by the pair of technology levels $(k, k-m)$ of a current industry leader and a laggard. $m$ is the laggard's technological gap. To obtain a closed-form solution, I assume that the technological gap between the firms cannot exceed one level. ${ }^{13}$ At any date $t$, an industry is in one of two states: neck-and-neck, $m=0$; or unleveled, $m=1$.

The equilibrium profit of each firm depends on the relative unit production cost of the two firms,

\footnotetext{
${ }^{13}$ The knowledge spillover between the leader and the laggard is such that if the firm, which is already one step ahead, innovates, the lagging firm automatically learns the leader's previous technology. Aghion et al. (2005) use the same assumption. Aghion et al. (2001) analyze the case when $m>1$ and show that the main conclusions are qualitatively equivalent to the one-lag model.
} 
the degree of substitutability between the two goods, and the nature of product market competition. Similarly to Aghion et al. (2005), I follow the reduced-form approach and define $\pi_{1}\left(\pi_{-1}\right)$ to be the profit flow of the leader (the laggard) in the unleveled state and $\pi_{0}$ to be the profit flow of each firm in the neck-and-neck state, where $\pi_{1} \geq \pi_{0} \geq \pi_{-1}>0$ and $\Pi \equiv \pi_{1}-\pi_{-1}>0$. Note that the monopoly rent brought about by technological leadership $\Pi$ is independent of the leader's technology level $k .^{14}$

The intensity of competition is modeled as the degree to which the two firms in the neck-andneck state are able to collude against consumers, which is captured by parameter $\Delta \in\left[\frac{1}{2}, 1\right]$ in the profit flow $\pi_{0} \equiv \pi_{-1}+(1-\Delta) \Pi{ }^{15}$ If competition is intense, $\Delta=1$, each firm earns profit flow $\pi_{-1}$ equal to the laggard's profit flow in the unleveled state. In the opposite case, if competition is relaxed, $\Delta=\frac{1}{2}$, each firm earns profit flow $\pi_{-1}+\frac{1}{2} \Pi$ as the two firms share, in the same proportion, a collusion rent equal to the monopoly rent derived from technological leadership $\Pi{ }^{16}$

Moving one technological step ahead happens at the rate determined by the amount of cash invested in $R \& D$. In the unleveled state, if the laggard invests $y$ in $R \& D$ he innovates and catches up with the leader with a Poisson hazard rate ('innovation intensity') $\sqrt{y}+h$. Parameter $1>h \geq 0$ captures the intensity of the innovation spillover effect. ${ }^{17}$ The leader does not invest in R\&D as she

\footnotetext{
${ }^{14}$ As discussed in Aghion, Harris, and Vickers (1997), in a variety of product market competition settings-including Bertrand and Cournot - firms' equilibrium profit flows depend only on the technological gap and not on the technology level.

${ }^{15}$ An increase in the degree of substitutability between the two goods leads to an analogous reduced-form parameterization of profit flow $\pi_{0}$.

${ }^{16}$ For simplicity, in the version of the model presented here, the monopoly rent derived from technological leadership $\Pi$ is independent of competition (i.e., the advantage of a cost reduction achieved by innovation does not depend on competition). As argued in Boone (2008), more intense competition (brought about by more aggressive interaction among existing firms) makes more efficient firms benefit disproportionately more relative to less efficient firms, which means that $\Pi$ increases with competition. This reinforces the model's predictions: The wedge between the first-best and financially-constrained aggregate innovation intensity is even higher.

${ }^{17}$ The predictions of the model about the effect of financial constraints on innovation activity do not depend on
} 
derives no advantage by innovating. In the neck-and-neck state, by investing $x$ in $\mathrm{R} \& \mathrm{D}$ each firm moves one technological step ahead (becomes the leader) with innovation intensity $\sqrt{x}$.

Finally, I assume that the firms have no access to external finance. In both states, no firm can invest more than its current profit, $x \leq \pi_{0}$ and $y \leq \pi_{-1} \cdot{ }^{18}$ This assumption is strong for two reasons. Firms cannot transfer cash across states of the industry, and they do not have access to any risk-sharing technology (financial system) that allows cash transfers across industries. To study the model including these characteristics is interesting, but not the focus of this paper. This paper answers the question: What is the consequence of financial constraints for innovation activity? Therefore, I contrast the first-best equilibria derived when financial constraints are not present (e.g., when firms decide their R\&D investments based on their incentives only) with corresponding equilibria under no access to external finance.

\subsection{Unconstrained Equilibrium}

I analyze the symmetric stationary Markov equilibrium. Proposition 1 presents the equilibrium R\&D investment $x(y)$ in the neck-and-neck (the unleveled) state which solves each neck-and-neck firm's (the laggard's) optimization problem ignoring the financial constraints.

Proposition 1 1. In the neck-and-neck state, each firm invests

$$
x=\left(\sqrt{(h+r)^{2}+\Delta \Pi}-(h+r)\right)^{2} .
$$

2. In the unleveled state, the laggard invests

$$
y=\left(\sqrt{(h+r)^{2}+\Delta \Pi}-\sqrt{(h+r)^{2}+\Pi+x}\right)^{2} .
$$

whether the innovation spillover effect is present or not. As existing literature typically studies this class of models including the innovation spillover, I solve the model when $h>0$.

${ }^{18}$ I assume the simplest form of financial constraints. No results are changed if firms can only invest a fraction of their profits: $x \leq \alpha \pi_{0}$ and $y \leq \beta \pi_{-1}$, where $\alpha \in(0,1], \beta \in(0,1]$. 
In the next Corollary, I present comparative static properties of equilibrium R\&D investments $x$ and $y$ with respect to the intensity of competition, technological leadership rent, innovation spillover intensity, and rate of time preference.

Corollary 1 1. In the neck-and-neck state, each firm's RESD investment satisfies

$$
\frac{\partial x}{\partial \Delta}>0, \frac{\partial x}{\partial \Pi}>0, \frac{\partial x}{\partial h}<0, \text { and } \frac{\partial x}{\partial r}<0 .
$$

2. In the unleveled state, the laggard's RED investment satisfies

$$
\frac{\partial y}{\partial \Delta}<0, \frac{\partial y}{\partial \Pi}>0, \frac{\partial y}{\partial h}<0, \text { and } \frac{\partial y}{\partial r}<0 .
$$

In the neck-and-neck state, an increase in competition decreases current profit $\pi_{0}$ and increases the incremental payoff from innovating for fixed $\pi_{1}$. Therefore, the incentive to innovate and the R\&D investment of each firm in the neck-and-neck state increases with competition - the 'escapecompetition' effect (Aghion, Harris, and Vickers, 1997). ${ }^{19}$ In contrast, the laggard's R\&D investment decreases with competition. This is because for a given technological leadership rent $\Pi$, the laggard's incentive to innovate increases with profit $\pi_{0}$ he gets when he catches up with the leader. As profit $\pi_{0}$ decreases if competition intensifies, more intense competition lowers the incremental payoff from successful innovation and disincentivizes R\&D investment (the so-called Schumpeterian effect).

In both states, the firms' R\&D investments increase with the technological leadership rent and decrease with the innovation spillover intensity and rate of time preference. The former result obtains because the difference between the value of being the leader and the laggard increases with the technological leadership rent. The latter result obtains because an increase in the innovation

\footnotetext{
${ }^{19}$ In the extreme case, when $\Delta=1$, the profit of each firm in the neck-and-neck state is $\pi_{0}=\pi_{-1}$ and the incremental payoff from a successful innovation is $\Pi$. In contrast, when $\Delta=\frac{1}{2}$, the profit of each firm in the neck-and-neck state is $\pi_{0}=\pi_{-1}+\frac{1}{2} \Pi$ as each firm already enjoys a collusion rent equal to half of the technological leadership rent. In this case, the incremental payoff from successful innovation is only $\frac{1}{2} \Pi$.
} 
spillover intensity (the rate of time preference) crowds out incentives to innovate by investing in R\&D in both states (lowers payoffs from innovating through heavier discounting).

As the economy has a continuum of industries of mass one and each industry is either in the unleveled or in the neck-and-neck state, the aggregate innovation intensity is the weighted sum of the two firms' innovation intensities in the neck-and-neck state and the laggard's innovation intensity in the unleveled state, $I \equiv 2 \lambda \sqrt{x}+(1-\lambda)(\sqrt{y}+h)$. Weights $\lambda$ and $(1-\lambda)$ are the fractions of industries in the two states, respectively. Fraction $\lambda$ is endogenous as it depends on the firms' R\&D investments in the two states. Corollary 2 presents the steady state ${ }^{20}$ equilibrium aggregate innovation intensity as a function of $\mathrm{R} \& \mathrm{D}$ investments $x$ and $y$, as well as its comparative static properties with respect to the intensity of competition and innovation spillover intensity.

Corollary 2 1. The aggregate innovation intensity is

$$
I=\frac{4 \sqrt{x}(\sqrt{y}+h)}{2 \sqrt{x}+\sqrt{y}+h}
$$

2. When the innovation spillover effect is absent, the aggregate innovation intensity decreases with competition: $\frac{\partial I}{\partial \Delta}<0$ when $h=0$.

3. When the innovation spillover intensity is sufficiently high, the competition-aggregate innovation relationship has an inverted- $U$ shape: $\frac{\partial I}{\partial \Delta}>0$ for $\Delta \in\left[\frac{1}{2}, \Delta_{\text {peak }}\right)$ and $\frac{\partial I}{\partial \Delta}<0$ for $\Delta \in\left(\Delta_{\text {peak }}, 1\right]$.

4. The aggregate innovation intensity has an inverted- $U$ shape with respect to the innovation spillover intensity: $\frac{\partial I}{\partial h}>0$ for $h \in\left[0, h_{\text {peak }}\right)$ and $\frac{\partial I}{\partial h}<0$ for $\Delta \in\left(h_{\text {peak }}, 1\right]{ }^{21}$

Aggregate innovation intensity $I$ is established as an endogenous combination of the 'escapecompetition' and the Schumpeterian effects that drive firm-level R\&D investments in the two states.

\footnotetext{
${ }^{20}$ In the steady state, the flow of industries from the neck-and-neck state to the unleveled state matches the opposite flow, $2 \lambda \sqrt{x}=(1-\lambda)(\sqrt{y}+h)$.

${ }^{21}$ Explicit formulas for threshold quantities $\Delta_{\text {peak }}$ and $h_{p e a k}$ are in Appendix C.
} 
If there is no innovation spillover effect $(h=0)$, most industries are in the unleveled state in which only the Schumpeterian effect operates, and the aggregate innovation intensity always decreases with competition. A positive innovation spillover effect $(h>0)$ makes more industries switch from the unleveled to the neck-and-neck state and the Schumpeterian effect no longer dominates. When the innovation spillover intensity is sufficiently high, the fraction of industries that are in the neck-andneck state is high enough for the 'escape-competition' effect to win over the Schumpeterian effect. The 'escape-competition' effect wins earlier if competition is low as, in this case, the laggards invest a lot in $\mathrm{R} \& \mathrm{D}$ which pushes the fraction of industries that are in the neck-and-neck state further up. As a result, the aggregate innovation intensity increases with competition at low competition levels while it decreases with competition at high competition levels. ${ }^{22}$

Interestingly, despite the fact that the firms' R\&D investments are decreasing in the innovation spillover intensity in both states, the aggregate innovation intensity has an inverted-U shape with respect to $h$. This result obtains because higher innovation spillover intensity reduces the firms' incentives to invest in $R \& D$ in both states, but the laggard innovates more often for any $R \& D$ investment level. At low levels of innovation spillover intensity, most industries are in the unleveled state where only the laggards invest in R\&D. In this case, if the innovation spillover intensity increases, the negative effect on the laggards' incentives to invest in $R \& D$ is dominated by their extra innovating due to a higher innovation spillover. As a result, the aggregate innovation intensity increases if the innovation spillover effect increases from an initially low level. At high levels of innovation spillover intensity, more industries are in the neck-and-neck state where both firms invest in R\&D and - as they employ the same technology - do not innovate due to the innovation spillover effect. Therefore, if the innovation spillover intensity is high and increases, the negative effect on incentives to invest in $\mathrm{R} \& \mathrm{D}$ dominates and the aggregate innovation intensity decreases.

\footnotetext{
${ }^{22}$ This confirms Aghion et al.'s (2005) competition-innovation inverted-U result. Interestingly, the necessary condition for the inverted- $\mathrm{U}$ is $h>0$. I verified that the same necessary condition is present in Aghion et al. (2005).
} 


\subsection{Binding Financial Constraints}

In the previous section, I solved for the equilibrium in the absence of financial constraints. Proposition 2 characterizes the parameter space for which the unconstrained equilibrium of Proposition 1 does not exist as the financial constraints are violated, i.e., $x>\pi_{0}$ or $y>\pi_{-1}$.

Proposition 2 1. In the neck-and-neck state, each firm's RESD investment exceeds profit, $x>$ $\pi_{0}$, if and only if

$$
\pi_{-1}<\frac{\pi_{1}}{2} \text { and } \frac{\pi_{1}}{2 \Pi}<\Delta \text { and } h+r<\frac{2 \Delta \Pi-\pi_{1}}{2 \sqrt{\pi_{1}-\Delta \Pi}} .
$$

The necessary condition for $x>\pi_{0}$ is $\Delta>\bar{\Delta}$, where $\bar{\Delta}$ is the competition level at which the financial constraint of a firm in the neck-and-neck state is just satisfied

$$
\bar{\Delta} \equiv \frac{\pi_{1}+(h+r)\left(\sqrt{(h+r)^{2}+2 \pi_{1}}-(h+r)\right)}{2 \Pi} .
$$

2. In the unleveled state, when $h=0$ and $r=0$, the laggard's $R \mathscr{B} D$ investment exceeds profit, $y>\pi_{-1}$, if and only if

$$
\begin{aligned}
& \left(\pi_{-1}<\frac{2-\sqrt{2}}{4} \pi_{1}\right) \text { or }\left(\pi_{-1}=\frac{2-\sqrt{2}}{4} \pi_{1} \text { and } \Delta<1\right) \text { or } \\
& \left(\frac{2-\sqrt{2}}{4} \pi_{1}<\pi_{-1}<\frac{3-\sqrt{3}}{6} \pi_{1} \text { and } \Delta<\frac{\left(\Pi-\pi_{-1}\right)^{2}}{4 \pi_{-1} \Pi}\right) .
\end{aligned}
$$

When $h+r>0$, the necessary condition for $y>\pi_{-1}$ is $\Delta<\underline{\Delta}$, where $\underline{\Delta}$ is the competition level at which the laggard's financial constraint is just satisfied

$$
\underline{\Delta} \equiv \frac{\left(\Pi-\pi_{-1}\right)^{2}+4(h+r)^{2}\left[\Pi-2 \pi_{-1}-2(h+r) \sqrt{\pi_{-1}}\right]}{4\left(\sqrt{\pi_{-1}}+h+r\right)^{2} \Pi} .
$$

Since firms' R\&D investments are increasing in the technological leadership rent in both states, a high-enough leadership rent is sufficient for the firms' financial constraints to become binding. In contrast, the effect of competition on financial constraints is opposite in the two states. A firm in the neck-and-neck state becomes financially constrained if competition is intense enough, while the laggard's financial constraint is binding when competition is relaxed. This follows from the fact that 
the R\&D investment of a firm in the neck-and-neck state (of the laggard) increases (decreases) with competition and therefore it hits the limit set by the profit at a high (low) competition level. In Proposition 2, I present the threshold competition intensities $\underline{\Delta}(\bar{\Delta})$ at which the financial constraint of the laggard (of a firm in the neck-and-neck state) is just satisfied.

Quantities $\underline{\Delta}$ and $\bar{\Delta}$ split all admissible competition levels into three regions: (i) The relaxed competition region, $\Delta \in\left[\frac{1}{2}, \underline{\Delta}\right]$, in which the laggard is financially constrained; (ii) The intermediate competition region, $\Delta \in(\underline{\Delta}, \bar{\Delta})$, in which the unconstrained equilibrium of Proposition 1 exists; (iii) The intense competition region, $\Delta \in[\bar{\Delta}, 1]$, in which the firms in the neck-and-neck state are constrained. The necessary and sufficient condition for the existence of these three competition regions, i.e., $\frac{1}{2}<\underline{\Delta}<\bar{\Delta}<1$, is stated in Appendix $\mathrm{C}$ while proving Proposition 2.

An increase in the innovation spillover intensity (in the rate of time preference) makes the financial constraints binding for a smaller set of competition levels in both states $(\underline{\Delta}$ decreases and $\bar{\Delta}$ increases). This is because, for given profits $\pi_{1}, \pi_{-1}$ and competition level $\Delta$, a higher innovation spillover intensity (rate of time preference) decreases the firms' R\&D investments in both states. Similarly, an increase in $\pi_{1}$ (or a decrease in $\pi_{-1}$ ) makes the set of competition levels for which the financial constraints are binding larger. ${ }^{23}$

To summarize, the effect of a competition increase (decrease) on the degree to which firms' financial constraints are binding is non-trivial. Technology laggards become less (more) constrained while firms operating similar technology become more (less) constrained. These results are illustrated in Figure 1.

\footnotetext{
${ }^{23}$ See the proof of Proposition 2 in Appendix C for a complete comparative static analysis of threshold intensities $\underline{\Delta}$ and $\bar{\Delta}$.
} 


\subsection{Financially Constrained Equilibrium}

In this section, I describe the firms' equilibrium R\&D investments and the equilibrium aggregate innovation intensity in the presence of financial constraints. Proposition 3 presents the equilibrium R\&D investments which solve the optimization problem of a firm in the neck-and-neck state and the optimization problem of the laggard when their financial constraints are binding.

Proposition 3 Consider the model under the set of parameters $\left\{\pi_{1}, \pi_{-1}, h, r\right\}$ such that $\frac{1}{2}<\Delta<$ $\bar{\Delta}<1$.

1. In the relaxed competition region, $\Delta \in\left[\frac{1}{2}, \underline{\Delta}\right]$, the laggard's $R \mathscr{E} D$ investment is $y_{c}=\pi_{-1}$, while each firm in the neck-and-neck state invests $x_{u}$.

2. In the intense competition region, $\Delta \in[\bar{\Delta}, 1]$, the laggard's REDD investment is $y_{u}$, while each firm in the neck-and-neck state invests $x_{c}=\pi_{0} \cdot{ }^{24}$

In Corollary 3, I compare R\&D investments $x_{u}$ and $y_{u}$ with their counterparts derived in the case of no financial constraints (Proposition 1).

Corollary 3 Consider the model under the set of parameters $\left\{\pi_{1}, \pi_{-1}, h, r\right\}$ such that $\frac{1}{2}<\triangleq<$ $\bar{\Delta}<1$.

1. In the relaxed competition region, $\Delta \in\left[\frac{1}{2}, \Delta\right]$, each firm's $R \mathscr{E} D$ investment in the neck-andneck state satisfies

$$
x_{u}>x \text { for } \Delta \in\left[\frac{1}{2}, \underline{\Delta}\right) \text { and } x_{u}=x \text { at } \Delta=\underline{\Delta} .
$$

2. In the intense competition region, $\Delta \in[\bar{\Delta}, 1]$, the laggard's $R \mathscr{B} D$ investment satisfies

$$
y_{u}>y \text { for } \Delta \in(\bar{\Delta}, 1] \text { and } y_{u}=y \text { at } \Delta=\bar{\Delta} \text {. }
$$

Relative to the model of section 2.2 with no financial constraints, the laggard's R\&D investment has to be lower in the relaxed competition region as his financial constraint binds. This decreases

\footnotetext{
${ }^{24}$ Explicit formulas $x_{u}$ and $y_{u}$ are in Appendix C.
} 
the probability that the laggard catches up with the leader, and that means the industry is in the unleveled state with a higher probability at any point in time, which increases (decreases) the value of being the leader (the laggard) for given $\pi_{1}, \pi_{-1}, h$, and $r$. For the same reason, the incremental payoff from becoming the leader (the laggard) if a firm is currently in the neckand-neck state increases (decreases) and therefore its R\&D investment is higher, $x_{u}>x$. At the threshold competition intensity $\underline{\Delta}$, the R\&D investment of each firm in the neck-and-neck state is the same as in the case with no financial constraints, $x_{u}=x$. The laggard's incentive is to maximize the probability of leaving the unleveled state, his financial constraint is binding, and his $\mathrm{R} \& \mathrm{D}$ investment is limited at $y_{c}=\pi_{-1}$ for all $\Delta \in\left[\frac{1}{2}, \underline{\Delta}\right]$.

The presence of financial constraints changes the way competition affects the firms' $R \& D$ investments. Within the relaxed competition region, a higher competition level does not make the laggard invest less in R\&D. His financial constraint is binding and he invests all his profit - the Schumpeterian effect of higher competition does not unfold. In contrast, the 'escape-competition' effect of the neck-and-neck state is stronger in comparison to the case with no financial constraints, as the incremental payoff achieved when a firm becomes the leader is higher.

A similar intuition works when firms in the neck-and-neck state are constrained. Relative to the no-financial-constraints model, the R\&D investment of each firm in the neck-and-neck state has to be lower within the intense competition region as their financial constraints are binding. Lower neck-and-neck state R\&D investment means that the industry is in this state with a higher probability at any point in time. For given $\pi_{1}, \pi_{-1}, h$, and $r$, this increases the incremental payoff of the laggard from switching into the neck-and-neck state and therefore induces him to invest more in $\mathrm{R} \& \mathrm{D}, y_{u}>y$. At the threshold competition intensity $\bar{\Delta}$, the laggard's R\&D investment is the same as in the case with no financial constraints, $y_{u}=y$. The laggard's extra incentive to switch to the neck-and-neck state and to increase his $R \& D$ investment above $y$ is lower the higher the competition level. This is because intense competition reduces $\pi_{0}$ and makes the neck-and-neck 
state less desirable. The value of a firm in the neck-and-neck state is lower, the bigger the deviation of its R\&D investment from the optimal unconstrained level. Therefore, the financial constraints in the neck-and-neck state are binding and the equilibrium R\&D investment of each firm is limited at $x_{c}=\pi_{0}$ for all $\Delta \in[\bar{\Delta}, 1]$.

In contrast to the case without financial constraints, a higher competition level within the intense competition region is associated with lower $\mathrm{R} \& \mathrm{D}$ investments of firms in the neck-and-neck state. These firms want to invest a lot to escape very high competition but, as $\pi_{0}$ decreases with competition, they have only a small amount of cash available, which makes the effect of a competition increase particularly strong. The wedge between the no-financial-constraints and the financiallyconstrained $\mathrm{R} \& \mathrm{D}$ investment is larger the closer the competition level is to its maximum level. The presence of financial constraints in the neck-and-neck state reverses the 'escape-competition' effect.

Quantities $x_{u}, x_{c}, y_{u}$, and $y_{c}$ are presented in Figure 2. The R\&D investment of a firm in the neck-and-neck state (the laggard) in the relaxed competition region, $x_{u}\left(y_{c}\right)$, is depicted using the red (light) solid lines in the top (bottom) right graph of Figure 2. The same two graphs depict the R\&D investment of a firm in the neck-and-neck state (the laggard) in the intense competition region, $x_{c}\left(y_{u}\right)$. Finally, for ease of comparison, the blue (dark) dashed lines depict the corresponding optimal R\&D investments in the no-financial-constraints model.

Corollary 4 presents the steady state equilibrium aggregate innovation intensity as a function of $\mathrm{R} \& \mathrm{D}$ investments $x_{u}$ and $y_{c}\left(x_{c}\right.$ and $\left.y_{u}\right)$ in the relaxed (intense) competition region. It also compares the aggregate innovation intensity with the one derived in the case of no financial constraints (Corollary 2).

Corollary 4 Consider the model under the set of parameters $\left\{\pi_{1}, \pi_{-1}, h, r\right\}$ such that $\frac{1}{2}<\underline{\Delta}<$ $\bar{\Delta}<1$.

1. In the relaxed competition region, $\Delta \in\left[\frac{1}{2}, \underline{\Delta}\right]$, the aggregate innovation intensity is $I_{\left\{x_{u}, y_{c}\right\}}=$ 
$\frac{4 \sqrt{x_{u}}\left(\sqrt{y_{c}}+h\right)}{2 \sqrt{x_{u}}+\sqrt{y_{c}}+h}$ and satisfies

$$
I_{\left\{x_{u}, y_{c}\right\}}<I \text { for } \Delta \in\left[\frac{1}{2}, \underline{\Delta}\right) \text { and } I_{\left\{x_{u}, y_{c}\right\}}=I \text { at } \Delta=\underline{\Delta} \text {. }
$$

2. In the intense competition region, $\Delta \in[\bar{\Delta}, 1]$, the aggregate innovation intensity is $I_{\left\{x_{c}, y_{u}\right\}}=$ $\frac{4 \sqrt{x_{c}}\left(\sqrt{y_{u}}+h\right)}{2 \sqrt{x_{c}}+\sqrt{y_{u}}+h}$ and satisfies

$$
I_{\left\{x_{c}, y_{u}\right\}}<I \text { for } \Delta \in(\bar{\Delta}, 1] \text { and } I_{\left\{x_{c}, y_{u}\right\}}=I \text { at } \Delta=\bar{\Delta} \text {. }
$$

The aggregate innovation intensities $I_{\left\{x_{u}, y_{c}\right\}}$ and $I_{\left\{x_{c}, y_{u}\right\}}$ are derived using the steady state condition that the flow of industries from the neck-and-neck state to the unleveled state matches the opposite flow. The flows are determined by the firms' R\&D investments $\left\{x_{u}, y_{c}\right\}$ and $\left\{x_{c}, y_{u}\right\}$ in the relaxed and the intense competition region, respectively. The aggregate innovation intensities $I_{\left\{x_{u}, y_{c}\right\}}$ and $I_{\left\{x_{c}, y_{u}\right\}}$ are strictly below the unconstrained aggregate innovation intensity inside both extreme competition regions and are equal to it at the threshold competition levels $\underline{\Delta}$ and $\bar{\Delta}$.

Quantities $I, I_{\left\{x_{u}, y_{c}\right\}}$, and $I_{\left\{x_{c}, y_{u}\right\}}$ are displayed in the top left graph of Figure 2. The blue inverted-U line which depicts the aggregate innovation intensity of the model with no financial constraints has three segments: The solid middle part, where the unconstrained equilibrium of Proposition 1 exists; and the two dashed parts, which depict the aggregate innovation intensity of Corollary 2 ignoring financial constraints. The aggregate innovation intensities of the model with financial constraints are depicted in the same graph using solid red lines in both constrained regions: $I_{\left\{x_{u}, y_{c}\right\}}$ for $\Delta \in\left[\frac{1}{2}, \Delta\right]$ and $I_{\left\{x_{c}, y_{u}\right\}}$ for $\Delta \in[\bar{\Delta}, 1]$.

When I compare the steady state equilibria of industries with very intense and extremely intense (very relaxed and extremely relaxed) competition levels, the wedge between the unconstrained and the financially constrained aggregate innovation intensity is larger in the industries with extreme levels. The competition-innovation relationship has a more pronounced inverted-U shape in the presence of financial constraints. The wedge is especially marked if the competition level is close to its maximum. In this case, the $R \& D$ investments of both firms in the neck-and-neck state are 
severely constrained by their low profits. The result of low R\&D investments is that many industries are in the neck-and-neck state, thus many industries invest only a small amount in $\mathrm{R} \& \mathrm{D}$, and the aggregate innovation intensity is very low. Without access to external finance the firms are trapped in the neck-and-neck state and the economy is in high competition, low profit, and low innovation equilibrium.

The negative direct effect of financial constraints on aggregate innovation intensity is partially offset by the fact that the unconstrained firm strategically increases its R\&D investment if it faces a constrained competitor. To illustrate the magnitude of this effect, the top left graph of Figure 2 also depicts (red dashed lines) the aggregate innovation intensities under the assumption that the unconstrained firm does not change its $\mathrm{R} \& \mathrm{D}$ investment in response to the fact that its competitor is constrained..$^{25}$

Finally, to facilitate intuition on how the firms' R\&D investments are combined into the aggregate innovation intensity in industry equilibrium, the bottom left graph of Figure 2 shows the equilibrium probabilities of an industry to be in the neck-and-neck state as a function of competition.

\subsection{Testable Predictions}

The main aggregate-level prediction follows from Corollary 4, which states that the effect of competition on aggregate innovation intensity differs depending on whether firms have frictionless access to external finance or are subject to financial constraints. In the presence of constraints, there is a positive wedge between the first-best and financially-constrained aggregate innovation intensity at both intense and very relaxed levels of competition. In addition, when I compare the steady state equilibria of industries with very intense and extremely intense (very relaxed and extremely relaxed)

\footnotetext{
${ }^{25}$ The red dashed lines show the aggregate innovation intensity determined as follows. For $\Delta \in\left[\frac{1}{2}, \underline{\Delta}\right]$, the laggard invests $y_{c}=\pi_{-1}$ and each firm in the neck-and-neck state invests $x$ (part one of Proposition 1 ). For $\Delta \in[\bar{\Delta}, 1]$, each firm in the neck-and-neck state invests $x_{c}=\pi_{0}$ and the laggard invests $y$ (part two of Proposition 1).
} 
competition levels, the wedge is larger in industries with more extreme competition levels. Empirically, one can contrast the competition-innovation pattern across economies with/without financial constraints, e.g., across countries with highly- and less developed financial systems. Specifically, the slope of the competition-innovation pattern in less financially developed systems is steeper relative to the benchmark observed in countries with highly developed financial systems for very relaxed as well as intense competition levels. The slope is the same at intermediate competition levels (see the top left graph of Figure 2). This prediction is tested in section 3 .

In addition, there are multiple micro-level predictions that are testable if one is able to (i) empirically distinguish the neck-and-neck from the unleveled industries; (ii) measure innovation at the firm level; and (iii) identify financially constrained firms. First, the model has predictions about firms in industries with low productivity dispersion (firms in the neck-and-neck state) and high competition (the intense competition region according to the notation of my model). When firms in such industries have frictionless access to external finance, higher competition is associated with higher innovation (part one of Corollary 1), while the opposite holds if the same firms are financially constrained (part two of Proposition 3). Second, the model has predictions about relatively lowproductive firms in industries with high productivity dispersion (laggards in the unleveled state) and low competition (the relaxed competition region of my model). When firms in such industries have frictionless access to external finance, higher competition is associated with lower innovation (part two of Corollary 1), while innovation does not change with competition if the same firms are financially constrained (part one of Proposition 3). I test the firm-level predictions in Bena (2008) using European Patent Office data matched with financial statements from the Amadeus database for the period 1997-2005. 


\section{Empirical Analysis}

In this section I explain the empirical model, describe the data, and present the results from testing whether the aggregate predictions of the theory are consistent with real data.

\subsection{Methodology}

Consistent with the theory, my empirical approach maintains that the primary channel through which competition affects innovation is economic rent. ${ }^{26}$ Rents are determined by competition, but they also depend on productivity which is driven by innovation (Griffith, Harrison, and Simpson, 2006). Therefore, trying to disentangle the effect of competition on innovation empirically raises a fundamental identification problem: one needs to isolate the part of variation in competition that is unrelated to innovation. I address the endogeneity by using a set of instruments that provides an exogenous variation in the degree of competitiveness across industries and countries. The instruments indicate (ex-ante) the industry-country pairs expected to be affected by introduction of the EU's product market reform ('single market' launched in 1993) because of the pre-existing barriers to competition. The corresponding empirical model is

$$
\begin{aligned}
R \& D_{i c t} & =\alpha_{1}+\beta_{1} \cdot \varphi\left(\text { Margin }_{i c t}\right)+\eta_{i}+\gamma_{c}+\delta_{t}+\zeta_{i c t} \\
\text { Margin }_{i c t} & =\alpha_{2}+S M P_{i c}^{\prime} \cdot \beta_{2}+\eta_{i}+\gamma_{c}+\delta_{t}+\varepsilon_{i c t},
\end{aligned}
$$

\footnotetext{
${ }^{26}$ Existing empirical work also uses economic rent: Gorodnichenko, Švejnar, and Terrell (2007), Griffith, Harrison, and Simpson (2006), Nickell (1996), or Nickell, Nicolitsas, and Dryden (1997). Alternatives to the price-cost margin (economic rent) are measures of market concentration (concentration ratios, Herfindahl-Hirschman index, number of firms), the elasticity of a firm's profit with respect to its cost level (Boone, van Ours, and van der Wiel, 2007), and the relative profit difference (Boone, 2008). Contrary to first-hand intuition, Sutton (2007) shows that, under general assumptions, an increase in competition leads to higher concentration and a lower number of firms surviving in the market. This is due to the reallocation effect: If competition increases, more efficient firms gain at the expense of less efficient firms (intensive margin), and less efficient firms leave the market (extensive margin). Boone's measures correct for the reallocation effect but require detailed firm-level data that are unavailable in a large cross-section.
} 
where Margin $_{i c t}$ denotes a price-cost margin of industry $i$ in country $c$ in year $t$, and $R \& D_{i c t}$ denotes total R\&D expenditures. Function $\varphi()$ stands for non-linear semi-parametric specifications, as my model predicts a non-linear pattern. Margin $_{\text {ict }}$ is an endogenous variable in the innovation equation (1a). Vector $S M P_{i c}^{\prime}$ contains $L$ instruments excluded from $(1 a)$. Industry, country, and year dummies that control for industry-, country-, and annual-specific unobservable exogenous factors in both equations are denoted as $\eta_{i}, \gamma_{c}$, and $\delta_{t}$, respectively. The inclusion of dummy variables transforms the data relative to industry-, country-, and annual means and the main coefficient of interest $\beta_{1}$ is identified by comparing affected (not affected) industries in a subset of countries with the same industries that are not affected (are affected) in the counterpart countries.

The empirical measures of competition and innovation used in $(1 a)$ have theoretical counterparts as follows. According to the model, the empirical measure of competition, Margin $_{i c t}$, has an expected value of $2 \lambda \pi_{0}+(1-\lambda)\left(\pi_{1}+\pi_{-1}\right)$ and is strictly decreasing in theoretical measure of competition $\Delta$ in both the unconstrained as well as financially constrained equilibrium. Similarly, the empirical measure of innovation activity, $R \& D_{i c t}$, has an expected value of $2 \lambda x+(1-\lambda) y$ and is strictly increasing in $\Delta$ in the unconstrained equilibrium. Therefore, when there are no financial constraints the model predicts that $R \& D_{i c t}$ decreases with Margin $_{i c t}$; in other words, more intense competition as measured by the price-cost margin leads to a higher innovation activity as measured by $R \& D$ investment. In the financially constrained equilibrium, the empirical measure of innovation, $R \& D_{i c t}$, has an expected value of $2 \lambda x_{u}+(1-\lambda) y_{c}$ in the relaxed competition region (strictly increasing in $\Delta$ ), while it has an expected value of $2 \lambda x_{c}+(1-\lambda) y_{u}$ in the intense competition region (strictly decreasing in $\Delta$ ). Moreover, there is a wedge between the first-best and financially constrained empirical measure of innovation activity, $R \& D_{i c t}$, when the empirical measure of competition, Margin ict, is both high (intense competition region) and low (relaxed competition region). 
To test the main prediction of the model, I investigate the competition-innovation pattern across countries with different levels of financial development. As the quality of the financial system is important in overcoming market frictions and securing outside financing for intangible and highrisk projects (like R\&D), financial development proxies the severity of financial constraints at the country level. My main set of results comes from the parsimonious full-interaction specification

$$
R \& D_{i c t}=\alpha_{1}+\sum_{j \in\{H, L\}} \beta_{1}^{j} \cdot \varphi\left(\operatorname{Margin}_{i c t}\right) \cdot F D_{c}^{j}+\eta_{i}+\gamma_{c}+\delta_{t}+\zeta_{i c t}
$$

which replaces equation $(1 a)$. Term $\sum_{j \in\{H, L\}} \beta_{1}^{j} \cdot \varphi\left(\operatorname{Margin}_{i c t}\right) \cdot F D_{c}^{j}$ stands for the interaction of the industry price-cost margin with the indicator variables equal to unity for countries with above/below median values of financial development measure $\left(F D_{c}^{H}\right.$ and $F D_{c}^{L}$, respectively). In the spirit of Rajan and Zingales (1998), the interaction term together with the country- and industrylevel fixed effects helps to overcome the endogeneity between innovation and financial development. The interaction term contains only that part of the variation in financial development that is unrelated to unobservable current and future growth opportunities which drive current innovation activity at the country- and industry level. Regression (2) asks whether the above/below median development of financial markets alters the way in which product market competition affects innovation activity conditional on all country-, industry-, and year-specific factors. The indicators of financial development are measured as of the beginning of the EU's 'single market'.

I estimate the empirical model using the generalized method of moments (Hansen, 1982) and instrumental variables estimators. ${ }^{27}$ The correlation of instruments with the price-cost margin is examined by the fit of the first-stage regression (1b). I use Bound, Jaeger, and Baker (1995) statis-

\footnotetext{
${ }^{27}$ GMM estimators are more efficient in the presence of heteroskedasticity and no worse asymptotically than IV estimators if heteroskedasticity is not present (Baum, Schaffer, and Stillman, 2003). Also, while the consistency of the IV coefficient estimates is not affected by the presence of heteroskedasticity, the classic IV estimates of the standard errors are inconsistent and the usual forms of diagnostic tests for endogeneity and overidentifying restrictions are invalid if heteroskedasticity is present. On the other hand, IV is preferable to GMM in small samples if the error is homoskedastic. My results are very similar regardless of what estimation method I use, which is reassuring.
} 
tics: The $R^{2}$ of the first-stage regression with the included instruments 'partialled-out' and the F-test of the joint significance of excluded instruments. As I have multiple endogenous regressors in specification (2) I also report the statistic proposed by Shea (1997): The 'partial- $R^{2}$ ' measure that takes the intercorrelation among instruments into account. Typically, I have more excluded instruments than endogenous regressors (equations (1a) and (2) are overidentified), which allows testing moment conditions. ${ }^{28}$ In the case of the GMM and heteroskedastic-robust IV estimator I report the $J$ statistic; in the case of the standard IV estimator I report Sargan's statistic (Sargan, 1958). As Margin $_{i c t}$ and $R \& D_{i c t}$ are stable over time (annual factors explain almost no variation, see ANOVAs in Table A.6), the error terms in equations (1a), (1b), and (2) are likely to exhibit some degree of autocorrelation. Therefore, my preferred estimator is a GMM estimator with autocorrelation-consistent or heteroskedastic-and-autocorrelation-consistent standard errors.

\subsection{Data}

\subsubsection{Industry-Level Variables}

The industry-country-level variables: price-cost margin and $\mathrm{R} \& \mathrm{D}$ expenditures come from Eurostat's Structural Business Statistics database. This database is based on detailed data on all enterprises and is available at NACE 3-digit level for the manufacturing sector of all EU countries. For robustness, I use capital expenditures as an alternative to R\&D in all specifications. Capital expenditures are highly correlated with $\mathrm{R} \& \mathrm{D}$ and better covered across industries and countries. Typically, capital expenditures regressions are based on more than twice as many observations compared to analogous R\&D specifications. See Table 1 for coverage and basic descriptive statistics and Table DA.1 for the exact definition of the variables.

\footnotetext{
${ }^{28}$ Define vector $Z_{i c t} \equiv\left[S M P_{i c}^{\prime} \eta_{i} \gamma_{c} \delta_{t}\right]$ that contains all exogenous variables (excluded and included instruments). Under the assumption $E\left[Z_{i c t} \cdot \zeta_{i c t}\right]=0$, excluded instruments give $L$ moment conditions $g_{i c t}(\widehat{\beta})=Z_{i c t}^{\prime} \cdot \widehat{\zeta}_{i c t}=$ $Z_{i c t}^{\prime} \cdot\left(R \& D_{i c t}-X_{i c t} \cdot \widehat{\beta}\right)$, where $X_{i c t} \equiv\left[\varphi\left(\operatorname{Margin}_{i c t}\right) \eta_{i} \gamma_{c} \delta_{t}\right]$ consists of both endogenous and exogenous regressors in $(1 a)$. The case with equation (2) is analogous.
} 


\subsubsection{EU 'Single Market Programme' Instrumental Variables}

The list of country-sectors most affected by the introduction of the EU's 'Single Market Programme' (SMP) in 1993 (EU-wide product market reform) comes from Buigues, Ilzkovitz, and Lebrun (1990), part of the Cecchini report. ${ }^{29}$ The list was composed mainly on the basis of the following structural criteria: (i) The level of non-tariff barriers (standards, frontier formalities, limited access to public procurement, differences in VAT and excise duties, etc.), which measures the degree of protection of the sectors; (ii) The dispersion of prices for identical products between EU member states, which measures the level of fragmentation of the EU market; (iii) The rate of penetration by imports, which measures the share of domestic demand accounted for by imports.

The indicators were constructed for 120 industrial sectors out of which 40 sectors were identified as ones where non-tariff barriers impede intra-EU trade. The selected 40 sectors represent about 50 percent of industrial value-added in the EU (ranges from 55 percent in Germany to 39 percent in Spain). Finally, national experts were requested to verify the pertinence of the list of 40 sectors relevant at the EU level for their own countries. Table 4 provides basic characteristics of the industry-country pairs affected by the reform while Table DA.1 lists the affected industries and follows Buigues, Ilzkovitz, and Lebrun (1990) in classifying them into six groups.

\subsubsection{Financial Development Indicators}

Data on financial development are drawn from the World Bank's Financial Structure and Economic Development Database (March 2005 version) described in detail in Beck, Demirgüç-Kunt, and Levine (2000). To make my results comparable with those in the literature I use a number of measures of finance activity to proxy financial development. I start with traditional measures of activity in the credit and stock markets, namely the ratio of private credit to GDP and the ratio of stock market capitalization and stock market total value traded to GDP. All proxies for financial

\footnotetext{
${ }^{29}$ These instruments were recently used by Griffith, Harrison, and Simpson (2006).
} 
development are averaged over the years 1990-1994, that is, as of the establishment of the 'single market'. ${ }^{30}$

In addition to volume-of-finance-activity measures of financial development, I also use a proxy for the institutional quality of financial markets. Specifically, I follow Beck et al. (2004) and use the indicator of the 'quality of accounting standards', produced by International Accounting and Auditing Trends (Center for International Financial Analysis \& Research, Inc.). This indicator rates companies' 1990 annual reports on the basis of their inclusion or omission of 90 items in the balance sheets and income statements and ranges from 0 to 90 .

All four indicators of financial development are summarized across the EU countries in Table 2. Despite the extensive integration of EU national product markets up to 1994, there is still substantial diversity in the degree of financial development across the EU. The coefficient of variation is particularly high for the measures of stock market activity. The middle panel of Table 2 presents correlations (with statistical significance levels) among different measures of financial development. The correlations suggest that these measures, although closely related, are nevertheless meaningfully different. The bottom panel of Table 2 classifies EU countries into high/low financial development groups based on above/below median values of each financial development measure. Table 3 summarizes price-cost margin and R\&D/capital expenditures in low-, medium-, and high-competition-level industries separately for high/low financial development country groups.

\subsection{Results}

Table 5 reports estimates of equation $(1 a)$ with linear specification obtained using OLS, IV, and GMM estimators. Regardless of the method used, there is a significant negative relationship between price-cost margin and $\mathrm{R} \& \mathrm{D} /$ capital expenditures, which means a positive relationship between competition and R\&D/capital expenditures. The IV and GMM coefficients are larger than the

\footnotetext{
${ }^{30} \mathrm{I}$ rely on time averages to avoid year-to-year fluctuations.
} 
ones obtained by OLS. Table 5 confirms the prediction of the model and is consistent with results obtained by Griffith, Harrison, and Simpson (2006). Specifications (2) and (3) of Table 5 are rejected using the Hansen $J$-test but the preferred ones, (4) and (5), are not. The instruments in the first-stage regression are highly significant. ${ }^{31}$

Table 6 reports estimates of high/low financial development full-interaction specification (2) obtained using the GMM estimator with autocorrelation-consistent and heteroskedastic-and-autocorrelationconsistent standard errors. Table 6 also reports analogous estimates obtained using the GMM estimator with standard errors clustered at the country-industry level. These results reveal that the negative relationship between competition and $\mathrm{R} \& \mathrm{D} /$ capital expenditures comes mainly from less financially developed countries, whereas there is no significant pattern in the high financially developed country group.

Tables 7 and 8 report the results from the test of the main model's prediction. The slope of the competition-innovation pattern in less financially developed systems is steeper relative to the benchmark observed in countries with highly developed financial systems for intense (Table 7) as well as relaxed competition levels (Table 8). The estimates in Tables 7 and 8 are obtained using analogous regressions to the ones in Table 6 . The only difference is that in Table 7 I only interact the bottom 25 percent of the price-cost margin variable (i.e., the industry-country cells with very intense competition levels) with financial development. In line with the model, the coefficients in front of the interaction term between the price-cost margin and the low FD country group dummy are positive and significant in all specifications, while it is never significant and sometimes negative for the interaction term with the high FD country group dummy. In less financially developed countries, within the most competitive industries an increase in competition leads to a reduction in $\mathrm{R} \& \mathrm{D} /$ capital expenditures. In the most financially developed countries, there is no significant effect of competition on $\mathrm{R} \& \mathrm{D} /$ capital expenditures within the most competitive industries.

\footnotetext{
${ }^{31}$ See Table A.7 for the full first-stage regression results.
} 
Table 8 focuses on the upper 50 percent of the price-cost margin variable, i.e., the industrycountry cells with relaxed competition. In contrast to Table 7 , the coefficients in front of the interaction term between the price-cost margin and the low FD country group dummy are negative and significant in all specifications. The coefficients in front of the interaction term with the high FD country group dummy are typically negative, but only marginally significant. In less financially developed countries, within the relaxed competition industries an increase in competition leads to an increase in $\mathrm{R} \& \mathrm{D} /$ capital expenditures.

The results of Table 7 and 8 are depicted in Figure 3. The competition-innovation relationship recovered empirically for high/low FD country groups closely mimics the theoretical competitioninnovation pattern of the unconstrained/financially constrained regime depicted in Figure 2.

In non-reported regressions, I tried different threshold levels of the profit-cost margin variable to define intense and relaxed competition regions. These alternative specifications led to results analogous to those reported in Tables 7 and 8. To illustrate the robustness of results to threshold definitions and to further explore the difference in the competition-innovation relationship between high and low FD country groups, Figure 4 depicts fitted lines obtained from high/low financial development full-interaction specifications analogous to the ones reported in the top panel of Table 6 but estimated separately on all quintiles of the price-cost margin variable.

\subsection{Robustness checks}

Tables A.1 and A.2 show robustness to autocorrelation and clustering. The estimates are fully robust to autocorrelation but the estimates' significance is lost when I cluster standard errors at the industry-country level. This loss of significance is of minor concern, if one assumes that industry-country-level variables ( $\mathrm{R} \& \mathrm{D} /$ capital expenditures and price-cost margin) represent-in each year - the equilibrium of the model developed in the first half of the paper.

Tables A.3, A.4, and A.5 report estimates of specifications in which instead of high/low finan- 
cial development country group full-interaction specifications I interact the price-cost margin with continuous measures of financial development. For all practical purposes, the results are unchanged and robust to this alternative type of interaction.

\section{Conclusion}

This paper examines how the $R \& D$ investment of financially constrained firms and endogenously determined aggregate innovation activity depend on product market competition. The novel findings come from an analysis of the interaction between competition and lack of external finance. The presence of financial constraints affects innovation through two channels: The constraints set an upper bound on firms' R\&D investments, and they also change their incentives to innovate - firms change their R\&D strategies depending on whether their competitors are financially constrained or not. This demonstrates the importance of analyzing the impact of financial frictions on firms' individual decisions in a model of market interaction.

I show that if firms finance R\&D activities only out of current profits, they underinvest the most in industries with intense and very relaxed competition. On the aggregate level, the presence of financial constraints results in a stronger inverted-U competition-innovation pattern than when firms have frictionless access to external finance. The key to these results is the assumption that, in order to innovate, firms need to invest cash in $R \& D$ and that competition affects the amount they can invest. The paper models this idea in a very tractable way.

In the empirical part I find that the interaction between competition and financial development is an important determinant of the shape of the aggregate competition-innovation relationship, which is consistent with the presented theory. Relative to the competition-innovation pattern in the most financially developed countries, the competition-innovation relationship has an inverted-U shape in less financially developed systems. This finding is established when I identify the causal impact of 
competition on innovation by exploiting a major EU product market reform, the introduction of the 'single market', and is robust to a number of alternative specifications. The empirical analysis helps to explain why the shape of the competition-innovation pattern has not been fully resolved to date; it may be that many papers in this area do not control for the presence of financial constraints, an important determinant of this relationship.

This paper contributes to policy discussions by stressing the importance of external finance supply for innovation success. The theoretical argument and empirical analysis developed in this paper suggest that innovation-enhancing policies implemented through competition reforms ought to be complemented by promoting financial development. 


\section{Appendix A}

Figure 1: The top (middle) two graphs depict the $R \& D$ investment of each firm in the neckand-neck state (of the laggard) as a function of competition, while the bottom two graphs show the aggregate innovation intensity. The blue (dark) solid lines are the R\&D investments from Proposition 1 depicted for competition levels at which the financial constraints do not bind. The blue dashed lines depict the same quantities ignoring financial constraints. The red (light) solid lines depict profit $\pi_{0}\left(\pi_{-1}\right)$ each firm in the neck-and-neck state (the laggard) gets for competition levels at which the financial constraints are binding. In the top (middle) graphs, red lines connect to blue ones at threshold competition levels $\bar{\Delta}(\underline{\underline{\Delta}})$; in the bottom graphs the dashed lines switch to solid ones at $\underline{\Delta}$ and back to dashed ones at $\bar{\Delta}$ (see Proposition 2). Parameters: Left: $\pi_{1}=0.94$, $\pi_{-1}=0.08, h=0.30, r=0.02$; Right: $\pi_{1}=0.73, \pi_{-1}=0.14, h=0.00, r=0.02$.
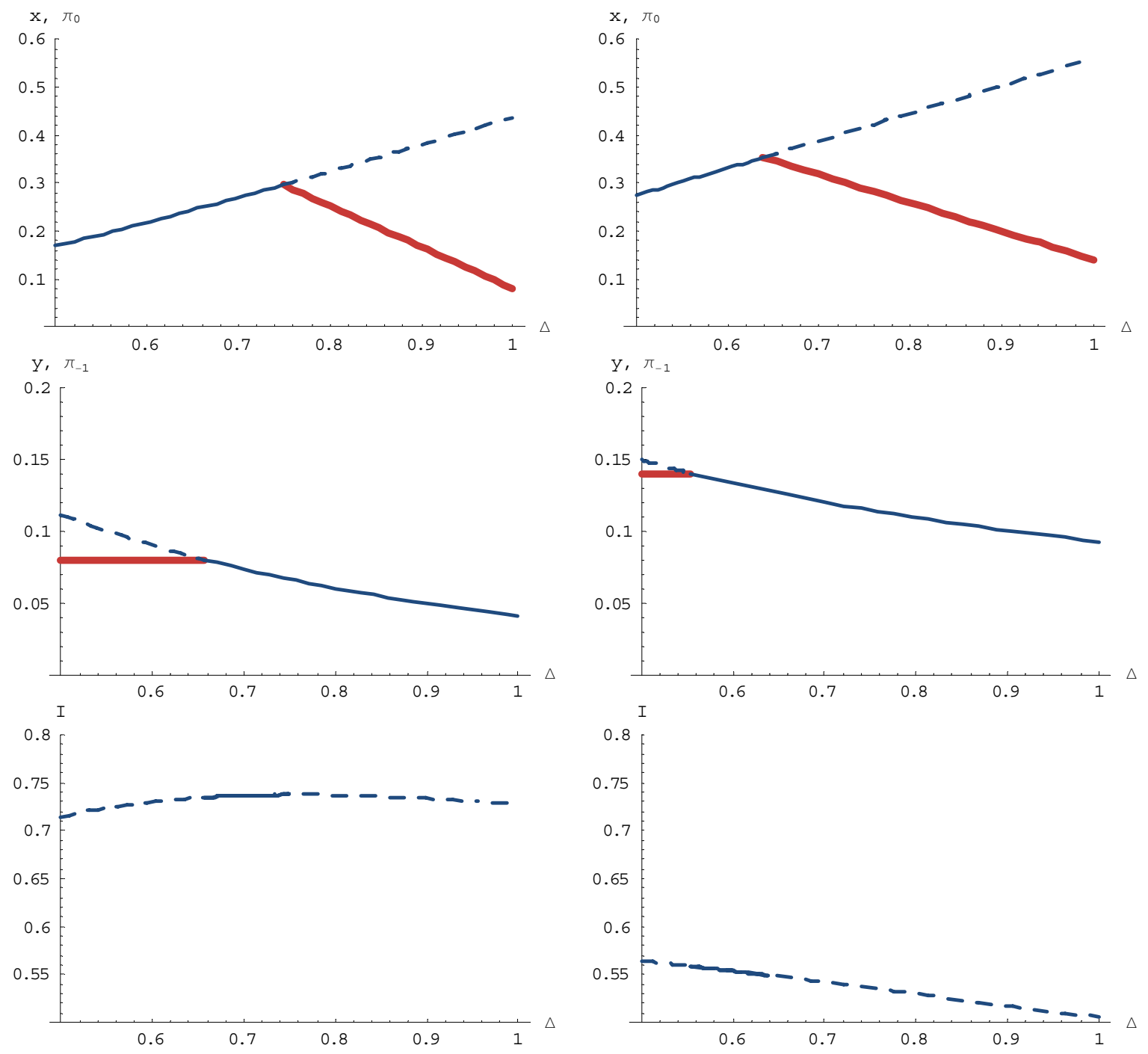
Figure 2: The top (bottom) graph on the right depicts the firm's R\&D investments in the neck-andneck (the laggard's R\&D investment in the unleveled) state as a function of competition: (i) The blue (dark) solid lines are the firm's R\&D investments from Proposition 1 depicted for intermediate competition levels at which the unconstrained equilibrium exists, $\Delta \in(\underline{\Delta}, \bar{\Delta})$; (ii) The blue dashed lines depict the same quantities if financial constraints are ignored in the relaxed competition region, $\Delta \in\left[\frac{1}{2}, \underline{\Delta}\right]$, and the intense competition region, $\Delta \in[\bar{\Delta}, 1]$; (iii) The red (light) solid lines are the firm's R\&D investments from Proposition 3 if financial constraints are binding. The top left graph shows the corresponding aggregate innovation intensities, while the bottom left graph shows the fraction of industries in the neck-and-neck state. Parameters: $\pi_{1}=0.95, \pi_{-1}=0.09, h=0.25$, $r=0.02$.
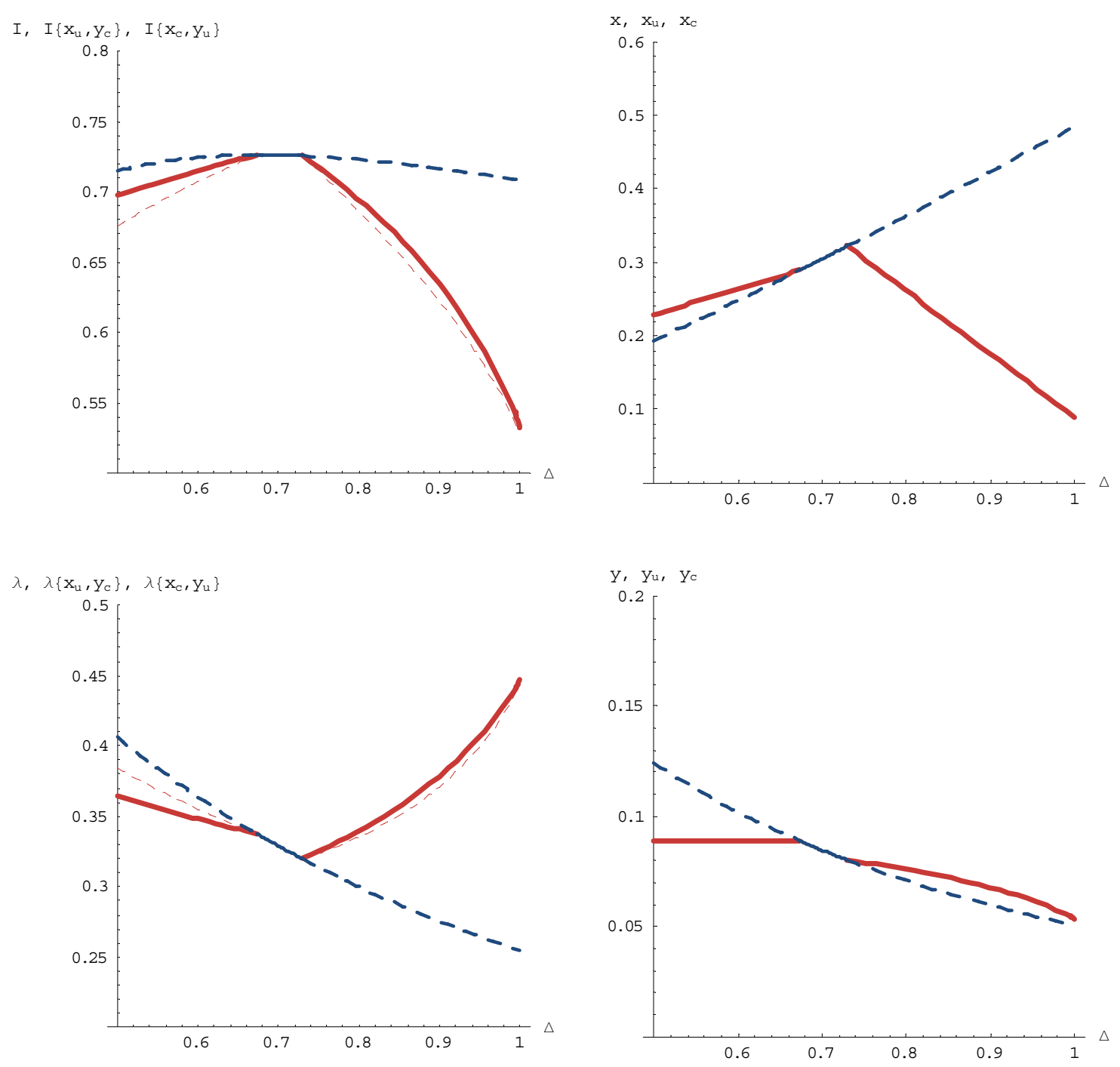
Figure 3: The Figure depicts fitted lines obtained from high/low financial development full-interaction specifications based on 0 to 25 percent of the profit-cost margin variable from Table 7 columns (2) and (6), and similar specifications based on 50 to 100 percent of the profit-cost margin variable from Table 8 columns (2) and (6). The dependent variable in the top two graphs is R\&D expenditures while the dependent variable in the bottom two graphs is capital expenditures. Red (light) line: Fitted regression line based on the coefficient in front of the low financial development country group interaction variable; Blue (dark) line: Fitted regression line based on the coefficient in front of the high financial development country group interaction variable. Thick (thin) line denotes significance (no significance) at the $5 \%$ level.

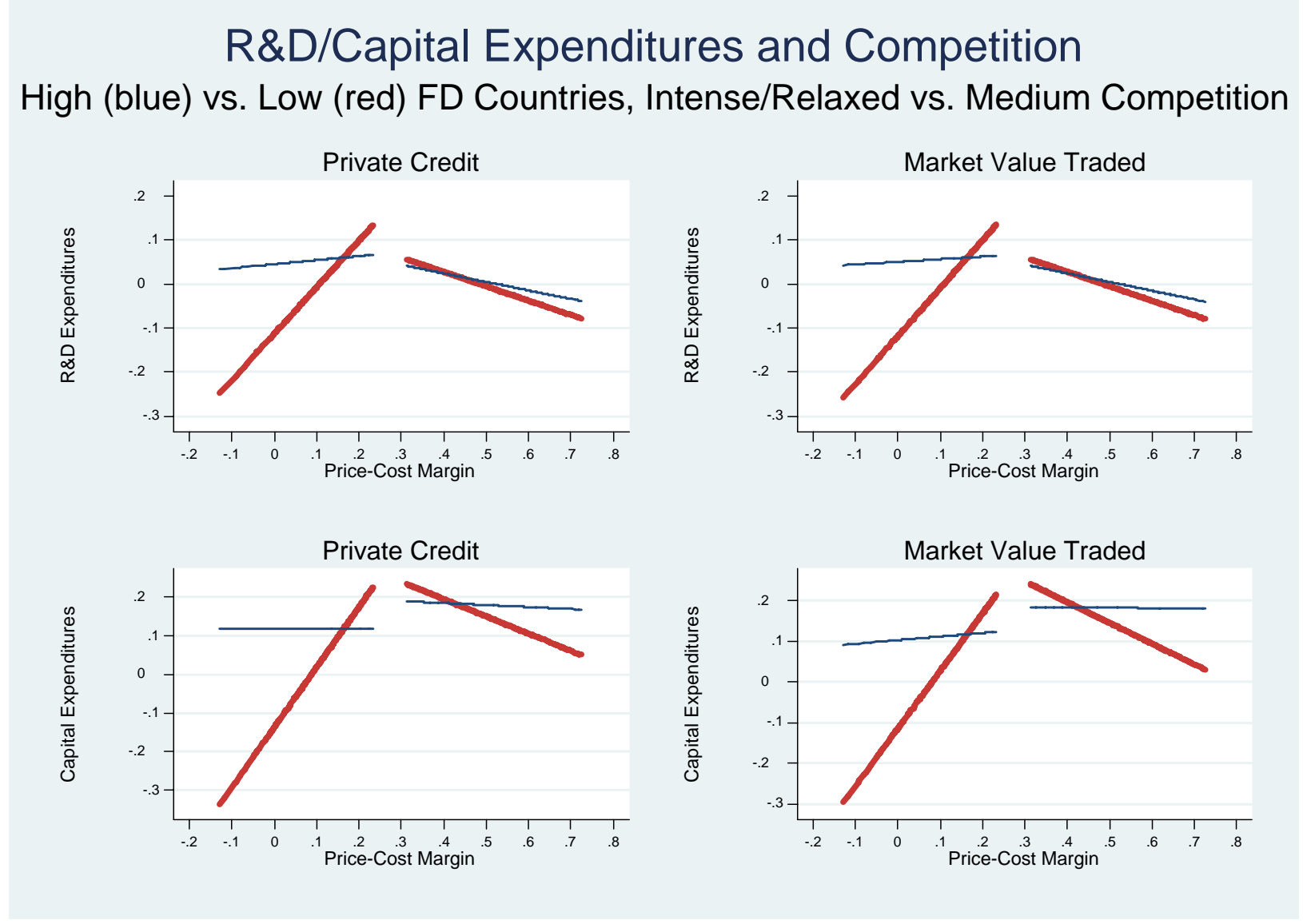


Figure 4: The Figure depicts fitted lines obtained from high/low financial development full-interaction specifications analogous to the ones reported in the top panel of Table 6 but estimated separately on all quintiles of the profit-cost margin variable. The dependent variable is $R \& D$ expenditures in all graphs. Red (light) line: Fitted regression line based on the coefficient in front of the low financial development country group interaction variable; Blue (dark) line: Fitted regression line based on the coefficient in front of the high financial development country group interaction variable. Thick (thin) line denotes significance (no significance) at the $5 \%$ level.

\section{R\&D Expenditures and Competition: Semi-Parametric Specification High (blue) vs. Low (red) FD Countries, Competition by Quintiles}
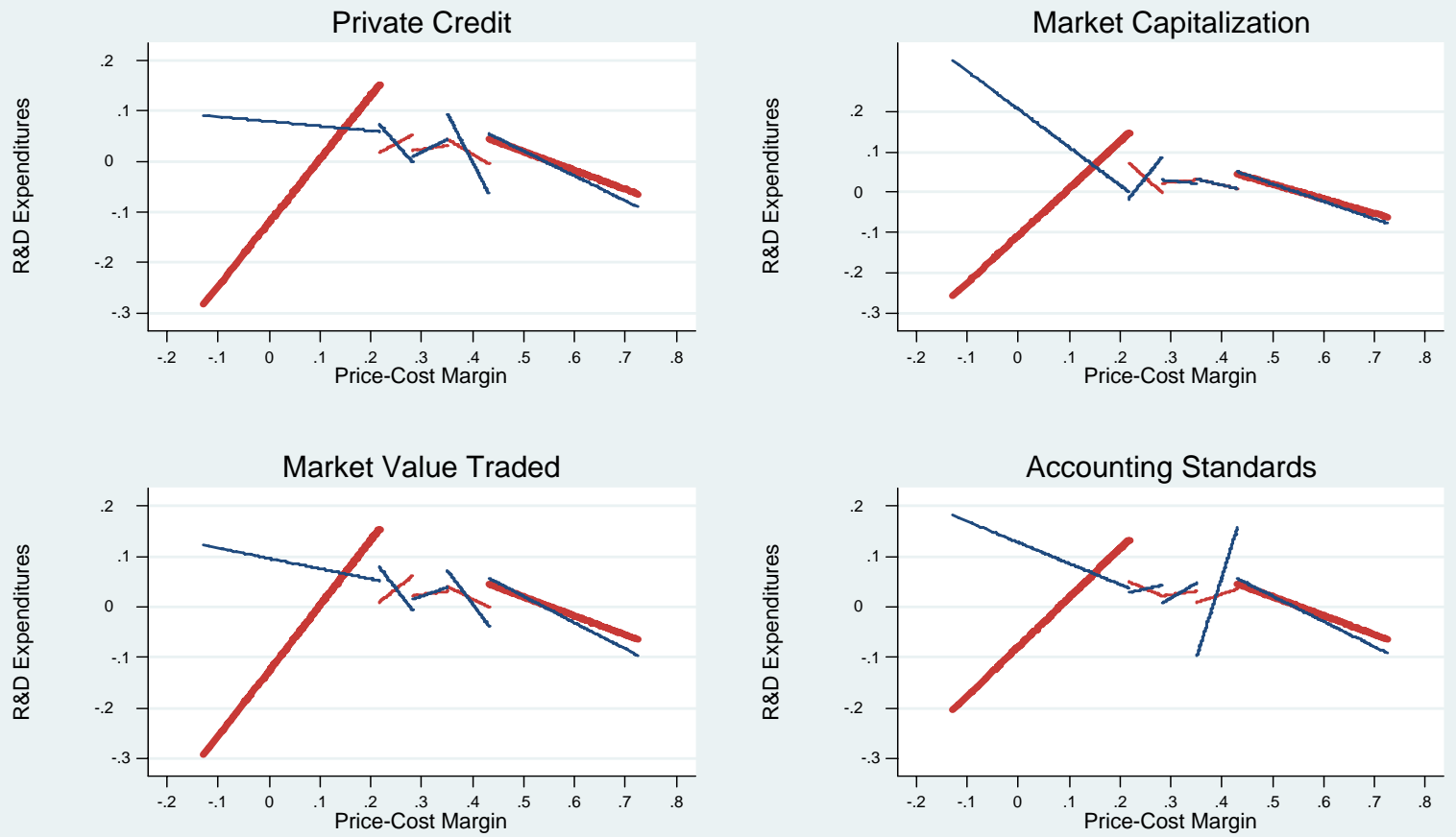


\section{Appendix B}

Table 1: EU ‘single-market’ Industry-Country-Year Data in 1995-2004

Table 2: Financial Development: EU ‘single-market’ Countries in 1990-1994

Table 3: Descriptive Statistics by Competition and Financial Development

Table 4: EU 'Single Market Programme' (SMP): Industry-Country Pairs Affected by the Reform

Table 5: R\&D / Capital Expenditures and Competition

Table 6: Competition: Financial Development (FD) Full Interaction Specification

Table 7: 'Intense' Competition: Financial Development (FD) Full Interaction Specification

Table 8: 'Relaxed' Competition: Financial Development (FD) Full Interaction Specification

Table A.1: 'Intense' Competition: Robustness to Autocorrelation and Clustering

Table A.2: 'Relaxed' Competition: Robustness to Autocorrelation and Clustering

Table A.3: R\&D / Capital Expenditures and Competition: Financial Development (FD) Continuous Interaction

Table A.4: 'Intense' Competition: Financial Development (FD) Continuous Interaction Specification

Table A.5: 'Relaxed' Competition: Financial Development (FD) Continuous Interaction Specification

Table A.6: ANOVAs: EU 'single-market' Countries in 1995-2004

Table A.7: First-Stage: Competition and the EU 'Single Market Programme' (SMP) Instruments

Table DA.1: Definition of Variables 


\section{Appendix $\mathbf{C}$}

\section{Proof of Proposition 1}

Consider the value functions of the leader, of each firm in the neck-and-neck state, and of the laggard when their rival's strategy is characterized by the $\mathrm{R} \& \mathrm{D}$ investment pair $\{\bar{x}, \bar{y}\}$ in the two states. Let $V_{1}, V_{0}$, and $V_{-1}$ denote the steady state values of being currently the leader in the unleveled state, a firm in the neck-and-neck state, and the laggard in the unleveled state, respectively. $V_{0}$ is obtained from the optimization problem

$$
V_{0}=\max _{x}\left\{\left(\pi_{0}-x\right) d t+e^{-r d t}\left[\sqrt{x} V_{1} d t+\sqrt{\bar{x}} V_{-1} d t+[1-(\sqrt{x}+\sqrt{\bar{x}}) d t] V_{0}\right]\right\} .
$$

$V_{1}$ and $V_{-1}$ are determined analogously. For $d t$ small, $e^{-r d t} \approx 1-r d t$, the terms of order $(d t)^{2}$ can be ignored, and the system of equations becomes

$$
\begin{aligned}
r V_{0} & =\max _{x}\left\{\left(\pi_{0}-x\right)+\sqrt{x}\left(V_{1}-V_{0}\right)-\sqrt{\bar{x}}\left(V_{0}-V_{-1}\right)\right\} \\
r V_{-1} & =\max _{y}\left\{\left(\pi_{-1}-y\right)+(\sqrt{y}+h)\left(V_{0}-V_{-1}\right)\right\} \\
r V_{1} & =\pi_{1}-(\sqrt{\bar{y}}+h)\left(V_{1}-V_{0}\right)
\end{aligned}
$$

The first line of (3), which describes the optimization problem of each firm in the neck-and-neck state, reads as follows. The annuity value of being a firm in the neck-and-neck state at date $t, r V_{0}$, equals current profit flow minus $\mathrm{R} \& \mathrm{D}$ investment flow, $\pi_{0}-x$, plus capital gain, $V_{1}-V_{0}$, in case the firm innovates and becomes the leader (which happens with intensity $\sqrt{x}$ ), minus capital loss, $V_{0}-V_{-1}$, in case the firm's competitor innovates and the firm becomes the laggard (which happens with intensity $\sqrt{\bar{x}}$ ). In the second line of (3), the annuity value of being the laggard at date $t$, $r V_{-1}$, equals current profit flow minus R\&D investment flow, $\pi_{-1}-y$, plus the expected capital gain $(\sqrt{y}+h)\left(V_{0}-V_{-1}\right)$ in case the laggard innovates and catches up with the leader. Finally, the annuity value of being the leader at date $t, r V_{1}$, equals current profit flow $\pi_{1}$ minus expected capital loss $(\sqrt{\bar{y}}+h)\left(V_{1}-V_{0}\right)$ in case the laggard innovates and the industry switches to the neckand-neck state. The first order conditions are $V_{1}=2 \sqrt{x}+V_{0}$ and $V_{-1}=-2 \sqrt{y}+V_{0}$ for a firm in the neck-and-neck state and the laggard, respectively. System of equations (3) together with FOCs and symmetry $(x=\bar{x}, y=\bar{y})$ leads to

$$
\begin{aligned}
\pi_{0} & =r V_{0}+2 \sqrt{x} \sqrt{y}-x, \\
\pi_{1} & =r V_{0}+2 \sqrt{x}(h+r+\sqrt{y}), \\
\pi_{-1} & =r V_{0}-2(h+r) \sqrt{y}-y .
\end{aligned}
$$

Solving (4) when $\pi_{0} \equiv \pi_{-1}+(1-\Delta)\left(\pi_{1}-\pi_{-1}\right)$ and simplifying using $\Pi \equiv \pi_{1}-\pi_{-1}$ and $H \equiv h+r$ gives

$$
\left\{\begin{array}{l}
x=\Pi \Delta+2 H\left(H-\sqrt{H^{2}+\Pi \Delta}\right) \\
y=4 H^{2}+(1+2 \Delta) \Pi-2 H \sqrt{H^{2}+\Pi \Delta}- \\
2 \sqrt{\left(H^{2}+\Pi \Delta\right)\left(3 H^{2}+(1+\Delta) \Pi-2 H \sqrt{H^{2}+\Pi \Delta}\right)}
\end{array}\right\} .
$$


Further simplification yields the results presented in Proposition 1. Solution (5) is the only one with $x \geq 0$ and $y \geq 0$ for $\Pi>0$ and $H \geq 0$ (within the class of symmetric stationary Markov equilibria). In the special case when $r=0$ and $h=0$ result (5) simplifies to

$$
\{x=\Pi \Delta, y=\Pi[1+2(\Delta-\sqrt{\Delta(1+\Delta)})]\} .
$$

\section{Proof of Corollary 1}

Comparative static results obtained by differentiating the $R \& D$ investment of a firm in the neckand-neck state (part one of Proposition 1) and simplifying using $\Pi \equiv \pi_{1}-\pi_{-1}, H \equiv h+r$, and $\Omega \equiv \sqrt{H^{2}+\Delta \Pi}>H$ are

$$
\frac{\partial x}{\partial \Delta}=\Pi\left(1-\frac{H}{\Omega}\right)>0, \frac{\partial x}{\partial \Pi}=\Delta\left(1-\frac{H}{\Omega}\right)>0 \text {, and } \frac{\partial x}{\partial H}=-\frac{2(\Omega-H)^{2}}{\Omega}<0 .
$$

Similarly, comparative static properties of the laggard's R\&D investment in the unleveled state (part two of Proposition 1) are

$$
\begin{aligned}
\frac{\partial y}{\partial \Delta} & =\Pi\left(2-\frac{H}{\Omega}-\frac{2 H^{2}+\Pi-3 H \Omega+2 \Omega^{2}}{\Omega \sqrt{2 H^{2}+\Pi-2 H \Omega+\Omega^{2}}}\right)<0 \\
\frac{\partial y}{\partial \Pi} & =1+2 \Delta-\frac{\Delta H}{\Omega}-\frac{(1+4 \Delta) H^{2}+2 \Delta(1+\Delta) \Pi-3 \Delta H \Omega}{\Omega \sqrt{2 H^{2}+\Pi-2 H \Omega+\Omega^{2}}}>0, \text { and } \\
\frac{\partial y}{\partial H} & =8 H-\frac{2 H^{2}}{\Omega}-2 \Omega+\frac{2\left(3 H^{4}+5 \Delta H^{2} \Pi+\Omega^{4}-H \Omega\left(2 H^{2}+\Pi+4 \Omega^{2}\right)\right)}{\Omega \sqrt{2 H^{2}+\Pi-2 H \Omega+\Omega^{2}}}<0 .
\end{aligned}
$$

As $0<x<\Pi$ and $0<y<\Pi$, if the technological leadership rent satisfies $\Pi \leq 1$ so that $0<\sqrt{x}<1$ and $0<\sqrt{y}<1$, innovation intensities $\sqrt{x}$ and $\sqrt{y}$ are well-defined probabilities.

\section{Proof of Corollary 2}

In the steady state, the flow of industries from the neck-and-neck state to the unleveled state matches the opposite flow

$$
2 \lambda \sqrt{x}=(1-\lambda)(\sqrt{y}+h) .
$$

Solving (7) for $\lambda$ gives the steady state fraction of industries in the neck-and-neck state

$$
\lambda=\frac{\sqrt{y}+h}{2 \sqrt{x}+\sqrt{y}+h}
$$

Substituting (7) and (8) into the definition of the aggregate innovation intensity $I \equiv 2 \lambda \sqrt{x}+(1-$ $\lambda)(\sqrt{y}+h)$ and simplifying gives

$$
I=\frac{4 \sqrt{x}(\sqrt{y}+h)}{2 \sqrt{x}+\sqrt{y}+h},
$$

where $x$ and $y$ are the R\&D investments from Proposition 1. Differentiating (9) with respect to $\Pi$, 
$r, \Delta$, and $h$ and applying the comparative static results derived in Corollary 1 gives

$$
\begin{aligned}
\frac{\partial I}{\partial \Pi} & =\frac{2(\sqrt{y}+h)^{2} \sqrt{y} \frac{\partial x}{\partial \Pi}+4 x^{\frac{3}{2}} \frac{\partial y}{\partial \Pi}}{\sqrt{x}(2 \sqrt{x}+\sqrt{y}+h)^{2} \sqrt{y}}>0, \\
\frac{\partial I}{\partial r} & =\frac{2(\sqrt{y}+h)^{2} \sqrt{y} \frac{\partial x}{\partial r}+4 x^{\frac{3}{2}} \frac{\partial y}{\partial r}}{\sqrt{x}(2 \sqrt{x}+\sqrt{y}+h)^{2} \sqrt{y}}<0, \\
\frac{\partial I}{\partial \Delta} & =\frac{2(\sqrt{y}+h)^{2} \sqrt{y} \frac{\partial x}{\partial \Delta}+4 x^{\frac{3}{2}} \frac{\partial y}{\partial \Delta}}{\sqrt{x}(2 \sqrt{x}+\sqrt{y}+h)^{2} \sqrt{y}}<0, \text { and } \\
\frac{\partial I}{\partial h} & =\frac{2\left[(\sqrt{y}+h)^{2} \sqrt{y} \frac{\partial x}{\partial h}+2 x^{\frac{3}{2}}\left(2 \sqrt{y}+\frac{\partial y}{\partial h}\right)\right]}{\sqrt{x}(2 \sqrt{x}+\sqrt{y}+h)^{2} \sqrt{y}}<0 .
\end{aligned}
$$

Substituting the R\&D investments from Proposition 1 into (9) and applying restrictions $r=0$, $h=0$ gives

$$
I=\sqrt{\Pi} \frac{4 \sqrt{\Delta} \sqrt{1+2 \Delta-2 \sqrt{\Delta(1+\Delta)}}}{2 \sqrt{\Delta}+\sqrt{1+2 \Delta-2 \sqrt{\Delta(1+\Delta)}}} .
$$

Differentiating (14) with respect to $\Delta$ and solving equation $\frac{\partial I}{\partial \Delta}=0$ reveals that $\frac{\partial I}{\partial \Delta}>0$ for $\Delta<\frac{1}{3}$ while $\frac{\partial I}{\partial \Delta}<0$ for $\Delta>\frac{1}{3}$. This proves statement two in Corollary 2 .

Analyzing (12) when $r>0$ and $h>0$ reveals that there exist $0<h^{-}<h^{+}<1$ such that when $h \in\left(h^{-}, h^{+}\right): \frac{\partial I}{\partial \Delta}>0$ for $\Delta \in\left[\frac{1}{2}, \Delta_{\text {peak }}\right)$ and $\frac{\partial I}{\partial \Delta}<0$ for $\Delta \in\left(\Delta_{\text {peak }}, 1\right]$. Condition $\frac{\partial I}{\partial \Delta}=0$ determines $\Delta_{\text {peak }}$ as a solution to the implicit equation $\frac{4 x^{3}}{\left(\frac{\partial x}{\partial \Delta}\right)^{2}}=\frac{(\sqrt{y}+h)^{4} y}{\left(\frac{\partial y}{\partial \Delta}\right)^{2}}$. Analyzing (13) when $r>0$ and $h>0$ reveals that there exist $0<h_{\text {peak }}<1$ such that $\frac{\partial I}{\partial h}>0$ for $h \in\left[0, h_{\text {peak }}\right)$ and $\frac{\partial I}{\partial h}<0$ for $\Delta \in\left(h_{\text {peak }}, 1\right]$. Condition $\frac{\partial I}{\partial h}=0$ determines $h_{\text {peak }}$ as a solution to the implicit equation $\frac{4 x^{3}}{\left(\frac{\partial x}{\partial h}\right)^{2}}=\frac{(\sqrt{y}+h)^{4}\left(\frac{\partial x}{\partial h}-2 \sqrt{y}\right)^{2} y}{\left[\left(\frac{\partial y}{\partial h}\right)^{2}-4 y\right]^{2}}$.

Examples of peaks of the two inverted-Us: For $\pi_{1}=0.9, \pi_{-1}=0.2, r=0.03, h=0.15$, solution to equation $\frac{\partial I}{\partial \Delta}=0$ is at $\Delta=0.554$, the equilibrium R\&D investment of a firm in the neck-and-neck state is $x=0.219<\pi_{0}=0.512$, the equilibrium $\mathrm{R} \& \mathrm{D}$ investment of the laggard in the unleveled state is $y=0.107<\pi_{-1}$, and the aggregate innovation intensity is $I=0.632$. For $\pi_{1}=0.9$, $\pi_{-1}=0.2, r=0.03, \Delta=0.6$, solution to equation $\frac{\partial I}{\partial h}=0$ is at $h=0.399$, the equilibrium R\&D investment of a firm in the neck-and-neck state is $x=0.188<\pi_{0}=0.340$, the equilibrium $\mathrm{R} \& \mathrm{D}$ investment of the laggard in the unleveled state is $y=0.030<\pi_{-1}$, and the aggregate innovation intensity is $I=0.689$.

\section{Proof of Proposition 2}

Part one is obtained by solving the system of inequalities

$$
\left\{x>\pi_{-1}+(1-\Delta)\left(\pi_{1}-\pi_{-1}\right), \pi_{1}>\pi_{-1}>0, \frac{1}{2} \leq \Delta \leq 1, H>0\right\},
$$


where $H \equiv h+r$ and $x$ is from Proposition 1 for parameters $\left\{\pi_{1}, \pi_{-1}, \Delta, H\right\}$. The threshold competition intensity of a firm in the neck-and-neck state, $\bar{\Delta}$, presented in part one of Proposition 2 solves $x=\pi_{0}$ for $\Delta$. Similarly, part two of Proposition 2 is obtained by solving the system of inequalities

$$
\left\{y>\pi_{-1}, \pi_{1}>\pi_{-1}>0, \frac{1}{2} \leq \Delta \leq 1\right\} \text { for parameters }\left\{\pi_{1}, \pi_{-1}, \Delta\right\}
$$

under a simplifying restriction $H=0$. The laggard's threshold competition intensity, $\underline{\Delta}$, presented in part two of Proposition 2 solves $y=\pi_{-1}$ for $\Delta$ when $H>0$.

Solving the system of inequalities

$$
\left\{\bar{\Delta}<1, \pi_{1}>\pi_{-1}>0, H>0\right\} \text { for parameters }\left\{\pi_{1}, \pi_{-1}, H\right\}
$$

gives

$$
\bar{\Delta}<1 \Longleftrightarrow\left(\pi_{-1}<\frac{\pi_{1}}{2} \text { and } H<\frac{\Pi-\pi_{-1}}{2 \sqrt{\pi_{-1}}}\right) .
$$

Similarly, solving the system of inequalities

$$
\left\{\frac{1}{2}<\underline{\Delta}, \pi_{1}>\pi_{-1}>0, H>0\right\} \text { for parameters }\left\{\pi_{1}, \pi_{-1}, H\right\}
$$

gives

$$
\begin{aligned}
\frac{1}{2}< & \Delta \Longleftrightarrow\left(\pi_{-1}<\frac{3-\sqrt{3}}{6} \pi_{1} \text { and } H<H I G H\left(\pi_{1}, \pi_{-1}\right)\right) \text { or } \\
& \left(\frac{3+\sqrt{3}}{6} \pi_{1}<\pi_{-1} \text { and } H<\bar{H}\left(\pi_{1}, \pi_{-1}\right)\right),
\end{aligned}
$$

where

$$
\begin{aligned}
\operatorname{HIGH}\left(\pi_{1}, \pi_{-1}\right) \equiv & \frac{\sqrt{\frac{\pi_{1}^{2}-26 \pi_{1} \pi_{-1}+41 \pi_{-1}^{2}}{\pi_{-1}}+\frac{\sqrt[3]{S U B_{H I G H}^{2}}+\pi_{1}^{4}-4 \pi_{1}^{3} \pi_{-1}+38 \pi_{1}^{2} \pi_{-1}^{2}-20 \pi_{1} \pi_{-1}^{3}+49 \pi_{-1}^{4}}{\pi_{-1} \sqrt[3]{S U B_{H I G H}}}}}{4 \sqrt{3}} \text { and } \\
S U B_{H I G H} \equiv & \pi_{1}^{6}-6 \pi_{1}^{5} \pi_{-1}+63 \pi_{1}^{4} \pi_{-1}^{2}-140 \pi_{1}^{3} \pi_{-1}^{3}+567 \pi_{1}^{2} \pi_{-1}^{4}+210 \pi_{1} \pi_{-1}^{5}-343 \pi_{-1}^{6}+ \\
& +48 \sqrt{6} \pi_{1} \sqrt{\pi_{-1}^{7}\left(\pi_{1}^{3}-5 \pi_{1}^{2} \pi_{-1}+43 \pi_{1} \pi_{-1}^{2}-49 \pi_{-1}^{3}\right)} .
\end{aligned}
$$

Threshold function $\bar{H}\left(\pi_{1}, \pi_{-1}\right)$ is available upon request. Solving the system of inequalities

$$
\left\{\underline{\Delta}<\bar{\Delta}, \pi_{1}>\pi_{-1}>0, H>0\right\} \text { for parameters }\left\{\pi_{1}, \pi_{-1}, H\right\}
$$

gives

$$
\underline{\Delta}<\bar{\Delta} \Leftrightarrow\left(\pi_{-1}<\frac{3-\sqrt{5}}{4} \pi_{1} \text { and } \operatorname{LOW}\left(\pi_{1}, \pi_{-1}\right)<H\right) \text { or }\left(\frac{3-\sqrt{5}}{4} \pi_{1} \leq \pi_{-1}\right) \text {, }
$$


where

$$
\begin{aligned}
\operatorname{LOW}\left(\pi_{1}, \pi_{-1}\right) & \equiv \sqrt{\pi_{-1}\left(1+\frac{\pi_{1}^{2}}{\sqrt[3]{6} \sqrt[3]{S U B_{L O W}}}\right)-\pi_{1}+\frac{\sqrt[3]{S U B_{L O W}}}{2 \pi_{-1} \sqrt[3]{6^{2}}}} \text { and } \\
S U B_{L O W} & \equiv 9 \pi_{1}^{4} \pi_{-1}^{2}+\sqrt{81 \pi_{1}^{8} \pi_{-1}^{4}-48 \pi_{1}^{6} \pi_{-1}^{6}}
\end{aligned}
$$

By combining the conditions for $\frac{1}{2}<\underline{\Delta}, \bar{\Delta}<1$, and $\underline{\Delta}<\bar{\Delta}$ I obtain the necessary and sufficient condition for the existence of three competition regions: (i) The relaxed competition region, $\Delta \in$ $\left[\frac{1}{2}, \underline{\Delta}\right]$, in which the laggard is financially constrained; (ii) The intermediate competition region, $\Delta \in(\underline{\Delta}, \bar{\Delta})$, in which the unconstrained equilibrium of Proposition 1 exists; (iii) The intense competition region, $\Delta \in[\bar{\Delta}, 1]$, in which the firms in the neck-and-neck state are constrained, i.e., $\frac{1}{2}<\underline{\Delta}<\bar{\Delta}<1 ;$ as follows

$$
\begin{aligned}
& \left(\pi_{-1}<\frac{3-\sqrt{5}}{4} \pi_{1} \text { and } \operatorname{LOW}\left(\pi_{1}, \pi_{-1}\right)<h+r<\operatorname{HIGH}\left(\pi_{1}, \pi_{-1}\right)\right) \text { or } \\
& \left(\frac{3-\sqrt{5}}{4} \pi_{1} \leq \pi_{-1}<\frac{3-\sqrt{3}}{6} \pi_{1} \text { and } h+r<\operatorname{HIGH}\left(\pi_{1}, \pi_{-1}\right)\right) .
\end{aligned}
$$

By differentiating, the threshold competition intensity of a firm in the neck-and-neck state, $\bar{\Delta}$, satisfies

$$
\begin{aligned}
\frac{\partial \bar{\Delta}}{\partial \pi_{1}} & =\frac{H^{2}-\pi_{-1}-\frac{H\left(H^{2}+\pi_{-1}+\pi_{1}\right)}{\sqrt{H^{2}+2 \pi_{1}}}}{2 \Pi^{2}}<0, \\
\frac{\partial \bar{\Delta}}{\partial \pi_{-1}} & =\frac{\pi_{1}+\left(\sqrt{H^{2}+2 \pi_{1}}-H\right) H}{2 \Pi^{2}}>0, \text { and } \\
\frac{\partial \bar{\Delta}}{\partial H} & =\frac{1}{\Pi}\left(\frac{H^{2}+\pi_{1}}{\sqrt{H^{2}+2 \pi_{1}}}-H\right)>0 .
\end{aligned}
$$

Similarly, the laggard's threshold competition intensity, $\underline{\Delta}$, satisfies

$$
\begin{gathered}
\frac{\partial \underline{\Delta}}{\partial \pi_{1}}=\frac{8 H^{2} \sqrt{\pi_{-1}}\left(H+\sqrt{\pi_{-1}}\right)+\left(\Pi-\pi_{-1}\right) \pi_{1}}{4\left(H+\sqrt{\pi_{-1}}\right)^{2} \Pi^{2}}>0 \Longleftrightarrow \\
\Longleftrightarrow\left(\pi_{-1} \leq \frac{\pi_{1}}{2}\right) \text { or }\left(\frac{\pi_{1}}{2}<\pi_{-1} \text { and } \underline{H}_{1}\left(\pi_{1}, \pi_{-1}\right)<H\right), \\
\frac{\partial \underline{\Delta}}{\partial \pi_{-1}}=\pi_{1}^{2} \frac{\pi_{-1}-\Pi-4 H^{2}-3 H \sqrt{\pi_{-1}}}{4\left(H+\sqrt{\pi_{-1}}\right)^{3} \Pi^{2} \sqrt{\pi_{-1}}}-H\left(\frac{\sqrt{\pi_{-1}}}{\Pi^{2}}+\frac{\left(H^{2}-2 \pi_{-1}\right) \pi_{1}}{\left(H+\sqrt{\pi_{-1}}\right)^{2} \Pi^{2} \sqrt{\pi_{-1}}}\right)<0 \Longleftrightarrow \\
\Longleftrightarrow\left(\pi_{-1} \leq \frac{\pi_{1}}{2}\right) \text { or }\left(\frac{\pi_{1}}{2}<\pi_{-1}<\widehat{\pi_{-1}}\left(\pi_{1}\right) \text { and } \underline{H}_{2}\left(\pi_{1}, \pi_{-1}\right)<H\right) \text { or } \\
\frac{\partial \triangleq}{\partial H}=\frac{\left.4\left(H+\sqrt{\pi_{-1}}\right) \sqrt{\pi_{-1}}\left[\pi_{1}\right) \leq \pi_{-1} \text { and }\left(H+\sqrt{\pi_{-1}}\right)^{2}\right]-\pi_{1}^{2}}{2\left(H+\sqrt{\pi_{-1}}\right)^{3} \Pi}<0 .
\end{gathered}
$$


Threshold functions $\underline{H}_{1}\left(\pi_{1}, \pi_{-1}\right), \underline{H}_{2}\left(\pi_{1}, \pi_{-1}\right), \underline{H}_{3}\left(\pi_{1}, \pi_{-1}\right)$, and $\widehat{\pi_{-1}}\left(\pi_{1}\right)$ are available upon request.

\section{Proof of Proposition 3}

Assume that the laggard invests $\pi_{-1}$ in the relaxed competition region $\Delta \in\left[\frac{1}{2}, \Delta\right]$. The system of equations (3) together with the FOC for a firm in the neck-and-neck state, $V_{1}=2 \sqrt{x_{u}}+V_{0}$, the restriction on laggard's $R \& D$ investment $y_{c}=\pi_{-1}$, and symmetry $\left(x_{u}=\bar{x}_{u}, y_{c}=\bar{y}_{c}\right)$ leads to

$$
\begin{aligned}
\pi_{0} & =r V_{0}+\sqrt{x_{u}}\left(V_{0}-V_{-1}\right)-x_{u}, \\
\pi_{1} & =r V_{0}+2 \sqrt{x_{u}}\left(h+r+\sqrt{\pi_{-1}}\right), \\
r V_{-1} & =\left(h+\sqrt{\pi_{-1}}\right)\left(V_{0}-V_{-1}\right) .
\end{aligned}
$$

Solving (15) when $\pi_{0} \equiv \pi_{-1}+(1-\Delta)\left(\pi_{1}-\pi_{-1}\right)$ and simplifying using $\Pi \equiv \pi_{1}-\pi_{-1}$ and $H \equiv h+r$ gives

$$
\begin{aligned}
x_{u} & =\frac{(3 \Delta-2) \Pi+2\left(H+2 \sqrt{\pi_{-1}}\right) H-S U B_{x_{u}}}{9}+\frac{\left(S U B_{x_{u}}+\pi_{1}\right) \pi_{1}}{18\left(H+\sqrt{\pi_{-1}}\right)^{2}}, \text { where } \\
S U B_{x_{u}} & \equiv \sqrt{\pi_{1}^{2}+4\left(H+\sqrt{\pi_{-1}}\right)^{2}\left[\left(H+\sqrt{\pi_{-1}}\right)^{2}+3 \Delta \Pi-\pi_{1}\right]} .
\end{aligned}
$$

Assume that a firm in the neck-and-neck state invests $\pi_{0}$ in the intense competition region $\Delta \in[\bar{\Delta}, 1]$. The system of equations (3) together with the FOC for the laggard, $V_{-1}=-2 \sqrt{y_{u}}+V_{0}$, the restriction on $\mathrm{R} \& \mathrm{D}$ investment of a firm in the neck-and-neck state $x_{c}=\pi_{0}$, and symmetry $\left(x_{c}=\bar{x}_{c}, y_{u}=\bar{y}_{u}\right)$ leads to

$$
\begin{aligned}
r V_{0} & =\sqrt{\pi_{0}}\left(V_{1}-V_{0}\right)-2 \sqrt{\pi_{0}} \sqrt{y_{u}}, \\
\pi_{1} & =r V_{1}+\left(h+\sqrt{y_{u}}\right)\left(V_{1}-V_{0}\right), \\
\pi_{-1} & =r V_{0}-2 \sqrt{y_{u}}(h+r)-y_{u} .
\end{aligned}
$$

Eliminating $V_{0}$ and $V_{1}$ from (17), applying $\pi_{0} \equiv \pi_{-1}+(1-\Delta)\left(\pi_{1}-\pi_{-1}\right)$ and simplifying using $\Pi \equiv \pi_{1}-\pi_{-1}$ and $H \equiv h+r$ gives equation

$$
y_{u}+2 H \sqrt{y_{u}}+\pi_{-1}=\frac{\left[\pi_{1}-2\left(y_{u}+H \sqrt{y_{u}}\right)\right] \sqrt{\pi_{1}-\Delta \Pi}}{\sqrt{y_{u}}+H+\sqrt{\pi_{1}-\Delta \Pi}},
$$

which defines $y_{u}$ implicitly. Explicit solution of (18), though complicated, exists and is available upon request.

\section{Proof of Corollary 3}

The substitution of the threshold competition intensity $\underline{\Delta}$ from Proposition 2 into $x_{u}$ (Proposition 3) and into $x$ (Proposition 1) verifies that $x_{u}=x=\left(\frac{\pi_{1}}{2\left(H+\sqrt{\pi_{-1}}\right)}-\sqrt{\pi_{-1}}\right)^{2}$ at $\Delta=\underline{\Delta}$. This result together with the fact that $x_{u}$ is continuous,

$$
\frac{\partial x_{u}}{\partial \Delta}=\frac{\Pi}{3}\left(1+\frac{\pi_{1}-2\left(H+\sqrt{\pi_{-1}}\right)^{2}}{\sqrt{\pi_{1}^{2}+4\left(H+\sqrt{\pi_{-1}}\right)^{2}\left[\left(H+\sqrt{\pi_{-1}}\right)^{2}+3 \Delta \Pi-\pi_{1}\right]}}\right)>0, \text { and }
$$


$x_{u}>x$ when $\Delta=\frac{1}{2}$ establishes that $x_{u}>x$ for all $\Delta \in\left[\frac{1}{2}, \underline{\Delta}\right)$.

The substitution of the threshold competition intensity $\bar{\Delta}$ from Proposition 2 into $y_{u}$ (Proposition 3) and into $y$ (Proposition 1) verifies that

$$
y_{u}=y=\frac{1}{4}\left[\sqrt{2} S U B_{\underline{\Delta}}-2 \sqrt{H^{2}+\Pi+\left(H-\frac{S U B_{\underline{\Delta}}}{\sqrt{2}}\right)^{2}}\right]^{2}
$$

at $\Delta=\bar{\Delta}$, where $S U B_{\underline{\Delta}} \equiv \sqrt{\pi_{1}+H\left(H+\sqrt{H^{2}+2 \pi_{1}}\right)}$. Fact that $y_{u}>y$ for all $\Delta \in(\bar{\Delta}, 1]$ is established using numerical simulations. These simulations are available upon request.

\section{Proof of Corollary 4}

In the steady state, the flow of industries from the neck-and-neck state to the unleveled state matches the opposite flow $2 \lambda \sqrt{x_{u}}=(1-\lambda)\left(\sqrt{y_{c}}+h\right)$. Solving for $\lambda$ and substituting into the definition of the aggregate innovation intensity $I \equiv 2 \lambda \sqrt{x_{u}}+(1-\lambda)\left(\sqrt{y_{c}}+h\right)$ gives $I_{\left\{x_{u}, y_{c}\right\}}=\frac{4 \sqrt{x_{u}}\left(\sqrt{y_{c}}+h\right)}{2 \sqrt{x_{u}}+\sqrt{y_{c}}+h}$, where $x_{u}$ and $y_{c}$ are the $\mathrm{R} \& \mathrm{D}$ investments from Proposition 3. The aggregate innovation intensity $I_{\left\{x_{c}, y_{u}\right\}}$ is derived analogously.

Corollary 3 says that $x_{u}=x$ and $y_{c}=y$ at $\Delta=\underline{\Delta}$. Therefore, it must be that $I_{\left\{x_{u}, y_{c}\right\}}=I$ at $\Delta=\Delta$. Similarly, as $x_{c}=x$ and $y_{u}=y$ at $\Delta=\bar{\Delta}$, it must be that $I_{\left\{x_{c}, y_{u}\right\}}=I$ at $\Delta=\bar{\Delta}$. Facts that $I_{\left\{x_{u}, y_{c}\right\}}<I$ for $\Delta \in\left[\frac{1}{2}, \underline{\Delta}\right)$ and $I_{\left\{x_{c}, y_{u}\right\}}<I$ for $\Delta \in(\bar{\Delta}, 1]$ are established using numerical simulations. These simulations are available upon request. 


\section{References}

Acharya, Viral V.; Subramanian, Krishnamurthy; 2007, "Bankruptcy Codes and Innovation," Working Paper, London Business School.

Aghion, Philippe; Bloom, Nick; Blundell, Richard; Griffith, Rachel; Howitt, Peter; 2002, "Competition and Innovation: An Inverted-U Relationship," Institute for Fiscal Studies Working Paper No. 02/04.

Aghion, Philippe; Bloom, Nick; Blundell, Richard; Griffith, Rachel; Howitt, Peter; 2005, "Competition and Innovation: An Inverted-U Relationship," Quarterly Journal of Economics, Vol. 120, No. 2, pp. 701-728.

Aghion, Philippe; Blundell, Richard; Griffith, Rachel; Howitt, Peter; Prantl, Susanne; 2006, "Entry and Productivity Growth: Evidence from Micro-level Panel Data," Journal of European Economic Association, Papers and Proceedings, Vol. 2, No. 2-3, pp. 265-276.

Aghion, Philippe; Dewatripont, Mathias; Rey, Patrick; 1999, "Competition, Financial Discipline and Growth," Review of Economic Studies, Vol. 66, No. 4, pp. 825-852.

Aghion, Philippe; Harris, Christopher; Vickers, John; 1997, "Competition and Growth with Stepby-Step Innovation: An Example," European Economic Review, Papers and Proceedings, Vol. 41, pp. 771-782.

Aghion, Philippe; Harris, Christopher; Howitt, Peter; Vickers, John; 2001, "Competition, Imitation and Growth with Step-by-Step Innovation," Review of Economic Studies, Vol. 68, No. 3, pp. 467-492.

Aghion, Philippe; Howitt, Peter; 1992, "A Model of Growth through Creative Destruction," Econometrica, Vol. 60, pp. 323-351.

Aghion, Philippe; Howitt, Peter; 1998, "Endogenous Growth Theory," Cambridge MA, MIT Press.

Akdoğu, Evrim; MacKay, Peter; 2008, "Investment and Competition," Journal of Financial and Quantitative Analysis, Vol. 43, No. 2, pp. 299-330.

Arcot, Sridhar; Black, Julia; Owen, Geoffrey; 2007, "From Local to Global: The Rise of AIM as a Stock Market for Growing Companies," London School of Economics comprehensive report analyzing growth of AIM commissioned by the London Stock Exchange.

Baum, Christopher F.; Schaffer, Mark E.; Stillman, Steven; 2003, "Instrumental Variables and GMM: Estimation and Testing," Stata Journal, Vol. 3, No. 1, pp. 1-31.

Beck, Thorsten; Demirgüç-Kunt, Asli; 2006, "Small and Medium-Size Enterprises: Access to Finance as a Growth Constraint," Journal of Banking \& Finance, Vol. 30, pp. 2931-2943. 
Beck, Thorsten; Demirgüç-Kunt, Asli; Maksimovic, Vojislav; 2005, "Financial and Legal Constraints to Growth: Does Firm Size Matter?" Journal of Finance, Vol. 60, No. 1, pp. $137-177$.

Beck, Thorsten; Demirgüç-Kunt, Asli; Levine, Ross; 2000, "A New Database on the Structure and Development of the Financial Sector," World Bank Economic Review, Vol. 14, No. 3, pp. 597-605.

Bena, Jan; 2008, "Competition, Financial Constraints, and Firms' Decision to Innovate," mimeo, LSE.

Bena, Jan; Jurajda, Štěpán; 2007, "Which Firms Benefit More from Financial Development?" CEPR Discussion Paper No. 6392, CEPR.

Berger, Allen N.; Udell, Gregory F.; 2006, "A More Complete Conceptual Framework for SME Finance," Journal of Banking \& Finance, Vol. 30, No. 11, pp. 2945-2966.

Blundell, Richard; Griffith, Rachel; van Reenen, John; 1995, "Dynamic Count Data Model of Technological Innovations," Economic Journal, Vol. 105, pp. 333-344.

Blundell, Richard; Griffith, Rachel; van Reenen, John; 1999, "Market Share, Market Value and Innovation in a Panel of British Manufacturing Firms," Review of Economic Studies, Vol. 66, No. 3, pp. 529-554.

Bolton, Patrick; Roland, Gerard; 1992, "Privatization in Central and Eastern Europe," Economic Policy, No. 15, pp. 276-309.

Boone, Jan; 2008, "A New Way to Measure Competition," Economic Journal, Vol. 118, No. 531, pp. $1245-1261$.

Boone, Jan; van Ours, Jan C.; van der Wiel, Henry; 2007, "How (Not) to Measure Competition," CEPR Discussion Paper No. 6275, CEPR.

Boubakri, Narjess; Cosset, Jean-Claude; Guedhami, Omrane; 2004, "Privatization, Corporate Governance and Economic Environment: Firm-Level Evidence from Asia," Pacific-Basin Finance Journal, Vol. 12, No. 1, pp. 65-90.

Bound, John; Jaeger, David A.; Baker, Regina; 1995, "Problems with Instrumental Variables Estimation when the Correlation Between the Instruments and the Endogenous Explanatory Variable is Weak," Journal of the American Statistical Association, Vol. 90, No. 430, pp. 443-450.

Brander, James; Lewis, Tracey; 1986, "Oligopoly and Financial Structure: The Limited Liability Effect," American Economic Review, Vol. 76, pp. 956-970. 
Buigues, Pierre; Ilzkovitz, Fabienne; Lebrun, Jean-François; 1990, "The Impact of the Internal Market by Industrial Sector: The Challenge for Member States," European Economy, Special Issue.

Chevalier, Judith A.; Scharfstein, David S.; 1996, "Capital Market Imperfections and Countercyclical Markups: Theory and Evidence," American Economic Review, Vol. 86, pp. 703-725.

Cleary, Sean; Povel, Paul; Raith, Michael; 2007, "The U-Shaped Investment Curve: Theory and Evidence," Journal of Financial and Quantitative Analysis, Vol. 42, No. 1, pp. 1-40.

Djankov, Simeon; Murrell, Peter; 2002, "Enterprise Restructuring in Transition: A Quantitative Survey," Journal of Economic Literature, Vol. 40, No. 3, pp. 739-792.

Faure-Grimaud, Antoine; 2000, "Product Market Competition and Optimal Debt Contracts: The Limited Liability Effect Revisited," European Economic Review, Vol. 44, pp. 1823-1840.

Fazzari, Steven M.; Hubbard, Glen R.; Petersen, Bruce C.; 1988, "Financing Constraints and Corporate Investment," Brookings Papers on Economic Activity, Vol. 1, pp. 141-195.

Fazzari, Steven M.; Hubbard, Glen R.; Petersen, Bruce C.; 2000, "Investment-Cash Flow Sensitivities are Useful: A Comment on Kaplan-Zingales," Quarterly Journal of Economics, Vol. 115, pp. 695-705.

Fisman, Raymond; Love, Inessa; 2004, "Financial Development and Intersectoral Allocation: A New Approach," Journal of Finance, Vol. 59, No. 6, pp. 2785-2807.

Giroud, Xavier; Mueller, Holger; 2008, "Corporate Governance, Product Market Competition, and Equity Prices," ECGI - Finance Working Paper No. 219, European Corporate Governance Institute (ECGI).

Giroud, Xavier; Mueller, Holger; 2007, "Does Corporate Governance Matter in Competitive Industries?" ECGI - Finance Working Paper No. 185, European Corporate Governance Institute (ECGI).

Gorodnichenko, Yuriy; Švejnar, Jan; Terrell, Katherine; 2007, "Globalization and Innovation in Emerging Markets," IZA Discussion Paper No. 3299, Institute for the Study of Labor (IZA).

Griffith, Rachel; Harrison, Rupert; Simpson, Helen; 2006, "Product Market Reform and Innovation in the EU," IFS Working Paper No. 06/17, Institute for Fiscal Studies.

Hajivassiliou, Vassilis; Savignac, Frederique; 2007, "Financing Constraints and a Firm's Decision and Ability to Innovate: Establishing Direct and Reverse Effects," FMG Discussion Paper No. 594, London School of Economics - Financial Markets Group (FMG).

Hansen, Lars Peter; 1982, "Large Sample Properties of Generalized Method of Moments Estimators," Econometrica, Vol. 50, No. 3, pp. 1029-1054. 
Jaumotte, Florence; Pain, Nigel; 2005a, "From Ideas to Development: The Determinants of R\&D and Patenting," OECD Economics Department Working Papers, No. 457, OECD Publishing.

Jaumotte, Florence; Pain, Nigel; 2005b, "From Innovation Development to Implementation: Evidence from the Community Innovation Survey," OECD Economics Department Working Paper No. 458, OECD Publishing.

Kamien, Morton I.; Schwartz, Nancy L.; 1972, "Market Structure, Rivals' Response, and the Firm's Rate of Product Improvement," Journal of Industrial Economics, Vol. 20, No. 2, pp. $159-172$.

Kaplan, Steven N.; Zingales, Luigi; 1997, "Do Investment-Cash Flow Sensitivities Provide Useful Measures of Financing Constraints?" Quarterly Journal of Economics, Vol. 112, pp. 169-215.

Kaplan, Steven N.; Zingales, Luigi; 2000, "Investment-Cash Flow Sensitivities are not Valid Measures of Financing Constraints," Quarterly Journal of Economics, Vol. 115, pp. 707-712.

Köke, Jens; Renneboog, Luc; 2005, "Do Corporate Control and Product Market Competition Lead to Stronger Productivity Growth? Evidence from Market-Oriented and BlockholderBased Governance Regimes," Journal of Law and Economics, Vol. 48, pp. 475-516.

Levine, Ross; 1997, "Financial Development and Economic Growth: Views and Agenda," Journal of Economic Literature, Vol. 35, No. 2, pp. 688-726.

Li, Huagang; 1999, "State Factories in Transition-Openness, Competition, and Productivity," Journal of Development Economics, Vol. 58, No. 2, pp. 429-462.

Maurer, Boris; 1999, "Innovation and Investment under Financial Constraints and Product Market Competition," International Journal of Industrial Organization, Vol. 17, No. 4, pp. 455-476.

Nickell, Stephen J.; 1996, "Competition and Corporate Performance," Journal of Political Economy, Vol. 104, No. 4, pp. 724-746.

Nickell, Stephen J.; Nicolitsas, Daphne; Dryden, Neil; 1997, "What Makes Firms Perform Well?" European Economic Review, Vol. 41, No. 3-5, pp. 783-796.

Nicoletti, Giuseppe; Scarpetta, Stefano; 2005, "Regulation and Economic Performance: Product Market Reforms and Productivity in the OECD," OECD Economics Department Working Paper No. 460, OECD Publishing.

Povel, Paul; Raith, Michael; 2004, "Financial Constraints and Product Market Competition: Ex Ante vs. Ex Post Incentives," International Journal of Industrial Organization, Vol. 22, No. 7, pp. 917-949.

Rajan, Raghuram G.; Zingales, Luigi; 1998, "Financial Dependence and Growth," American Economic Review, Vol. 88, No. 3, pp. 559-586. 
Riddick, Leigh A.; Whited, Toni M.; 2008, "The Corporate Propensity to Save," Journal of Finance, forthcoming.

Roland, Gerard; 2001, "Ten Years After ... Transition and Economics," IMF Staff Papers, Vol. 48, Special Issue, International Monetary Fund, pp. 29-52.

Sargan, John D.; 1958, "The Estimation of Economic Relationships using Instrumental Variables," Econometrica, Vol. 26, No. 3, pp. 393-415.

Scherer, Fredrick; 1967, "Market Structure and the Employment of Scientists and Engineers," American Economic Review, Vol. 57, pp. 524-531.

Schmidt, Klaus M.; 1997, "Managerial Incentives and Product Market Competition," Review of Economic Studies, Vol. 64, No. 2, pp. 191-213.

Schumpeter, Joseph; 1943, "Capitalism, Socialism and Democracy," London: Allen Unwin.

Shea, John; 1997, "Instrument Relevance in Multivariate Linear Models: A Simple Measure," Review of Economics and Statistics, Vol. 79, No. 2, pp. 348-352.

Stock, James H.; Yogo, Motohiro; 2005, "Testing for Weak Instruments in Linear IV Regression," in Andrews D.W.K. and Stock J.H., eds., Identification and Inference for Econometric Models: Essays in Honor of Thomas Rothenberg, Cambridge University Press, pp. 80-108.

Sutton, John; 2007, "Market Structure: Theory and Evidence," in Armstrong, Mark and Porter, eds., Handbook of Industrial Organization, Elsevier, 1st Ed., Vol. 3, pp. 2301-2368. 
Table 1

EU 'single-market' Industry-Country-Year Data in 1995-2004

\begin{tabular}{|c|c|c|c|c|c|c|c|c|c|c|c|c|}
\hline & \multicolumn{4}{|c|}{ CapEx } & \multicolumn{4}{|c|}{$\mathrm{R} \& \mathrm{D}$} & \multicolumn{3}{|c|}{ Margin } & \multirow{2}{*}{$\begin{array}{c}\text { EU-SMP } \\
1993 \\
\end{array}$} \\
\hline & Mean & Median & S.D. & $\mathrm{N}$ & Mean & Median & S.D. & $\mathrm{N}$ & Mean & Median & S.D. & \\
\hline & \multicolumn{11}{|c|}{ by Country } & \\
\hline Austria & 0.143 & 0.129 & 0.076 & 902 & 0.044 & 0.021 & 0.067 & 912 & 0.315 & 0.309 & 0.119 & No \\
\hline Belgium & 0.162 & 0.142 & 0.089 & 547 & 0.027 & 0.005 & 0.063 & 652 & 0.337 & 0.332 & 0.114 & Yes \\
\hline Denmark & 0.160 & 0.141 & 0.083 & 775 & - & - & - & 0 & 0.297 & 0.294 & 0.100 & Yes \\
\hline Finland & 0.142 & 0.123 & 0.088 & 889 & - & - & - & 0 & 0.352 & 0.343 & 0.115 & No \\
\hline France & 0.139 & 0.121 & 0.070 & 859 & 0.051 & 0.017 & 0.097 & 740 & 0.249 & 0.236 & 0.113 & Yes \\
\hline Germany & 0.118 & 0.106 & 0.058 & 559 & 0.052 & 0.019 & 0.076 & 587 & 0.249 & 0.247 & 0.100 & Yes \\
\hline Ireland & 0.141 & 0.122 & 0.089 & 607 & - & - & - & 0 & 0.399 & 0.402 & 0.145 & Yes \\
\hline Italy & 0.180 & 0.161 & 0.083 & 981 & 0.022 & 0.004 & 0.056 & 277 & 0.414 & 0.422 & 0.103 & Yes \\
\hline Netherlands & 0.126 & 0.109 & 0.070 & 836 & - & - & - & 0 & 0.358 & 0.349 & 0.111 & Yes \\
\hline Portugal & 0.239 & 0.226 & 0.109 & 509 & 0.001 & 0.000 & 0.005 & 534 & 0.366 & 0.364 & 0.131 & Yes \\
\hline Spain & 0.134 & 0.116 & 0.077 & 974 & 0.027 & 0.012 & 0.047 & 168 & 0.359 & 0.351 & 0.109 & Yes \\
\hline Sweden & 0.148 & 0.131 & 0.077 & 880 & 0.050 & 0.010 & 0.093 & 259 & 0.287 & 0.278 & 0.127 & No \\
\hline \multirow[t]{2}{*}{ UK } & 0.122 & 0.107 & 0.066 & 836 & 0.035 & 0.009 & 0.084 & 593 & 0.390 & 0.386 & 0.122 & Yes \\
\hline & \multicolumn{11}{|c|}{ by NACE 2-digit Industry } & \\
\hline 15 - Food products and beverages & 0.203 & 0.184 & 0.089 & 720 & 0.007 & 0.004 & 0.008 & 340 & 0.427 & 0.422 & 0.105 & - \\
\hline $17-$ Textiles & 0.143 & 0.127 & 0.080 & 544 & 0.009 & 0.005 & 0.010 & 259 & 0.297 & 0.300 & 0.092 & - \\
\hline 18 - Apparel & 0.099 & 0.080 & 0.070 & 205 & 0.001 & 0.000 & 0.002 & 96 & 0.335 & 0.319 & 0.138 & - \\
\hline 19 - Leather & 0.093 & 0.083 & 0.047 & 204 & 0.004 & 0.003 & 0.006 & 89 & 0.314 & 0.307 & 0.099 & - \\
\hline 20 - Wood, products of wood and cork & 0.176 & 0.160 & 0.089 & 419 & 0.002 & 0.001 & 0.002 & 167 & 0.347 & 0.326 & 0.109 & - \\
\hline 21 - Pulp, paper and paper products & 0.198 & 0.180 & 0.088 & 169 & 0.006 & 0.005 & 0.004 & 75 & 0.418 & 0.419 & 0.100 & - \\
\hline 22 - Printing and publishing & 0.149 & 0.129 & 0.091 & 236 & 0.001 & 0.001 & 0.002 & 112 & 0.371 & 0.366 & 0.116 & - \\
\hline 23 - Coke, refined petroleum products and nuclear fuel & 0.214 & 0.203 & 0.124 & 46 & 0.021 & 0.007 & 0.029 & 32 & 0.558 & 0.584 & 0.133 & - \\
\hline 24 - Chemicals & 0.161 & 0.138 & 0.084 & 509 & 0.067 & 0.050 & 0.076 & 250 & 0.412 & 0.422 & 0.116 & - \\
\hline 25 - Rubber and plastics & 0.161 & 0.155 & 0.063 & 170 & 0.030 & 0.014 & 0.041 & 78 & 0.337 & 0.339 & 0.088 & - \\
\hline 26 - Other non-metallic mineral products & 0.173 & 0.158 & 0.088 & 597 & 0.008 & 0.004 & 0.010 & 281 & 0.391 & 0.386 & 0.132 & - \\
\hline 27 - Basic metals & 0.175 & 0.161 & 0.080 & 351 & 0.014 & 0.007 & 0.016 & 179 & 0.333 & 0.323 & 0.122 & - \\
\hline 28 - Fabricated metal products & 0.131 & 0.117 & 0.066 & 554 & 0.008 & 0.004 & 0.010 & 262 & 0.301 & 0.305 & 0.099 & - \\
\hline 29 - Machinery and equipment & 0.111 & 0.100 & 0.050 & 549 & 0.073 & 0.037 & 0.143 & 268 & 0.293 & 0.298 & 0.102 & - \\
\hline 31 - Electrical machinery & 0.126 & 0.115 & 0.066 & 469 & 0.050 & 0.037 & 0.049 & 218 & 0.300 & 0.307 & 0.123 & - \\
\hline 32 - Radio, television and communication equipment & 0.165 & 0.141 & 0.100 & 211 & 0.194 & 0.172 & 0.161 & 112 & 0.302 & 0.301 & 0.149 & - \\
\hline 33 - Medical, precision and optical instruments & 0.096 & 0.086 & 0.053 & 387 & 0.067 & 0.048 & 0.074 & 188 & 0.323 & 0.314 & 0.131 & - \\
\hline 34 - Motor vehicles & 0.173 & 0.159 & 0.096 & 237 & 0.062 & 0.019 & 0.079 & 117 & 0.302 & 0.291 & 0.128 & - \\
\hline 35 - Other transport equipment & 0.117 & 0.104 & 0.062 & 325 & 0.060 & 0.020 & 0.087 & 153 & 0.252 & 0.261 & 0.131 & - \\
\hline 36 - Manufacturing N.E.C. & 0.121 & 0.109 & 0.067 & 445 & 0.019 & 0.005 & 0.049 & 213 & 0.348 & 0.335 & 0.106 & - \\
\hline 37 - Recycling & 0.248 & 0.242 & 0.101 & 136 & 0.001 & 0.000 & 0.002 & 62 & 0.468 & 0.496 & 0.119 & - \\
\hline
\end{tabular}

Note: The number of observations, N, corresponds to industry-country-year observations with non-missing values of 'CapEx' and 'Margin' ('R\&D' and 'Margin') across 101 three-digit NACE manufacturing industries in $13 \mathrm{EU}$ countries over the period 1995-2004 'CapEx' is defined as gross investments in tangible goods divided by value-added. 'R\&D' is defined as total intra-mural R\&D expenditure divided by value-added. 'Margin' is defined as operating profit and is scaled by value-added. 'EU-SMP 1993' indicates which countries participated in the EU 'Single Market Programme' at its inception in 1993. Austria, Finland, and Sweden joined the EU in 1995. The statistics in the bottom panel are based on the 'EU-SMP 1993' countries only - my main sample. Before computing the statistics (Mean, Median, and Standard Deviation), I remove outliers by using the 1-to-99 percentile range of the variables. See the Data Appendix for complete definitions and sources of variables. 
Table 2

Financial Development: EU 'single-market' Countries in 1990-1994

\begin{tabular}{|c|c|c|c|c|}
\hline & $\begin{array}{l}\text { Private } \\
\text { Credit }\end{array}$ & $\begin{array}{c}\text { Market } \\
\text { Capitalization }\end{array}$ & $\begin{array}{c}\text { Market Value } \\
\text { Traded }\end{array}$ & $\begin{array}{c}\text { Accounting } \\
\text { Standards }\end{array}$ \\
\hline & \multicolumn{4}{|c|}{ Basic Statistics } \\
\hline Mean & 0.79 & 0.34 & 0.15 & 62 \\
\hline Median & 0.72 & 0.27 & 0.12 & 62 \\
\hline S.D. / Mean & 0.39 & 0.73 & 0.83 & 0.18 \\
\hline Min & 0.42 & 0.13 & 0.04 & 36 \\
\hline $\operatorname{Max}$ & 1.41 & 0.97 & 0.45 & 78 \\
\hline Min Country & Denmark & Belgium & Belgium & Belgium \\
\hline Max Country & Netherlands & UK & UK & UK \\
\hline \multirow[t]{2}{*}{$\mathrm{N}$} & 10 & 10 & 10 & 9 \\
\hline & \multicolumn{4}{|c|}{ Correlations } \\
\hline Private Credit & 1.00 & & & \\
\hline Market Capitalization & $0.58 *$ & 1.00 & & \\
\hline Market Value Traded & $0.66^{* *}$ & $0.89 * * *$ & 1.00 & \\
\hline \multirow[t]{2}{*}{ Accounting Standards } & 0.48 & $0.66^{*}$ & $0.65 *$ & 1.00 \\
\hline & \multicolumn{4}{|c|}{ High/Low Financial Development Country Groups } \\
\hline Austria & High & Low & Low & Low \\
\hline Belgium & Low & High & Low & Low \\
\hline Denmark & Low & High & Low & Low \\
\hline Finland & Low & Low & Low & High \\
\hline France & High & High & High & High \\
\hline Germany & High & Low & High & Low \\
\hline Ireland & Low & Low & High & - \\
\hline Italy & Low & Low & Low & Low \\
\hline Netherlands & High & High & High & High \\
\hline Portugal & Low & Low & Low & Low \\
\hline Spain & Low & Low & Low & High \\
\hline Sweden & High & High & High & High \\
\hline UK & High & High & High & High \\
\hline
\end{tabular}

Note: The top panel: I first compute the country average of each financial development measure in the period 1990-1994 (the exception is Accounting Standards, which corresponds to 1990). Second, I present the Mean, Median, Coefficient of Variation, Min, and Max of the country averages from the first step across 10 EU countries that participated in the EU 'Single Market Programme' at its inception in 1993 (see Table 1). The bottom panel classifies countries into a high or low financial development group based on above/below median levels of the respective financial development measure. The financial development measures and high/low indicators are used as explanatory variables in regressions. See the Data Appendix for complete definitions and sources of variables. 
Table 3

Descriptive Statistics by Competition and Financial Development

\begin{tabular}{|c|c|c|c|c|c|c|}
\hline & \multicolumn{2}{|c|}{$\begin{array}{c}\text { Intense Competition } \\
\text { Margin }<25 \mathrm{pct}\end{array}$} & \multirow{2}{*}{\multicolumn{2}{|c|}{$\begin{array}{c}\text { Medium Competition } \\
25 \mathrm{pct}<\text { Margin }<75 \mathrm{pct} \\
\text { Private Credit }\end{array}$}} & \multicolumn{2}{|c|}{$\begin{array}{c}\text { Relaxed Competition } \\
\text { Margin }>75 \mathrm{pct}\end{array}$} \\
\hline & & & & & & \\
\hline & High & Low & High & Low & High & Low \\
\hline Margin & 0.189 & 0.227 & 0.319 & 0.363 & 0.471 & 0.500 \\
\hline CapEx & 0.096 & 0.128 & 0.111 & 0.154 & 0.140 & 0.176 \\
\hline R\&D & 0.022 & 0.003 & 0.014 & 0.002 & 0.008 & 0.000 \\
\hline N - CapEx & 999 & 824 & 2,046 & 1,717 & 1,019 & 878 \\
\hline \multirow[t]{3}{*}{ N - R\&D } & 756 & 362 & 933 & 764 & 399 & 337 \\
\hline & \multicolumn{6}{|c|}{ Market Capitalization } \\
\hline & High & Low & High & Low & High & Low \\
\hline Margin & 0.194 & 0.224 & 0.315 & 0.367 & 0.471 & 0.503 \\
\hline CapEx & 0.107 & 0.105 & 0.125 & 0.144 & 0.135 & 0.176 \\
\hline R\&D & 0.015 & 0.015 & 0.011 & 0.002 & 0.005 & 0.000 \\
\hline N - CapEx & 945 & 913 & 1,945 & 1,821 & 963 & 896 \\
\hline \multirow[t]{3}{*}{ N - R\&D } & 603 & 580 & 907 & 708 & 475 & 278 \\
\hline & \multicolumn{6}{|c|}{ Market Value Traded } \\
\hline & High & Low & High & Low & High & Low \\
\hline Margin & 0.182 & 0.231 & 0.320 & 0.354 & 0.489 & 0.486 \\
\hline CapEx & 0.097 & 0.118 & 0.114 & 0.147 & 0.127 & 0.193 \\
\hline $\mathrm{R} \& \mathrm{D}$ & 0.022 & 0.003 & 0.014 & 0.002 & 0.008 & 0.001 \\
\hline N - CapEx & 913 & 909 & 1,858 & 1,922 & 926 & 955 \\
\hline \multirow[t]{3}{*}{ N - R\&D } & 701 & 390 & 916 & 802 & 303 & 439 \\
\hline & \multicolumn{6}{|c|}{ Accounting Standards } \\
\hline & High & Low & High & Low & High & Low \\
\hline Margin & 0.202 & 0.235 & 0.332 & 0.337 & 0.485 & 0.479 \\
\hline CapEx & 0.097 & 0.117 & 0.112 & 0.152 & 0.140 & 0.193 \\
\hline $\mathrm{R} \& \mathrm{D}$ & 0.017 & 0.015 & 0.014 & 0.003 & 0.008 & 0.001 \\
\hline N - CapEx & 862 & 1,443 & 1,766 & 1,688 & 877 & 847 \\
\hline$N-R \& D$ & 550 & 597 & 626 & 987 & 325 & 466 \\
\hline
\end{tabular}

Note: The Table reports Median of 'Margin', 'CapEx', and 'R\&D' across $10 \mathrm{EU}$ countries that participated in the EU 'Single Market Programme' at its inception in 1993 (see Table 1). Medians are reported individually for industries characterized by 'Intense Competition' (defined as the first quartile of 'Margin' variable), 'Medium Competition' (defined as the second together with the third quartile of 'Margin' variable), and 'Relaxed Competition' (defined as the fourth quartile of 'Margin' variable) separately for high/low financial development country groups (see Table 2). ' $\mathrm{N}$ - CapEx' is the number of industry-country. year observations with non-missing values of 'CapEx' and 'Margin'; ' $N$ - R\&D' is the number of industrycountry-year observations with non-missing values of 'R\&D' and 'Margin'. See the Data Appendix for complete definitions and sources of variables. 
Table 4

EU 'Single Market Programme' (SMP): Industry-Country Pairs Affected by the Reform

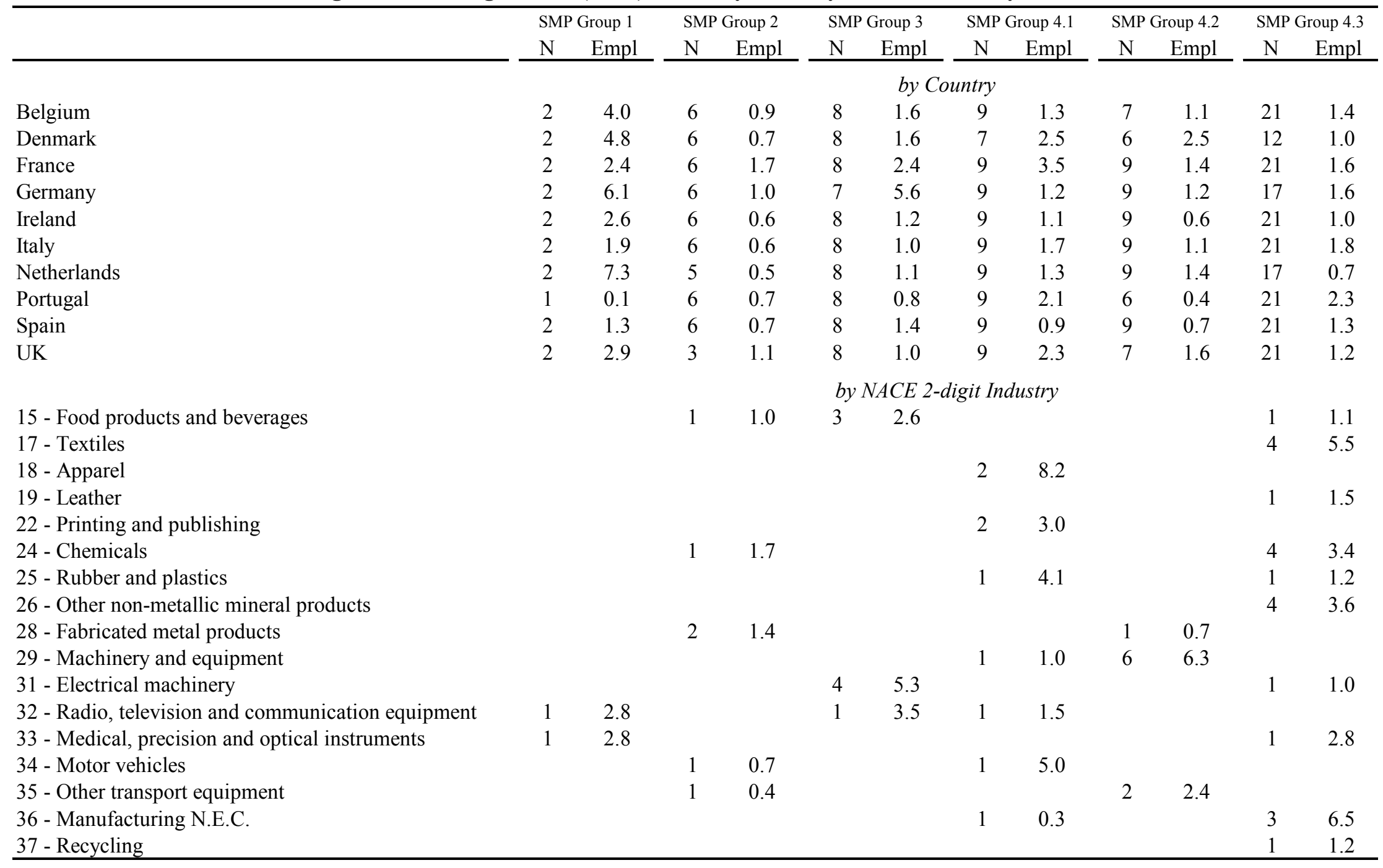

Note: The Table lists the number (columns 'N') of NACE 3-digit industries identified (ex ante) to be affected by introduction of the 'Single Market Programme' (SMP) of the EU in 1993 (EU-wide product market reform), and the typical size of an affected industry (columns 'Empl') measured as the median percentage share of affected industries in total manufacturing employment (average over 1985-1987) as presented in Buigues et al. (1990). The top panel of the Table counts the affected industries by country while the bottom panel groups the affected industries by NACE 2-digit industry codes. Based on the type of pre-existing barriers to competition, the affected industries were divided into six groups; SMP Group 1: High-technology, public-procurement markets; SMP Group 2: Traditional public-procurement and regulated markets (High price dispersion); SMP Group 3: Traditional public-procurement and regulated markets (Low price dispersion); SMP Group 4.1: Sectors with moderate non-tariff barriers (Consumer goods); SMP Group 4.2: Sectors with moderate non-tariff barriers (Investment goods); SMP Group 4.3: Sectors with moderate non-tariff barriers (Intermediate goods). See the Data Appendix for complete definitions and sources of variables. 
Table 5

R\&D / Capital Expenditures and Competition

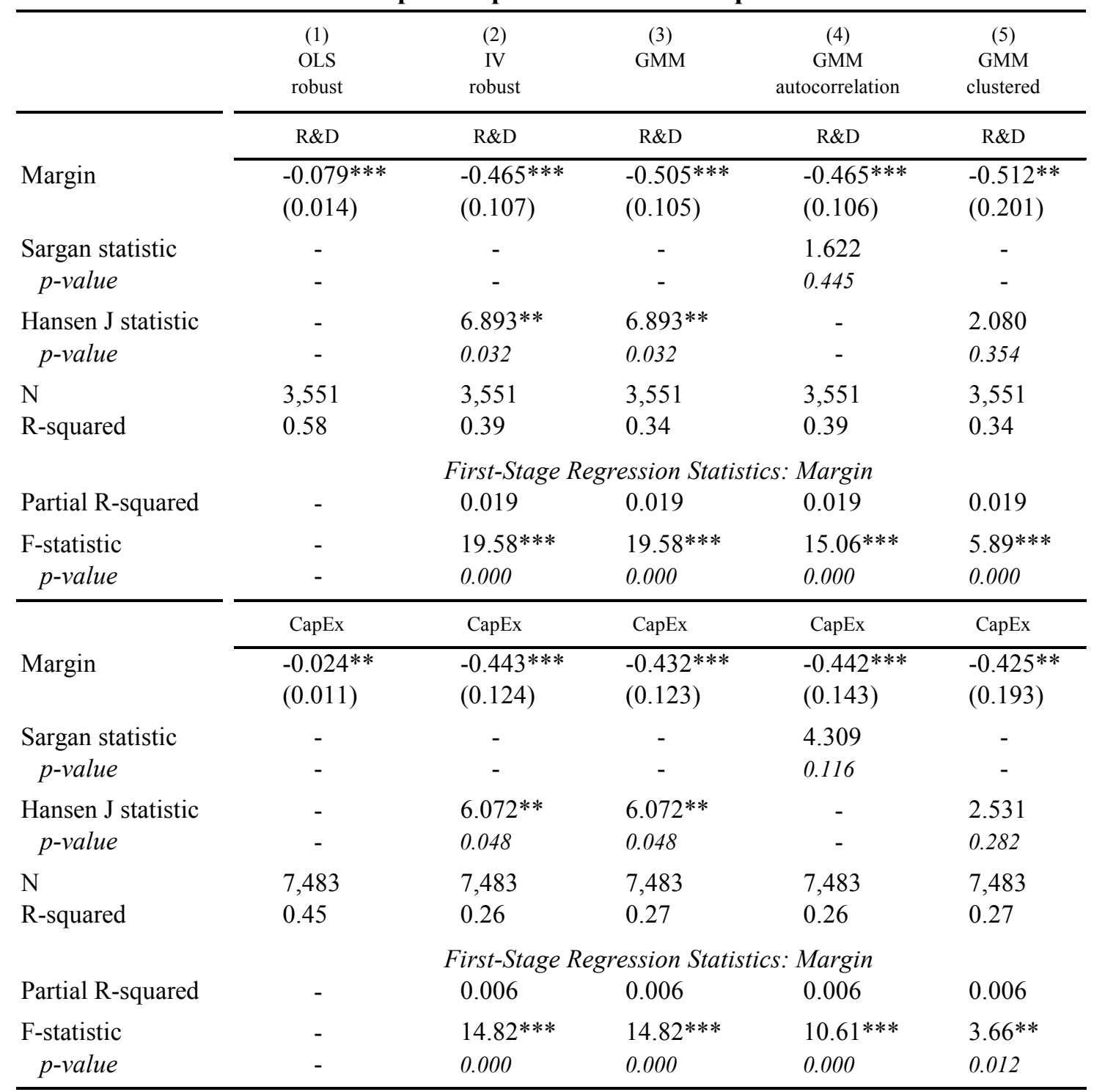

Note: The sample consists of 101 three-digit NACE manufacturing industries across 10 countries that participated in the EU 'Single Market Programme' at its inception in 1993 (see Table 1) over the period 1995-2004. The dependent variable in the first (second) panel is 'R\&D' ('CapEx'). 'Margin' is instrumented using the EU 'Single Market Programme' variables described in Table 4. The estimated specifications are as follows: (1) classical linear regression with heteroskedastic-robust standard errors; (2) instrumental variables (IV) estimator with heteroskedastic-robust standard errors (using EickerHuber-White "sandwich" variance-covariance matrix); (3) feasible heteroskedastic-efficient two-step generalized methods of moment (GMM) estimator; (4) GMM estimator with autocorrelation-consistent and heteroskedastic-and-autocorrelation-consistent standard errors; (5) GMM estimator with standard errors clustered at the country-industry level. Sargan (Hansen J) statistics correspond to tests of overidentifying restrictions. Partial R-squared is for the EU 'Single Market Programme' variables in the first-stage regressions; similarly, F-statistic is the test of the joint significance of these variables in the first-stage regressions. See the Data Appendix for complete definitions and sources of variables. I remove outliers by using the 1-to-99 percentile range of the dependent variable. I always control for 3digit-NACE industry, country, and year dummies, not shown. Standard errors are reported in parentheses; $* * *$, and $* * *$ denote significance at the $10 \%, 5 \%$, and $1 \%$ level, respectively. 
Table 6

Competition: Financial Development (FD) Full Interaction Specification

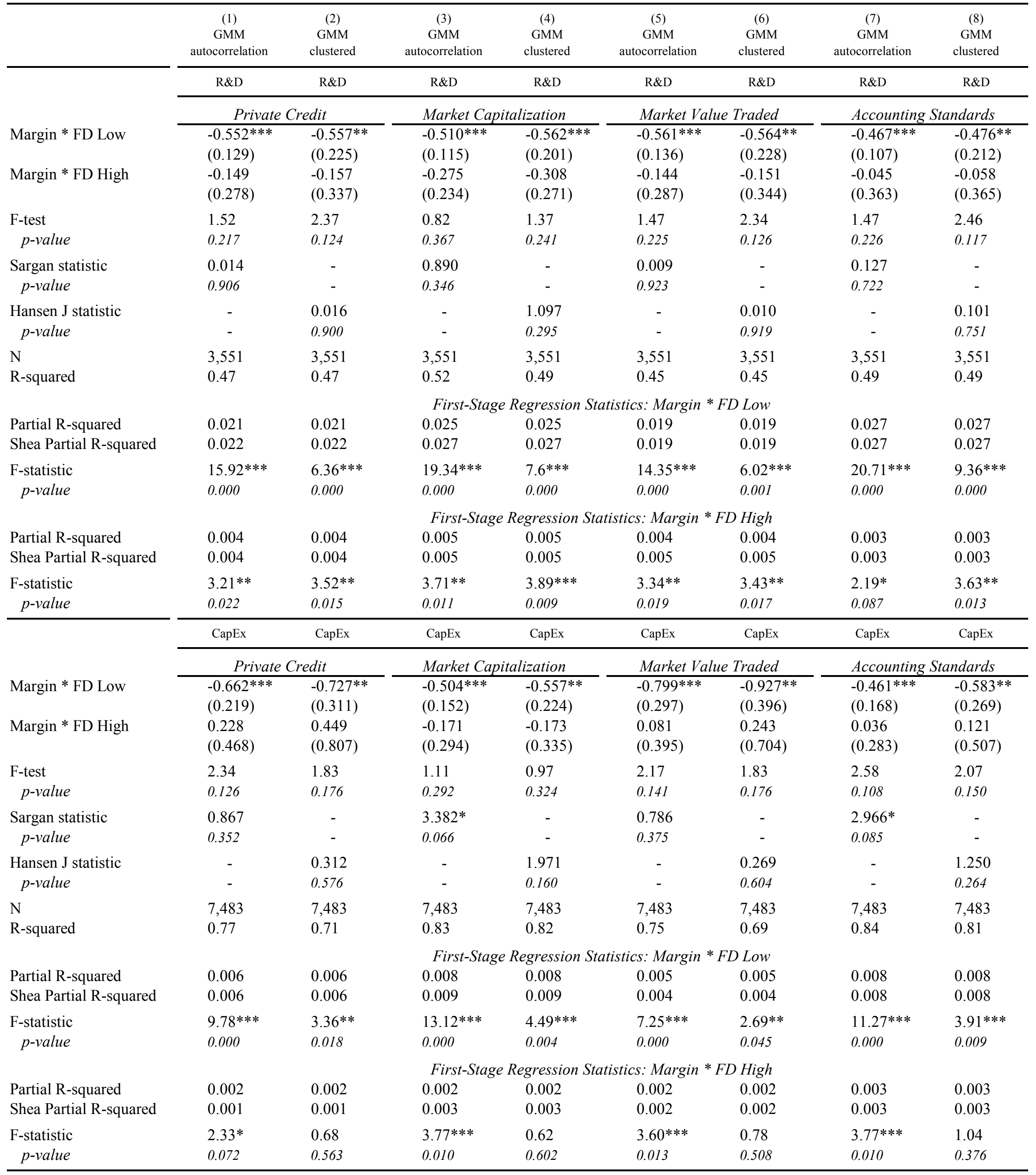

Note: The data are the same as in Table 5. The dependent variable in the top (bottom) panel is 'R\&D' ('CapEx'). 'Margin * FD Low' stands for 'Margin' variable interacted with 0/1 variable equal 1 for low financial development countries. 'Margin * FD High' is defined analogously. See Table 2 for definitions of High/Low financial development country groups. 'Margin * FD Low' and 'Margin * FD High' are instrumented using the EU 'Single Market Programme' variables described in Table 4. The estimated specifications (1), (3), (5), and (7) use the generalized method of moments (GMM) estimator with autocorrelation-consistent and heteroskedastic-and-autocorrelation-consistent standard errors; specifications (2), (4), (6), and (8) use the GMM estimator with standard errors clustered at the country-industry level. F-test is the test of the difference of coefficients 'Margin * FD Low' and 'Margin * FD High' in the second-stage regression. Sargan (Hansen J) statistic corresponds to tests of overidentifying restrictions. (Shea) Partial R-squared is for the EU 'Single Market Programme' variables in the first-stage regressions; similarly, F-statistic is the test of the joint significance of these variables in the first-stage regressions. See the Data Appendix for complete definitions and sources of variables. I remove outliers by using the 1-to-99 percentile range of the dependent variable. I always control for 3-digit-NACE industry, country, and year dummies, not shown. Standard errors are reported in parentheses; *, **, and *** denote significance at the $10 \%, 5 \%$, and $1 \%$ level, respectively. 
Table 7

'Intense' Competition: Financial Development (FD) Full Interaction Specification

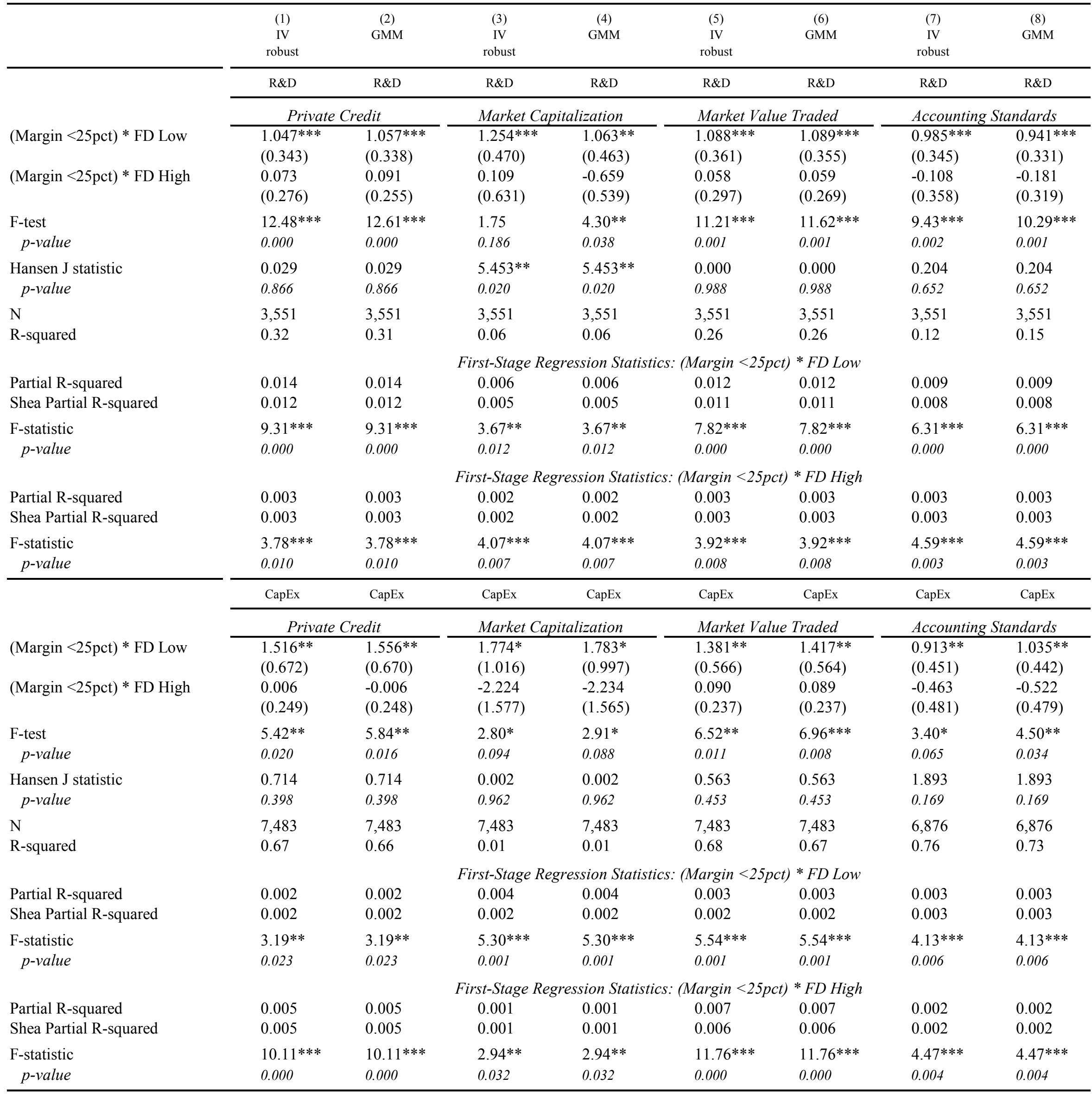

Note: The Table is analogous to Table 6 except I interact 0 to 25 percent of the 'Margin' variable. '(Margin $<25$ pct) * FD Low' and '(Margin $<25$ pct) * FD High' are instrumented using the EU 'Single Market Programme' variables described in Table 4. The estimated specifications (1), (3), (5), and (7) use instrumental variables (IV) estimator with heteroskedastic-robust standard errors (using Eicker-Huber-White "sandwich" variance-covariance matrix); specifications (2), (4), (6), and (8) use feasible heteroskedastic-efficient two-step generalized methods of moment (GMM) estimator. F-test is the test of the difference of coefficients '(Margin $<25 \mathrm{pct}) * \mathrm{FD}$ Low' and '(Margin <25pct) * FD High' in the second-stage regression. Hansen J statistic corresponds to tests of overidentifying restrictions. (Shea) Partial R-squared is for the EU 'Single Market Programme' variables in the first-stage regressions; similarly, F-statistic is the test of the joint significance of these variables in the firststage regressions. See the Data Appendix for complete definitions and sources of variables. I remove outliers by using the 1-to-99 percentile range of the dependent variable. I always control for 3-digit-NACE industry, country, and year dummies, not shown. Standard errors are reported in parentheses; *, **, and *** denote significance at the $10 \%, 5 \%$, and $1 \%$ level, respectively. 
Table 8

'Relaxed' Competition: Financial Development (FD) Full Interaction Specification

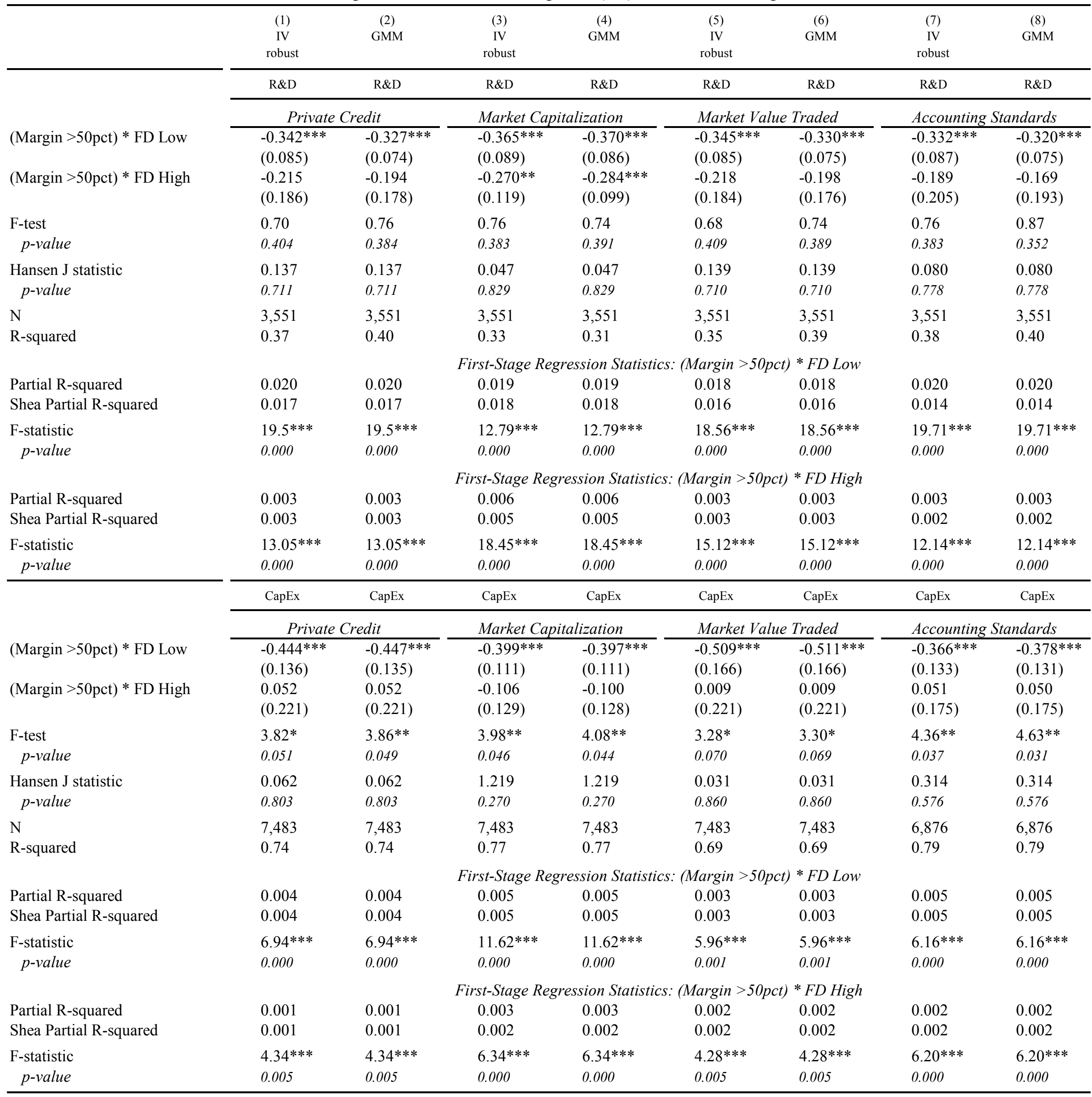

Note: The Table is analogous to Table 6 except I interact 50 to 100 percent of the 'Margin' variable. '(Margin $>50 \mathrm{pct}) *$ FD Low' and '(Margin $>50 \mathrm{pct}) *$ FD High' are instrumented using the EU 'Single Market Programme' variables described in Table 4. The estimated specifications (1), (3), (5), and (7) use instrumental variables (IV) estimator with heteroskedastic-robust standard errors (using Eicker-Huber-White "sandwich" variance-covariance matrix); specifications (2), (4), (6), and (8) use a feasible heteroskedastic-efficient two-step generalized methods of moment (GMM) estimator. F-test is the test of difference of coefficients '(Margin $>50 \mathrm{pct}) *$ FD Low' and '(Margin >50pct) * FD High' in the second-stage regression. Hansen J statistic corresponds to tests of overidentifying restrictions. (Shea) Partial R-squared is for the EU 'Single Market Programme' variables in the first-stage regressions; similarly, F-statistic is the test of the joint significance of these variables in the first-stage regressions. See the Data Appendix for complete definitions and sources of variables. I remove outliers by using the 1-to-99 percentile range of the dependent variable. I always control for 3-digit-NACE industry, country, and year dummies, not shown. Standard errors are reported in parentheses; *, $* *$, and $* * *$ denote significance at the $10 \%, 5 \%$, and $1 \%$ level, respectively. 
Table A.1

'Intense' Competition: Robustness to Autocorrelation and Clustering

\begin{tabular}{|c|c|c|c|c|c|c|c|c|}
\hline & $\begin{array}{c}\text { (1) } \\
\text { GMM } \\
\text { autocorrelation }\end{array}$ & $\begin{array}{c}(2) \\
\text { GMM } \\
\text { clustered }\end{array}$ & $\begin{array}{c}(3) \\
\text { GMM } \\
\text { autocorrelation }\end{array}$ & $\begin{array}{c}(4) \\
\text { GMM } \\
\text { clustered }\end{array}$ & $\begin{array}{c}(5) \\
\text { GMM } \\
\text { autocorrelation }\end{array}$ & $\begin{array}{c}(6) \\
\text { GMM } \\
\text { clustered }\end{array}$ & $\begin{array}{c}(7) \\
\text { GMM } \\
\text { autocorrelation }\end{array}$ & $\begin{array}{c}(8) \\
\text { GMM } \\
\text { clustered }\end{array}$ \\
\hline & $R \& D$ & $R \& D$ & $\mathrm{R} \& \mathrm{D}$ & $R \& D$ & $R \& D$ & $\mathrm{R} \& \mathrm{D}$ & $R \& D$ & $R \& D$ \\
\hline & \multicolumn{2}{|c|}{ Private Credit } & \multicolumn{2}{|c|}{ Market Capitalization } & \multicolumn{2}{|c|}{ Market Value Traded } & \multicolumn{2}{|c|}{ Accounting Standards } \\
\hline$($ Margin $<25 p c t) *$ FD Low & $\begin{array}{l}1.047 * * * \\
(0.270)\end{array}$ & $\begin{array}{l}1.071 \\
(0.664)\end{array}$ & $\begin{array}{l}1.254 * * * \\
(0.436)\end{array}$ & $\begin{array}{l}1.040 \\
(0.749)\end{array}$ & $\begin{array}{l}1.088^{* * *} \\
(0.285)\end{array}$ & $\begin{array}{l}1.090 \\
(0.686)\end{array}$ & $\begin{array}{l}0.985^{* * *} \\
(0.292)\end{array}$ & $\begin{array}{l}0.922 \\
(0.612)\end{array}$ \\
\hline$($ Margin $<25 \mathrm{pct}) *$ FD High & $\begin{array}{l}0.073 \\
(0.411)\end{array}$ & $\begin{array}{l}0.091 \\
(0.561)\end{array}$ & $\begin{array}{l}0.108 \\
(0.628)\end{array}$ & $\begin{array}{l}-0.322 \\
(0.955)\end{array}$ & $\begin{array}{l}0.058 \\
(0.429)\end{array}$ & $\begin{array}{l}0.059 \\
(0.591)\end{array}$ & $\begin{array}{l}-0.108 \\
(0.534)\end{array}$ & $\begin{array}{l}-0.144 \\
(0.711)\end{array}$ \\
\hline F-test & $5.44 * *$ & $3.09 *$ & 1.67 & 1.07 & $5.13 * *$ & $2.88^{*}$ & $4.28 * *$ & 2.45 \\
\hline p-value & 0.020 & 0.079 & 0.196 & 0.301 & 0.024 & 0.090 & 0.039 & 0.117 \\
\hline Sargan statistic & 0.023 & - & 2.569 & - & 0.000 & - & 0.129 & - \\
\hline p-value & 0.878 & - & 0.109 & - & 0.989 & - & 0.720 & - \\
\hline Hansen J statistic & - & 0.012 & - & 1.409 & - & 0.000 & - & 0.070 \\
\hline p-value & - & 0.914 & - & 0.235 & - & 0.993 & - & 0.791 \\
\hline $\mathrm{N}$ & 3,551 & 3,551 & 3,551 & 3,551 & 3,551 & 3,551 & 3,551 & 3,551 \\
\hline \multirow[t]{2}{*}{ R-squared } & 0.32 & 0.30 & 0.06 & 0.15 & 0.26 & 0.26 & 0.12 & 0.18 \\
\hline & \multicolumn{8}{|c|}{ First-Stage Regression Statistics: (Margin $<25 p c t) * F D$ Low } \\
\hline Partial R-squared & 0.014 & 0.014 & 0.006 & 0.006 & 0.012 & 0.012 & 0.009 & 0.009 \\
\hline Shea Partial R-squared & 0.012 & 0.012 & 0.005 & 0.005 & 0.011 & 0.011 & 0.008 & 0.008 \\
\hline F-statistic & $11.68 * * *$ & $2.84 * *$ & $5.21 * * *$ & 1.59 & $10.15 * * *$ & $2.53 *$ & $7.44 * * *$ & $2.83 * *$ \\
\hline \multirow[t]{2}{*}{ p-value } & 0.000 & 0.037 & 0.001 & 0.190 & 0.000 & 0.056 & 0.000 & 0.038 \\
\hline & \multicolumn{8}{|c|}{ First-Stage Regression Statistics: (Margin $<25 p c t) *$ FD High } \\
\hline Partial R-squared & 0.003 & 0.003 & 0.002 & 0.002 & 0.003 & 0.003 & 0.003 & 0.003 \\
\hline Shea Partial R-squared & 0.003 & 0.003 & 0.002 & 0.002 & 0.003 & 0.003 & 0.003 & 0.003 \\
\hline F-statistic & $2.63 * *$ & $2.29 *$ & 1.60 & 1.39 & $2.55^{*}$ & $2.59 *$ & $2.81 * *$ & $2.20 *$ \\
\hline \multirow[t]{3}{*}{$p$-value } & 0.048 & 0.078 & 0.188 & 0.245 & 0.054 & 0.052 & 0.038 & 0.087 \\
\hline & CapEx & CapEx & CapEx & CapEx & CapEx & CapEx & CapEx & CapEx \\
\hline & \multicolumn{2}{|c|}{ Private Credit } & \multicolumn{2}{|c|}{ Market Capitalization } & \multicolumn{2}{|c|}{ Market Value Traded } & \multicolumn{2}{|c|}{ Accounting Standards } \\
\hline$($ Margin $<25 \mathrm{pct}) *$ FD Low & $\begin{array}{l}1.513^{* *} \\
(0.589)\end{array}$ & $\begin{array}{l}1.673 \\
(1.218)\end{array}$ & $\begin{array}{l}1.774 \\
(1.125)\end{array}$ & $\begin{array}{l}1.788 \\
(1.676)\end{array}$ & $\begin{array}{l}1.379 * * * \\
(0.525)\end{array}$ & $\begin{array}{l}1.515 \\
(1.016)\end{array}$ & $\begin{array}{l}0.911 * * \\
(0.405)\end{array}$ & $\begin{array}{l}1.139 \\
(0.763)\end{array}$ \\
\hline$($ Margin $<25 \mathrm{pct}) *$ FD High & $\begin{array}{l}0.005 \\
(0.321)\end{array}$ & $\begin{array}{l}0.006 \\
(0.450)\end{array}$ & $\begin{array}{l}-2.224 \\
(1.738)\end{array}$ & $\begin{array}{l}-2.239 \\
(2.666)\end{array}$ & $\begin{array}{l}0.089 \\
(0.305)\end{array}$ & $\begin{array}{l}0.105 \\
(0.426)\end{array}$ & $\begin{array}{l}-0.462 \\
(0.502)\end{array}$ & $\begin{array}{l}-0.569 \\
(0.801)\end{array}$ \\
\hline F-test & $5.99 * *$ & 2.00 & 2.27 & 1.03 & $6.51 * *$ & 2.41 & $3.76^{*}$ & 1.84 \\
\hline p-value & 0.014 & 0.157 & 0.132 & 0.311 & 0.011 & 0.120 & 0.053 & 0.175 \\
\hline Sargan statistic & 0.935 & - & 0.002 & - & 0.660 & - & 2.129 & - \\
\hline p-value & 0.333 & - & 0.964 & - & 0.417 & - & 0.145 & - \\
\hline Hansen J statistic & - & 0.239 & - & 0.001 & - & 0.183 & - & 0.636 \\
\hline$p$-value & - & 0.625 & - & 0.979 & - & 0.668 & - & 0.425 \\
\hline $\mathrm{N}$ & 7,483 & 7,483 & 7,483 & 7,483 & 7,483 & 7,483 & 7,483 & 7,483 \\
\hline \multirow[t]{2}{*}{ R-squared } & 0.67 & 0.63 & 0.01 & 0.02 & 0.68 & 0.65 & 0.76 & 0.70 \\
\hline & \multicolumn{8}{|c|}{ First-Stage Regression Statistics: (Margin $<25 p c t) *$ FD Low } \\
\hline Partial R-squared & 0.002 & 0.002 & 0.004 & 0.004 & 0.003 & 0.003 & 0.003 & 0.003 \\
\hline Shea Partial R-squared & 0.002 & 0.002 & 0.002 & 0.002 & 0.002 & 0.002 & 0.003 & 0.003 \\
\hline F-statistic & $3.98 * * *$ & 1.08 & $7.04 * * *$ & $2.25^{*}$ & $4.9 * * *$ & 1.92 & $4.93 * * *$ & 1.41 \\
\hline \multirow[t]{2}{*}{$p$-value } & 0.008 & 0.355 & 0.000 & 0.082 & 0.002 & 0.124 & 0.002 & 0.238 \\
\hline & \multicolumn{8}{|c|}{ First-Stage Regression Statistics: (Margin $<25 p c t) *$ FD High } \\
\hline Partial R-squared & 0.005 & 0.005 & 0.001 & 0.001 & 0.007 & 0.007 & 0.002 & 0.002 \\
\hline Shea Partial R-squared & 0.005 & 0.005 & 0.001 & 0.001 & 0.006 & 0.006 & 0.002 & 0.002 \\
\hline F-statistic & $9.74 * * *$ & $5.75 * * *$ & 1.78 & 0.86 & $12.39 * * *$ & $6.9 * * *$ & $3.33 * *$ & 1.37 \\
\hline p-value & 0.000 & 0.001 & 0.149 & 0.460 & 0.000 & 0.000 & 0.019 & 0.251 \\
\hline
\end{tabular}

Note: The Table is analogous to Table 7 except here I use the generalized method of moments (GMM) estimator with autocorrelation-consistent and heteroskedasticand-autocorrelation-consistent standard errors in specifications (1), (3), (5), and (7); the and GMM estimator with standard errors clustered at the country-industry level in specifications (2), (4), (6), and (8). F-test is the test of difference of coefficients '(Margin <25pct) * FD Low' and '(Margin <25pct) * FD High' in the secondstage regression. Sargan (Hansen J) statistic corresponds to tests of overidentifying restrictions. Partial R-squared is for the EU 'Single Market Programme’ variables in the first-stage regressions; similarly, F-statistic is the test of the joint significance of these variables in the first-stage regressions. See the Data Appendix for complete definitions and sources of variables. I remove outliers by using the 1-to-99 percentile range of the dependent variable. I always control for 3-digit-NACE industry, country, and year dummies, not shown. Standard errors are reported in parentheses; *, **, and *** denote significance at the $10 \%$, $5 \%$, and $1 \%$ level, respectively. 
Table A.2

'Relaxed' Competition: Robustness to Autocorrelation and Clustering

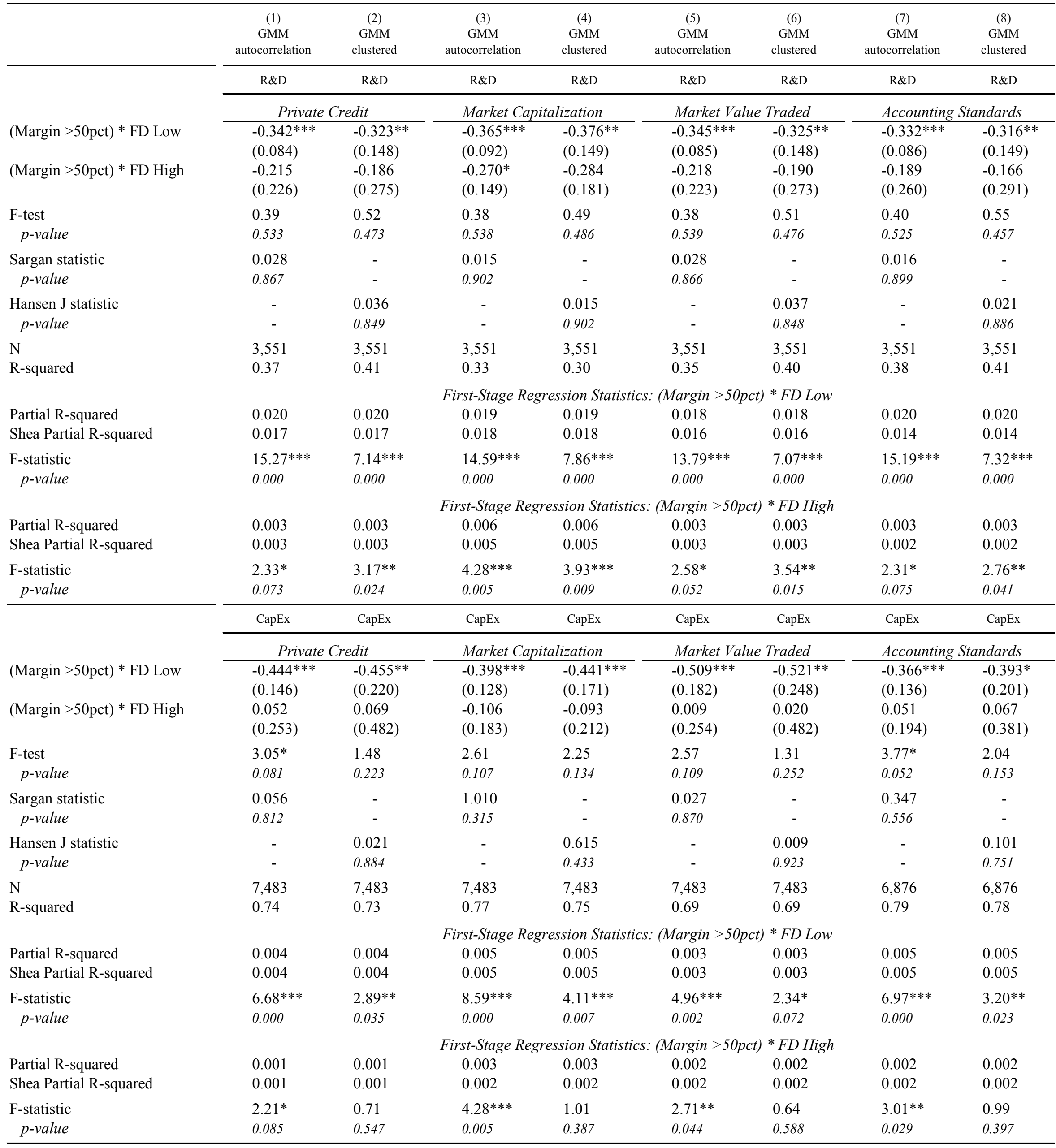

Note: The Table is analogous to Table 8 except here I use the generalized method of moments (GMM) estimator with autocorrelation-consistent and heteroskedasticand-autocorrelation-consistent standard errors in specifications (1), (3), (5), and (7); and the GMM estimator with standard errors clustered at the country-industry level in specifications (2), (4), (6), and (8). F-test is the test of difference of coefficients '(Margin >50pct) * FD Low' and '(Margin >50pct) * FD High' in the secondstage regression. Sargan (Hansen J) statistic corresponds to tests of overidentifying restrictions. Partial R-squared is for the EU 'Single Market Programme’ variables in the first-stage regressions; similarly, F-statistic is the test of the joint significance of these variables in the first-stage regressions. See the Data Appendix for complete definitions and sources of variables. I remove outliers by using the 1-to-99 percentile range of the dependent variable. I always control for 3-digit-NACE industry, country, and year dummies, not shown. Standard errors are reported in parentheses; *, **, and *** denote significance at the $10 \%$, $5 \%$, and $1 \%$ level, respectively. 
Table A.3

R\&D / Capital Expenditures and Competition: Financial Development (FD) Continuous Interaction

\begin{tabular}{|c|c|c|c|c|c|c|c|c|}
\hline & $\begin{array}{c}\text { (1) } \\
\text { GMM } \\
\text { autocorrelation }\end{array}$ & $\begin{array}{c}(2) \\
\text { GMM } \\
\text { clustered }\end{array}$ & $\begin{array}{c}(3) \\
\text { GMM } \\
\text { autocorrelation }\end{array}$ & $\begin{array}{c}(4) \\
\text { GMM } \\
\text { clustered }\end{array}$ & $\begin{array}{c}\text { (5) } \\
\text { GMM } \\
\text { autocorrelation }\end{array}$ & $\begin{array}{c}(6) \\
\text { GMM } \\
\text { clustered }\end{array}$ & $\begin{array}{c}\text { (7) } \\
\text { GMM } \\
\text { autocorrelation }\end{array}$ & $\begin{array}{c}(8) \\
\text { GMM } \\
\text { clustered }\end{array}$ \\
\hline & $R \& D$ & $R \& D$ & $R \& D$ & $R \& D$ & $R \& D$ & $R \& D$ & $\mathrm{R} \& \mathrm{D}$ & $\mathrm{R} \& \mathrm{D}$ \\
\hline & \multicolumn{2}{|c|}{ Private Credit } & \multicolumn{2}{|c|}{ Market Capitalization } & \multicolumn{2}{|c|}{ Market Value Traded } & \multicolumn{2}{|c|}{ Accounting Standards } \\
\hline Margin & $\begin{array}{l}-0.864 * * \\
(0.427)\end{array}$ & $\begin{array}{l}-0.944 * * \\
(0.372)\end{array}$ & $\begin{array}{l}-0.472 * * * \\
(0.118)\end{array}$ & $\begin{array}{l}-0.536^{* *} \\
(0.212)\end{array}$ & $\begin{array}{l}-0.478^{* * *} \\
(0.120)\end{array}$ & $\begin{array}{l}-0.546 * * \\
(0.213)\end{array}$ & $\begin{array}{l}-0.761 * * \\
(0.334)\end{array}$ & $\begin{array}{l}-0.833 * * \\
(0.324)\end{array}$ \\
\hline Margin * FD & $\begin{array}{l}0.620 \\
(0.642)\end{array}$ & $\begin{array}{l}0.654 \\
(0.500)\end{array}$ & $\begin{array}{l}0.035 \\
(0.244)\end{array}$ & $\begin{array}{l}0.077 \\
(0.236)\end{array}$ & $\begin{array}{l}0.131 \\
(0.581)\end{array}$ & $\begin{array}{l}0.233 \\
(0.548)\end{array}$ & $\begin{array}{l}0.647 \\
(0.695)\end{array}$ & $\begin{array}{l}0.671 \\
(0.570)\end{array}$ \\
\hline $\begin{array}{l}\text { Sargan statistic } \\
\text { p-value }\end{array}$ & $\begin{array}{l}0.687 \\
0.407\end{array}$ & $\begin{array}{l}- \\
-\end{array}$ & $\begin{array}{l}1.611 \\
0.204\end{array}$ & $\begin{array}{l}- \\
-\end{array}$ & $\begin{array}{l}1.580 \\
0.209\end{array}$ & $\begin{array}{l}- \\
-\end{array}$ & $\begin{array}{l}0.867 \\
0.352\end{array}$ & $\begin{array}{l}- \\
-\end{array}$ \\
\hline $\begin{array}{l}\text { Hansen J statistic } \\
\text { p-value }\end{array}$ & - & $\begin{array}{l}0.918 \\
0.338\end{array}$ & - & $\begin{array}{l}2.038 \\
0.153\end{array}$ & $\begin{array}{l}- \\
-\end{array}$ & $\begin{array}{l}2.023 \\
0.155\end{array}$ & - & $\begin{array}{l}1.174 \\
0.279\end{array}$ \\
\hline $\begin{array}{l}\mathrm{N} \\
\mathrm{R} \text {-squared }\end{array}$ & $\begin{array}{l}3,551 \\
0.50\end{array}$ & $\begin{array}{l}3,551 \\
0.46\end{array}$ & $\begin{array}{l}3,551 \\
0.49\end{array}$ & $\begin{array}{l}3,551 \\
0.45\end{array}$ & $\begin{array}{l}3,551 \\
0.49\end{array}$ & $\begin{array}{l}3,551 \\
0.44\end{array}$ & $\begin{array}{l}3,551 \\
0.53\end{array}$ & $\begin{array}{l}3,551 \\
0.49\end{array}$ \\
\hline $\begin{array}{l}\text { Partial R-squared } \\
\text { Shea Partial R-squared }\end{array}$ & $\begin{array}{l}0.019 \\
0.010\end{array}$ & $\begin{array}{l}0.019 \\
0.010\end{array}$ & $\begin{array}{l}\text { Firs } \\
0.019 \\
0.030\end{array}$ & $\begin{array}{l}\text { age Regres } \\
0.019 \\
0.030\end{array}$ & $\begin{array}{c}\text { Statistics: } M \\
0.019 \\
0.025\end{array}$ & $\begin{array}{l}0.019 \\
0.025\end{array}$ & $\begin{array}{l}0.019 \\
0.021\end{array}$ & $\begin{array}{l}0.019 \\
0.021\end{array}$ \\
\hline $\begin{array}{c}\text { F-statistic } \\
p \text {-value }\end{array}$ & $\begin{array}{l}15.06^{* * *} \\
0.000\end{array}$ & $\begin{array}{l}5.89 * * * \\
0.001\end{array}$ & $\begin{array}{l}15.06^{* * *} \\
0.000\end{array}$ & $\begin{array}{l}5.89 * * * \\
0.001\end{array}$ & $\begin{array}{l}15.06^{* * *} \\
0.000\end{array}$ & $\begin{array}{l}5.89 * * * \\
0.001\end{array}$ & $\begin{array}{l}15.06^{* * *} \\
0.000\end{array}$ & $\begin{array}{l}5.89 * * * \\
0.001\end{array}$ \\
\hline $\begin{array}{l}\text { Partial R-squared } \\
\text { Shea Partial R-squared }\end{array}$ & $\begin{array}{l}0.012 \\
0.006\end{array}$ & $\begin{array}{l}0.012 \\
0.006\end{array}$ & $\begin{array}{l}\quad \text { First-S } \\
0.014 \\
0.022\end{array}$ & $\begin{array}{l}\text { Regressio } \\
0.014 \\
0.022\end{array}$ & $\begin{array}{c}\text { atistics: Marg } \\
0.011 \\
0.015\end{array}$ & $\begin{array}{l}F D \\
0.011 \\
0.015\end{array}$ & $\begin{array}{l}0.011 \\
0.012\end{array}$ & $\begin{array}{l}0.011 \\
0.012\end{array}$ \\
\hline $\begin{array}{l}\text { F-statistic } \\
p \text {-value }\end{array}$ & $\begin{array}{l}9.39 * * * \\
0.000\end{array}$ & $\begin{array}{l}5.43^{* * *} \\
0.001\end{array}$ & $\begin{array}{l}10.86^{* * *} \\
0.000\end{array}$ & $\begin{array}{l}4.92 * * * \\
0.002\end{array}$ & $\begin{array}{l}8.73 * * * \\
0.000\end{array}$ & $\begin{array}{l}4.28 * * * \\
0.005\end{array}$ & $\begin{array}{l}8.68 * * * \\
0.000\end{array}$ & $\begin{array}{l}5.43 * * * \\
0.001\end{array}$ \\
\hline & CapEx & CapEx & CapEx & CapEx & CapEx & CapEx & CapEx & CapEx \\
\hline & \multicolumn{2}{|c|}{ Private Credit } & \multicolumn{2}{|c|}{ Market Capitalization } & \multicolumn{2}{|c|}{ Market Value Traded } & \multicolumn{2}{|c|}{ Accounting Standards } \\
\hline Margin & $\begin{array}{l}-1.408^{* *} \\
(0.627)\end{array}$ & $\begin{array}{l}-1.869^{*} \\
(1.018)\end{array}$ & $\begin{array}{l}-0.613 * * \\
(0.276)\end{array}$ & $\begin{array}{l}-0.610^{* *} \\
(0.309)\end{array}$ & $\begin{array}{l}-0.849 * * \\
(0.384)\end{array}$ & $\begin{array}{l}-0.784^{*} \\
(0.415)\end{array}$ & $\begin{array}{l}-1.740^{* *} \\
(0.682)\end{array}$ & $\begin{array}{l}-1.740^{* *} \\
(0.818)\end{array}$ \\
\hline Margin * FD & $\begin{array}{l}1.570 * \\
(0.898)\end{array}$ & $\begin{array}{l}2.031 \\
(1.320)\end{array}$ & $\begin{array}{l}2.038 \\
(1.631)\end{array}$ & $\begin{array}{l}2.829 \\
(1.818)\end{array}$ & $\begin{array}{l}5.992 \\
(3.738)\end{array}$ & $\begin{array}{l}6.120 \\
(3.771)\end{array}$ & $\begin{array}{l}3.285 * * \\
(1.600)\end{array}$ & $\begin{array}{l}3.293 \\
(2.152)\end{array}$ \\
\hline $\begin{array}{l}\text { Sargan statistic } \\
\text { p-value }\end{array}$ & $\begin{array}{l}2.871^{*} \\
0.090\end{array}$ & - & $\begin{array}{l}3.683^{*} \\
0.055\end{array}$ & - & $\begin{array}{l}0.762 \\
0.383\end{array}$ & - & $\begin{array}{l}0.001 \\
0.974\end{array}$ & - \\
\hline $\begin{array}{l}\text { Hansen J statistic } \\
\text { p-value }\end{array}$ & - & $\begin{array}{l}1.773 \\
0.183\end{array}$ & $\begin{array}{l}- \\
-\end{array}$ & $\begin{array}{l}2.160 \\
0.142\end{array}$ & - & $\begin{array}{l}0.398 \\
0.528\end{array}$ & - & $\begin{array}{l}0.000 \\
0.982\end{array}$ \\
\hline $\begin{array}{l}\mathrm{N} \\
\mathrm{R} \text {-squared }\end{array}$ & $\begin{array}{l}7,483 \\
0.77\end{array}$ & $\begin{array}{l}7,483 \\
0.70\end{array}$ & $\begin{array}{l}7,483 \\
0.74\end{array}$ & $\begin{array}{l}7,483 \\
0.59\end{array}$ & $\begin{array}{l}7,483 \\
0.60\end{array}$ & $\begin{array}{l}7,483 \\
0.58\end{array}$ & $\begin{array}{l}6,876 \\
0.79\end{array}$ & $\begin{array}{l}6,876 \\
0.79\end{array}$ \\
\hline & \multicolumn{8}{|c|}{ First-Stage Regression Statistics: Margin } \\
\hline $\begin{array}{l}\text { Partial R-squared } \\
\text { Shea Partial R-squared }\end{array}$ & $\begin{array}{l}0.006 \\
0.003\end{array}$ & $\begin{array}{l}0.006 \\
0.003\end{array}$ & $\begin{array}{l}0.006 \\
0.006\end{array}$ & $\begin{array}{l}0.006 \\
0.006\end{array}$ & $\begin{array}{l}0.006 \\
0.004\end{array}$ & $\begin{array}{l}0.006 \\
0.004\end{array}$ & $\begin{array}{l}0.005 \\
0.008\end{array}$ & $\begin{array}{l}0.005 \\
0.008\end{array}$ \\
\hline $\begin{array}{c}\text { F-statistic } \\
\text { p-value }\end{array}$ & $\begin{array}{l}9.91 * * * \\
0.000\end{array}$ & $\begin{array}{l}3.21 * * \\
0.023\end{array}$ & $\begin{array}{l}9.91 * * * \\
0.000\end{array}$ & $\begin{array}{l}3.21 * * \\
0.023\end{array}$ & $\begin{array}{l}9.91 * * * \\
0.000\end{array}$ & $\begin{array}{l}3.21 * * \\
0.023\end{array}$ & $\begin{array}{l}6.95^{* * *} \\
0.000\end{array}$ & $\begin{array}{l}2.16^{*} \\
0.091\end{array}$ \\
\hline & \multicolumn{8}{|c|}{ First-Stage Regression Statistics: Margin * FD } \\
\hline $\begin{array}{l}\text { Partial R-squared } \\
\text { Shea Partial R-squared }\end{array}$ & $\begin{array}{l}0.004 \\
0.002\end{array}$ & $\begin{array}{l}0.004 \\
0.002\end{array}$ & $\begin{array}{l}0.001 \\
0.001\end{array}$ & $\begin{array}{l}0.001 \\
0.001\end{array}$ & $\begin{array}{l}0.001 \\
0.001\end{array}$ & $\begin{array}{l}0.001 \\
0.001\end{array}$ & $\begin{array}{l}0.002 \\
0.004\end{array}$ & $\begin{array}{l}0.002 \\
0.004\end{array}$ \\
\hline $\begin{array}{c}\text { F-statistic } \\
p \text {-value }\end{array}$ & $\begin{array}{l}6.24 * * * \\
0.000\end{array}$ & $\begin{array}{l}1.67 \\
0.172\end{array}$ & $\begin{array}{l}1.18 \\
0.314\end{array}$ & $\begin{array}{l}0.68 \\
0.564\end{array}$ & $\begin{array}{l}1.97 \\
0.116\end{array}$ & $\begin{array}{l}1.00 \\
0.392\end{array}$ & $\begin{array}{l}3.07 * * \\
0.027\end{array}$ & $\begin{array}{l}0.82 \\
0.486\end{array}$ \\
\hline
\end{tabular}

Note: The data and the equation specification are analogous to the ones used in Table 5 except here I interact 'Margin' with continuous measures of financial development (see Table 2). The dependent variable in the first (second) panel is 'R\&D' ('CapEx'). 'Margin' and 'Margin * FD' are instrumented using the EU 'Single Market Programme' variables described in Table 4. The estimated specifications (1), (3), (5), and (7) use the GMM estimator with autocorrelationconsistent and heteroskedastic-and-autocorrelation-consistent standard errors; specifications (2), (4), (6), and (8) use the GMM estimator with standard errors clustered at the country-industry level. Sargan (Hansen J) statistic corresponds to tests of overidentifying restrictions. (Shea) Partial R-squared is for the EU 'Single Market Programme' variables in the first-stage regressions; similarly, F-statistic is the test of the joint significance of these variables in the first-stage regressions. See the Data Appendix for complete definitions and sources of variables. I remove outliers by using the 1-to-99 percentile range of the dependent variable. I always control for 3-digit-NACE industry, country, and year dummies, not shown. Standard errors are reported in parentheses; *, **, and *** denote significance at the $10 \%, 5 \%$, and $1 \%$ level, respectively. 
Table A.4

'Intense' Competition: Financial Development (FD) Continuous Interaction Specification

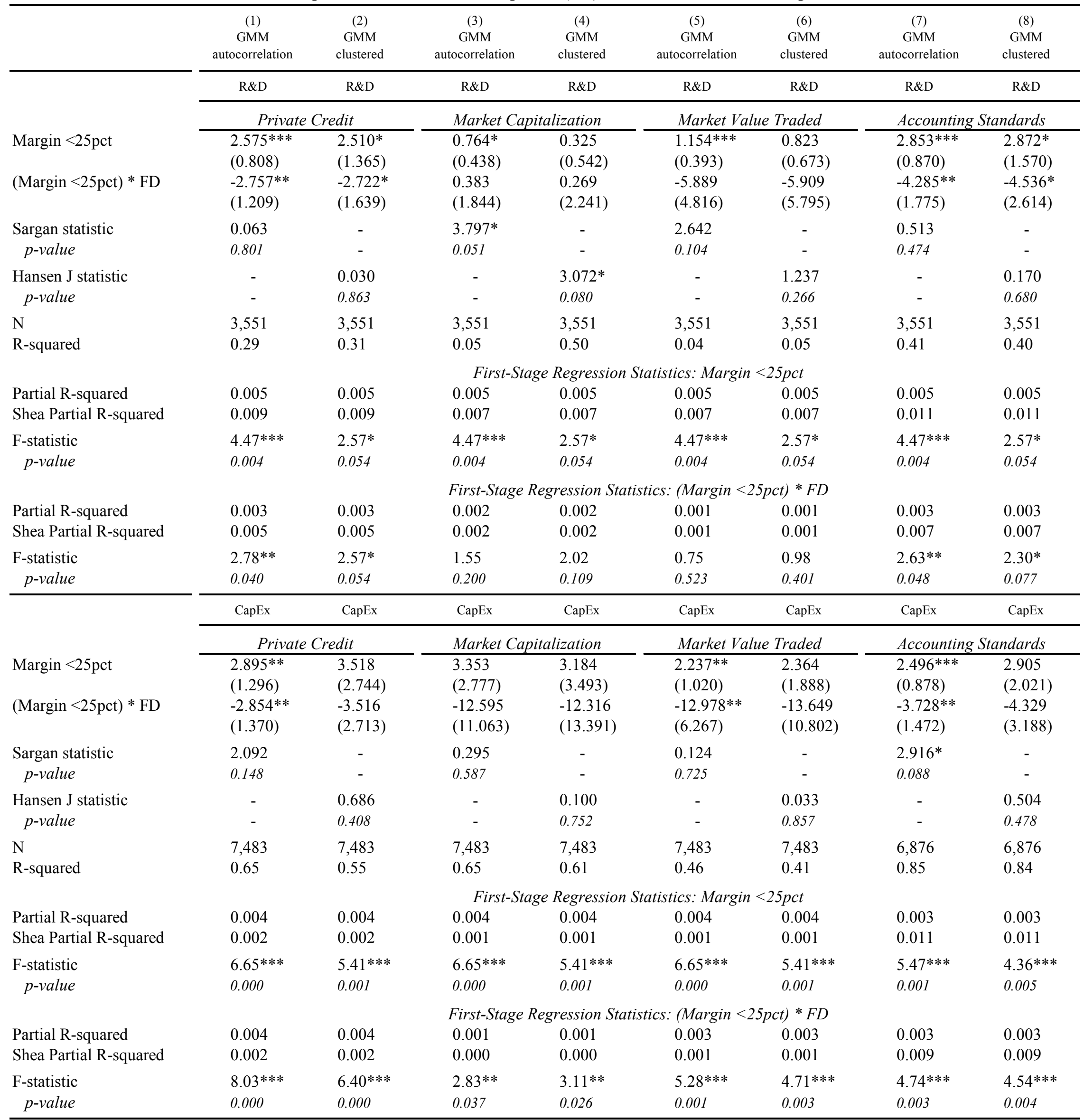

Note: The data are the same as in Table 5. The dependent variable in the top (bottom) panel is 'R\&D' ('CapEx'). 'Margin $<25 \mathrm{pct}$ ' stands for 0 to 25 percent of the 'Margin' variable, '(Margin $<25 \mathrm{pct})$ * FD' stands for 0 to 25 percent of the 'Margin' variable interacted with continuous measures of financial development (see Table 2). 'Margin <25pct' and '(Margin <25pct) * FD' are instrumented using the EU 'Single Market Programme' variables described in Table 4. The estimated specifications (1), (3), (5), and (7) use the GMM estimator with autocorrelation-consistent and heteroskedastic-and-autocorrelation-consistent standard errors; specifications (2), (4), (6), and (8) use the GMM estimator with standard errors clustered at the country-industry level. Sargan (Hansen J) statistic corresponds to tests of overidentifying restrictions. (Shea) Partial R-squared is for the EU 'Single Market Programme' variables in the first-stage regressions; similarly, F-statistic is the test of the joint significance of these variables in the first-stage regressions. See the Data Appendix for complete definitions and sources of variables. I remove outliers by using the 1-to-99 percentile range of the dependent variable. I always control for 3-digit-NACE industry, country, and year dummies, not shown. Standard errors are reported in parentheses; *, **, and *** denote significance at the $10 \%, 5 \%$, and $1 \%$ level, respectively. 
Table A.5

'Relaxed' Competition: Financial Development (FD) Continuous Interaction Specification

\begin{tabular}{|c|c|c|c|c|c|c|c|c|}
\hline & $\begin{array}{c}(1) \\
\text { GMM } \\
\text { autocorrelation }\end{array}$ & $\begin{array}{c}(2) \\
\text { GMM } \\
\text { clustered }\end{array}$ & $\begin{array}{c}(3) \\
\text { GMM } \\
\text { autocorrelation }\end{array}$ & $\begin{array}{c}(4) \\
\text { GMM } \\
\text { clustered }\end{array}$ & $\begin{array}{c}(5) \\
\text { GMM } \\
\text { autocorrelation }\end{array}$ & $\begin{array}{c}(6) \\
\text { GMM } \\
\text { clustered }\end{array}$ & $\begin{array}{c}(7) \\
\text { GMM } \\
\text { autocorrelation }\end{array}$ & $\begin{array}{c}(8) \\
\text { GMM } \\
\text { clustered }\end{array}$ \\
\hline & $\mathrm{R} \& \mathrm{D}$ & $\mathrm{R} \& \mathrm{D}$ & $\mathrm{R} \& \mathrm{D}$ & $\mathrm{R} \& \mathrm{D}$ & $\mathrm{R} \& \mathrm{D}$ & $\mathrm{R} \& \mathrm{D}$ & $\mathrm{R} \& \mathrm{D}$ & $\mathrm{R} \& \mathrm{D}$ \\
\hline & \multicolumn{2}{|c|}{ Private Credit } & \multicolumn{2}{|c|}{ Market Capitalization } & \multicolumn{2}{|c|}{ Market Value Traded } & \multicolumn{2}{|c|}{ Accounting Standards } \\
\hline Margin $>50 \mathrm{pct}$ & $\begin{array}{l}-0.478^{* *} \\
(0.228)\end{array}$ & $\begin{array}{l}-0.485^{* *} \\
(0.228)\end{array}$ & $\begin{array}{l}-0.365^{* * *} \\
(0.098)\end{array}$ & $\begin{array}{l}-0.401 * * \\
(0.168)\end{array}$ & $\begin{array}{l}-0.360 * * * \\
(0.094)\end{array}$ & $\begin{array}{l}-0.395 * * \\
(0.162)\end{array}$ & $\begin{array}{l}-0.449 * * \\
(0.189)\end{array}$ & $\begin{array}{l}-0.462 * * \\
(0.208)\end{array}$ \\
\hline$($ Margin $>50 \mathrm{pct}) * \mathrm{FD}$ & $\begin{array}{l}0.236 \\
(0.376)\end{array}$ & $\begin{array}{l}0.229 \\
(0.315)\end{array}$ & $\begin{array}{l}0.083 \\
(0.177)\end{array}$ & $\begin{array}{l}0.087 \\
(0.151)\end{array}$ & $\begin{array}{l}0.199 \\
(0.407)\end{array}$ & $\begin{array}{l}0.205 \\
(0.341)\end{array}$ & $\begin{array}{l}0.249 \\
(0.403)\end{array}$ & $\begin{array}{l}0.240 \\
(0.342)\end{array}$ \\
\hline $\begin{array}{l}\text { Sargan statistic } \\
\text { p-value }\end{array}$ & $\begin{array}{l}0.010 \\
0.919\end{array}$ & $\begin{array}{l}- \\
-\end{array}$ & $\begin{array}{l}0.155 \\
0.694\end{array}$ & - & $\begin{array}{l}0.137 \\
0.711\end{array}$ & $\begin{array}{l}- \\
-\end{array}$ & $\begin{array}{l}0.025 \\
0.873\end{array}$ & $\begin{array}{l}- \\
-\end{array}$ \\
\hline $\begin{array}{l}\text { Hansen J statistic } \\
\text { p-value }\end{array}$ & - & $\begin{array}{l}0.011 \\
0.917\end{array}$ & - & $\begin{array}{l}0.144 \\
0.705\end{array}$ & $\begin{array}{l}- \\
-\end{array}$ & $\begin{array}{l}0.127 \\
0.721\end{array}$ & $\begin{array}{l}- \\
-\end{array}$ & $\begin{array}{l}0.025 \\
0.875\end{array}$ \\
\hline $\begin{array}{l}\mathrm{N} \\
\mathrm{R} \text {-squared }\end{array}$ & $\begin{array}{l}3,551 \\
0.35\end{array}$ & $\begin{array}{l}3,551 \\
0.33\end{array}$ & $\begin{array}{l}3,551 \\
0.29\end{array}$ & $\begin{array}{l}3,551 \\
0.21\end{array}$ & $\begin{array}{l}3,551 \\
0.30\end{array}$ & $\begin{array}{l}3,551 \\
0.22\end{array}$ & $\begin{array}{l}3,551 \\
0.36\end{array}$ & $\begin{array}{l}3,551 \\
0.32\end{array}$ \\
\hline $\begin{array}{l}\text { Partial R-squared } \\
\text { Shea Partial R-squared }\end{array}$ & $\begin{array}{l}0.011 \\
0.013\end{array}$ & $\begin{array}{l}0.011 \\
0.013\end{array}$ & $\begin{array}{l}\quad \text { First-St } \\
0.011 \\
0.018\end{array}$ & $\begin{array}{l}\text { Regressior } \\
0.011 \\
0.018\end{array}$ & $\begin{array}{c}\text { tistics: Margi } \\
0.011 \\
0.016\end{array}$ & $\begin{array}{l}\text { Opct } \\
0.011 \\
0.016\end{array}$ & $\begin{array}{l}0.011 \\
0.028\end{array}$ & $\begin{array}{l}0.011 \\
0.028\end{array}$ \\
\hline $\begin{array}{l}\text { F-statistic } \\
\text { p-value }\end{array}$ & $\begin{array}{l}8.48 * * * \\
0.000\end{array}$ & $\begin{array}{l}3.62 * * \\
0.013\end{array}$ & $\begin{array}{l}8.48 * * * \\
0.000\end{array}$ & $\begin{array}{l}3.62 * * \\
0.013\end{array}$ & $\begin{array}{l}8.48 * * * \\
0.000\end{array}$ & $\begin{array}{l}3.62 * * \\
0.013\end{array}$ & $\begin{array}{l}8.48 * * * \\
0.000\end{array}$ & $\begin{array}{l}3.62 * * \\
0.013\end{array}$ \\
\hline $\begin{array}{l}\text { Partial R-squared } \\
\text { Shea Partial R-squared }\end{array}$ & $\begin{array}{l}0.006 \\
0.007\end{array}$ & $\begin{array}{l}0.006 \\
0.007\end{array}$ & $\begin{array}{c}\text { First-Stage } \\
0.011 \\
0.018\end{array}$ & $\begin{array}{l}\text { ression Stc } \\
0.011 \\
0.018\end{array}$ & $\begin{aligned} \text { ics: } & (\text { Margin }> \\
& 0.008 \\
& 0.013\end{aligned}$ & $\begin{array}{l}c t) * F D \\
0.008 \\
0.013\end{array}$ & $\begin{array}{l}0.006 \\
0.016\end{array}$ & $\begin{array}{l}0.006 \\
0.016\end{array}$ \\
\hline $\begin{array}{l}\text { F-statistic } \\
\text { p-value }\end{array}$ & $\begin{array}{l}4.68 * * * \\
0.003\end{array}$ & $\begin{array}{l}2.75 * * \\
0.042\end{array}$ & $\begin{array}{l}8.41 * * * \\
0.000\end{array}$ & $\begin{array}{l}4.36 * * * \\
0.005\end{array}$ & $\begin{array}{l}6.68 * * * \\
0.000\end{array}$ & $\begin{array}{l}3.15 * * \\
0.024\end{array}$ & $\begin{array}{l}4.73 * * * \\
0.003\end{array}$ & $\begin{array}{l}2.93 * * \\
0.033\end{array}$ \\
\hline & CapEx & CapEx & CapEx & CapEx & CapEx & CapEx & CapEx & CapEx \\
\hline & \multicolumn{2}{|c|}{ Private Credit } & \multicolumn{2}{|c|}{ Market Capitalization } & \multicolumn{2}{|c|}{ Market Value Traded } & \multicolumn{2}{|c|}{ Accounting Standards } \\
\hline Margin $>50 \mathrm{pct}$ & $\begin{array}{l}-1.099 * * \\
(0.501)\end{array}$ & $\begin{array}{l}-1.293 * \\
(0.745)\end{array}$ & $\begin{array}{l}-0.375^{* *} \\
(0.167)\end{array}$ & $\begin{array}{l}-0.439 \\
(0.281)\end{array}$ & $\begin{array}{l}-0.339 * * \\
(0.160)\end{array}$ & $\begin{array}{l}-0.283 \\
(0.283)\end{array}$ & $\begin{array}{l}-0.776^{* *} \\
(0.324)\end{array}$ & $\begin{array}{l}-0.783 * * \\
(0.379)\end{array}$ \\
\hline$($ Margin $>50 \mathrm{pct}) * \mathrm{FD}$ & $\begin{array}{l}1.154 \\
(0.742)\end{array}$ & $\begin{array}{l}1.332 \\
(0.998)\end{array}$ & $\begin{array}{l}0.140 \\
(0.883)\end{array}$ & $\begin{array}{l}0.605 \\
(1.299)\end{array}$ & $\begin{array}{l}1.702 \\
(1.801)\end{array}$ & $\begin{array}{l}2.575 \\
(2.403)\end{array}$ & $\begin{array}{l}1.554 \\
(1.401)\end{array}$ & $\begin{array}{l}1.500 \\
(2.374)\end{array}$ \\
\hline $\begin{array}{l}\text { Sargan statistic } \\
\text { p-value }\end{array}$ & $\begin{array}{l}0.592 \\
0.442\end{array}$ & $\begin{array}{l}- \\
-\end{array}$ & $\begin{array}{l}4.450 \\
0.035\end{array}$ & - & $\begin{array}{l}4.010 * * \\
0.045\end{array}$ & - & $\begin{array}{l}0.343 \\
0.558\end{array}$ & - \\
\hline $\begin{array}{l}\text { Hansen J statistic } \\
\text { p-value }\end{array}$ & - & $\begin{array}{l}0.251 \\
0.616\end{array}$ & - & $\begin{array}{l}1.387 \\
0.239\end{array}$ & $\begin{array}{l}- \\
-\end{array}$ & $\begin{array}{l}1.734 \\
0.188\end{array}$ & $\begin{array}{l}- \\
-\end{array}$ & \\
\hline $\begin{array}{l}\mathrm{N} \\
\mathrm{R} \text {-squared }\end{array}$ & $\begin{array}{l}7,483 \\
0.66\end{array}$ & $\begin{array}{l}7,483 \\
0.59\end{array}$ & $\begin{array}{l}7,483 \\
0.76\end{array}$ & $\begin{array}{l}7,483 \\
0.78\end{array}$ & $\begin{array}{l}7,483 \\
0.78\end{array}$ & $\begin{array}{l}7,483 \\
0.68\end{array}$ & $\begin{array}{l}6,876 \\
0.80\end{array}$ & $\begin{array}{l}6,876 \\
0.82\end{array}$ \\
\hline & \multicolumn{8}{|c|}{ First-Stage Regression Statistics: Margin >50pct } \\
\hline Partial R-squared & 0.002 & 0.002 & 0.002 & 0.002 & 0.002 & 0.002 & 0.001 & 0.001 \\
\hline Shea Partial R-squared & 0.002 & 0.002 & 0.004 & 0.004 & 0.004 & 0.004 & 0.011 & 0.011 \\
\hline $\begin{array}{c}\text { F-statistic } \\
p \text {-value }\end{array}$ & $\begin{array}{l}3.16^{* *} \\
0.024\end{array}$ & $\begin{array}{l}1.45 \\
0.226\end{array}$ & $\begin{array}{l}3.16^{* *} \\
0.024\end{array}$ & $\begin{array}{l}1.45 \\
0.226\end{array}$ & $\begin{array}{l}3.16^{* * *} \\
0.024\end{array}$ & $\begin{array}{l}1.45 \\
0.226\end{array}$ & $\begin{array}{l}2.22 * \\
0.084\end{array}$ & $\begin{array}{l}1.06 \\
0.363\end{array}$ \\
\hline & \multicolumn{8}{|c|}{ First-Stage Regression Statistics: $($ Margin $>50 p c t) * F D$} \\
\hline Partial R-squared & 0.001 & 0.001 & 0.000 & 0.000 & 0.000 & 0.000 & 0.000 & 0.000 \\
\hline Shea Partial R-squared & 0.001 & 0.001 & 0.001 & 0.001 & 0.001 & 0.001 & 0.001 & 0.001 \\
\hline F-statistic & 1.78 & 0.60 & 0.47 & 0.37 & 0.48 & 0.44 & 0.29 & 0.10 \\
\hline p-value & 0.149 & 0.613 & 0.702 & 0.775 & 0.693 & 0.725 & 0.833 & 0.960 \\
\hline
\end{tabular}

Note: The data are the same as in Table 5. The dependent variable in the top (bottom) panel is 'R\&D' ('CapEx'). 'Margin $>50$ pct' stands for 50 to 100 percent of the 'Margin' variable, '(Margin $>50 \mathrm{pct}$ ) * FD' stands for 50 to 100 percent of the 'Margin' variable interacted with continuous measures of financial development (see Table 2). 'Margin $>50$ pct' and '(Margin $>50 \mathrm{pct}$ ) * FD' are instrumented using the EU 'Single Market Programme' variables described in Table 4. The estimated specifications (1), (3), (5), and (7) use the GMM estimator with autocorrelation-consistent and heteroskedastic-and-autocorrelationconsistent standard errors; specifications (2), (4), (6), and (8) use the GMM estimator with standard errors clustered at the country-industry level. Sargan (Hansen J) statistic corresponds to tests of overidentifying restrictions. (Shea) Partial R-squared is for the EU 'Single Market Programme' variables in the firststage regressions; similarly, F-statistic is the test of the joint significance of these variables in the first-stage regressions. See the Data Appendix for complete definitions and sources of variables. I remove outliers by using the 1-to-99 percentile range of the dependent variable. I always control for 3-digit-NACE industry, country, and year dummies, not shown. Standard errors are reported in parentheses; *, **, and *** denote significance at the $10 \%, 5 \%$, and $1 \%$ level, respectively. 
Table A.6

ANOVAs: EU 'single-market' Countries in 1995-2004

\begin{tabular}{|c|c|c|c|c|c|c|}
\hline \multirow[b]{2}{*}{ Industry } & \multicolumn{2}{|c|}{ CapEx } & \multicolumn{2}{|c|}{ R\&D } & \multicolumn{2}{|c|}{ Margin } \\
\hline & $\begin{array}{l}15.77 \\
(101)\end{array}$ & $65 \%$ & $\begin{array}{l}10.10 \\
(101)\end{array}$ & $90 \%$ & $\begin{array}{l}38.80 \\
(101)\end{array}$ & $62 \%$ \\
\hline Country & $\begin{array}{l}7.19 \\
(10)\end{array}$ & $30 \%$ & $\begin{array}{r}0.96 \\
(7)\end{array}$ & $9 \%$ & $\begin{array}{r}23.27 \\
(10)\end{array}$ & $37 \%$ \\
\hline Year & $\begin{array}{l}1.13 \\
(10)\end{array}$ & $5 \%$ & $\begin{array}{l}0.01 \\
(10)\end{array}$ & $0 \%$ & $\begin{array}{l}0.60 \\
(10)\end{array}$ & $1 \%$ \\
\hline $\begin{array}{l}\text { Model } \\
\text { Total }\end{array}$ & $\begin{array}{l}24.11 \\
54.17\end{array}$ & $45 \%$ & $\begin{array}{l}11.16 \\
19.48\end{array}$ & $57 \%$ & $\begin{array}{r}62.79 \\
120.92\end{array}$ & $52 \%$ \\
\hline $\begin{array}{l}\mathrm{N} \\
\mathrm{R} \text {-squared }\end{array}$ & $\begin{array}{r}7,483 \\
0.44\end{array}$ & & $\begin{array}{r}3,551 \\
0.56\end{array}$ & & $\begin{array}{r}7,483 \\
0.51\end{array}$ & \\
\hline
\end{tabular}

Note: The Table presents three-factor (Industry, Country, Year) ANOVAs of 'CapEx', 'R\&D', and 'Margin' for 10 EU countries that participated in the EU 'Single Market Programme' at its inception in 1993 (see Table 1). Numbers in cells refer to the partial sum of squares while the numbers in parentheses refer to the number of indicators. Percentages show the fraction of the model's (total) variation explained by a given factor (model). I remove outliers by using the 1-to-99 percentile range of the dependent variable. All factors are significant at the $1 \%$ level, $p$-values not shown. See the Data Appendix for complete definitions and sources of variables. 
Table A.7

First-Stage: Competition and the EU 'Single Market Programme' (SMP) Instruments

\begin{tabular}{|c|c|c|c|c|}
\hline & $\begin{array}{c}\text { (1) } \\
\text { OLS } \\
\text { robust }\end{array}$ & $\begin{array}{c}(2) \\
\text { OLS } \\
\text { robust }\end{array}$ & $\begin{array}{c}(3) \\
\text { OLS } \\
\text { robust }\end{array}$ & $\begin{array}{c}(4) \\
\text { OLS } \\
\text { robust }\end{array}$ \\
\hline & Margin & Margin & Margin & Margin \\
\hline Affected Industries Classified as SMP Group 1 & $\begin{array}{l}-0.003 \\
(0.004)\end{array}$ & & $\begin{array}{l}-0.002 \\
(0.004)\end{array}$ & \\
\hline Affected Industries Classified as SMP Group 2 & $\begin{array}{l}0.036 * * * \\
(0.009)\end{array}$ & $\begin{array}{l}0.036^{* * *} \\
(0.009)\end{array}$ & $\begin{array}{l}0.037 * * * \\
(0.009)\end{array}$ & $\begin{array}{l}0.037 * * * \\
(0.009)\end{array}$ \\
\hline Affected Industries Classified as SMP Group 3 & $\begin{array}{l}-0.011 * * * \\
(0.004)\end{array}$ & $\begin{array}{l}-0.011 * * * \\
(0.004)\end{array}$ & $\begin{array}{l}-0.010 * * \\
(0.004)\end{array}$ & $\begin{array}{l}-0.010^{* *} \\
(0.004)\end{array}$ \\
\hline Affected Industries Classified as SMP Group 4.1 & $\begin{array}{l}-0.013 * * * \\
(0.003)\end{array}$ & $\begin{array}{l}-0.013 * * * \\
(0.003)\end{array}$ & $\begin{array}{l}-0.014 * * * \\
(0.003)\end{array}$ & $\begin{array}{l}-0.014 * * * \\
(0.003)\end{array}$ \\
\hline Affected Industries Classified as SMP Group 4.2 & $\begin{array}{l}0.001 \\
(0.006)\end{array}$ & & $\begin{array}{l}-0.001 \\
(0.005)\end{array}$ & \\
\hline Affected Industries Classified as SMP Group 4.3 & $\begin{array}{l}-0.002 * * * \\
(0.001)\end{array}$ & $\begin{array}{l}-0.002 * * * \\
(0.001)\end{array}$ & $\begin{array}{l}-0.002 * * \\
(0.001)\end{array}$ & $\begin{array}{l}-0.002 * * \\
(0.001)\end{array}$ \\
\hline Industry dummies & Yes & Yes & No & No \\
\hline Country dummies & Yes & Yes & No & No \\
\hline Industry-year dummies & No & No & Yes & Yes \\
\hline Country-year dummies & No & No & Yes & Yes \\
\hline $\begin{array}{c}\text { F-statistic } \\
p \text {-value }\end{array}$ & $\begin{array}{l}8.67 * * * \\
0.000\end{array}$ & $\begin{array}{l}12.88^{* * * *} \\
0.000\end{array}$ & $\begin{array}{l}7.75^{* * *} \\
0.000\end{array}$ & $\begin{array}{l}11.55^{* * *} \\
0.000\end{array}$ \\
\hline Partial R-squared & 0.008 & 0.008 & 0.009 & 0.009 \\
\hline $\mathrm{N}$ & 7,483 & 7,483 & 7,483 & 7,483 \\
\hline R-squared & 0.52 & 0.52 & 0.58 & 0.58 \\
\hline
\end{tabular}

Note: The sample consists of 101 three-digit NACE manufacturing industries across 10 countries that participated in the EU 'Single Market Programme' (SMP) at its inception in 1993 (see Table 1) over the period 1995-2004. The dependent variable is 'Margin' while regressors are based on the EU 'Single Market Programme' variables described in Table 4. The 'Affected Industries Classified as SMP Group 1' variable is created as follows: First, I take 0/1 variables equal 1 for NACE 3-digit industry-country pairs from the list of 'SMP Group 1' industries identified (ex ante) to be affected by the introduction of the EU's 'Single Market Programme' in 1993 (EU-wide product market reform). Second, I interact the indicator variables with the percentage share of each affected industry in total manufacturing employment in each country (average over 1985-1987). The remaining EU 'Single Market Programme' regressors are defined analogously for 'SMP Group 2', 'SMP Group 3', 'SMP Group 4.1', 'SMP Group 4.2', and 'SMP Group 4.3' industry groups. Partial R-squared is for the EU 'Single Market Programme' variables; similarly, Fstatistic is the test of the joint significance of these variables. See the Data Appendix for complete definitions and sources of variables. I remove outliers by using the 1-to-99 percentile range of the dependent variable. In specifications (1) and (2) I control for 3-digit-NACE industry, country, and year dummies; in specification (3) and (4) I control for 3digit-NACE industry-year and country-year dummies, not shown. Standard errors are reported in parentheses; *,**, and $* * *$ denote significance at the $10 \%, 5 \%$, and $1 \%$ level, respectively. 
Table DA.1

Definition of Variables

VA

CapEx

R\&D

Margin

Affected Industries

Classified as

SMP Group 1

Affected Industries

Classified as

SMP Group 2

Affected Industries

Classified as

SMP Group 3

Affected Industries

Classified as

SMP Group 4.1
Industry-level Variables

Industry-country-year-level (period 1995-2004) value-added at factor cost (v12150). Valueadded is the difference between what was produced and what was used as "inputs" by production. It is the main indicator of the wealth created in a company. Source: Eurostat, Structural Business Statistics, Detailed data on all enterprises.

Industry-country-year-level (period 1995-2004) gross investment in tangible goods (v15110) divided by value-added (VA). Source: Eurostat, Structural Business Statistics, Detailed data on all enterprises.

Industry-country-year-level (period 1995-2004) total intra-mural R\&D expenditure (v22110) divided by value-added (VA). Total intra-mural expenditures are all expenditures for Research $\&$ Development undertaken within the company, regardless of the source of funds. Source: Eurostat, Structural Business Statistics, Detailed data on all enterprises.

Industry-country-year-level (period 1995-2004) gross operating surplus (v12170) divided by value-added (VA). Gross operating surplus is surplus generated by operating activities after the labor factor input has been recompensed. It is the balance available to the company which allows it to recompense the providers of funds and debt, to pay taxes, and eventually to finance all or part of its investment. Income and expenditure classified as financial or extraordinary in company accounts is excluded from the gross operating surplus. Source: Eurostat, Structural Business Statistics, Detailed data on all enterprises.

\section{EU 'Single Market Programme' Variables}

First, we take $0 / 1$ variables equal 1 for NACE 3-digit industry-country pairs identified ex-ante to be affected by the introduction of the EU 'Single Market Programme' (SMP) in 1993 (EUwide product market reform). The list of industries (denoted 'SMP Group 1 - Hightechnology, public-procurement markets') considered is: 322 - Manufacture of television and radio transmitters and apparatus for line telephony and line telegraphy; 331 - Manufacture of medical and surgical equipment and orthopaedic appliances. Second, we interact the indicator variables with the percentage share of each affected industry in total manufacturing employment in each country (average over 1985-1987). Source: Buigues et al. (1990), Table 26 of statistical Annex, p. XVI.

First, we take $0 / 1$ variables equal 1 for NACE 3-digit industry-country pairs identified ex-ante to be affected by the introduction of the EU 'Single Market Programme' (SMP) in 1993 (EUwide product market reform). The list of industries (denoted 'SMP Group 2: Traditional public-procurement and regulated markets (High price dispersion)') considered is: 159 Manufacture of beverages; 244 - Manufacture of pharmaceuticals, medicinal chemicals and botanical products; 282 - Manufacture of tanks, reservoirs and containers of metal; manufacture of central heating radiators and boilers; 283 - Manufacture of steam generators, except central heating hot water boilers; 342 - Manufacture of bodies (coachwork) for motor vehicles; manufacture of trailers and semi-trailers; 352 - Manufacture of railway, tramway locomotives, rolling stock. Second, we interact the indicator variables with the percentage share of each affected industry in total manufacturing employment in each country (average over 1985-1987). Source: Buigues et al. (1990), Table 26 of statistical Annex, p. XVI.

First, we take 0/1 variables equal 1 for NACE 3-digit industry-country pairs identified ex-ante to be affected by the introduction of the EU 'Single Market Programme' (SMP) in 1993 (EUwide product market reform). The list of industries (denoted 'SMP Group 3: Traditional public-procurement and regulated markets (Low price dispersion)') considered is: 155 Manufacture of dairy products; 156 - Manufacture of grain mill products, starches and starch products; 158 - Manufacture of other food products; 311 - Manufacture of electric motors, generators and transformers; 312 - Manufacture of electricity distribution and control apparatus; 313 - Manufacture of insulated wire and cable; 316 - Manufacture of electrical equipment n.e.c.; 321 - Manufacture of electronic valves and tubes and other electronic components. Second, we interact the indicator variables with the percentage share of each affected industry in total manufacturing employment in each country (average over 19851987). Source: Buigues et al. (1990), Table 26 of statistical Annex, p. XVI.

First, we take 0/1 variables equal 1 for NACE 3-digit industry-country pairs identified ex-ante to be affected by the introduction of the EU 'Single Market Programme' (SMP) in 1993 (EUwide product market reform). The list of industries (denoted 'SMP Group 4.1: Sectors with moderate non-tariff barriers (Consumer goods)') considered is: 181 - Manufacture of leather clothes; 182 - Manufacture of other wearing apparel and accessories; 221 - Publishing; 223 Reproduction of recorded media; 252 - Manufacture of plastic products;297 - Manufacture of domestic appliances n.e.c.; 323 - Manufacture of television and radio receivers, sound or video recording or reproducing apparatus and associated goods; 341 - Manufacture of motor vehicles; 362 - Manufacture of jewellery and related articles. Second, we interact the indicator variables with the percentage share of each affected industry in total manufacturing employment in each country (average over 1985-1987). Source: Buigues et al. (1990), Table 26 of statistical Annex, p. XVI. 
Affected Industries

Classified as

SMP Group 4.2

Affected Industries

Classified as

SMP Group 4.3
First, we take 0/1 variables equal 1 for NACE 3-digit industry-country pairs identified ex-ante to be affected by the introduction of the EU 'Single Market Programme' (SMP) in 1993 (EUwide product market reform). The list of industries (denoted 'SMP Group 4.2: Sectors with moderate non-tariff barriers (Investment goods)') considered is: 286 - Manufacture of cutlery, tools and general hardware; 291 - Manufacture of machinery for the production and use of mechanical power, except aircraft, vehicle and cycle engines; 292 - Manufacture of other general purpose machinery; 293 - Manufacture of agricultural and forestry machinery; 294 Manufacture of machine-tools (split into DK2941, DK2942 and DK2943 in NACE Rev.1.1); 295 - Manufacture of other special purpose machinery; 296 - Manufacture of weapons and ammunition; 351 - Building and repairing of ships and boats; 353 - Manufacture of aircraft and spacecraft. Second, we interact the indicator variables with the percentage share of each affected industry in total manufacturing employment in each country (average over 19851987). Source: Buigues et al. (1990), Table 26 of statistical Annex, p. XVI.

First, we take 0/1 variables equal 1 for NACE 3-digit industry-country pairs identified ex-ante to be affected by the introduction of the EU 'Single Market Programme' (SMP) in 1993 (EUwide product market reform). The list of industries (denoted 'SMP Group 4.3: Sectors with moderate non-tariff barriers (Intermediate goods)') considered is: 151 - Production, processing, preserving of meat, meat products; 171 - Preparation and spinning of textile fibres; 172 - Textile weaving; 174 - Manufacture of made-up textile articles, except apparel; 175 - Manufacture of other textiles; 193 - Manufacture of footwear; 241 - Manufacture of basic chemicals; 242 - Manufacture of pesticides and other agro-chemical products; 245 Manufacture of soap, detergents, cleaning, polishing; 246 - Manufacture of other chemical products; 251 - Manufacture of rubber products; 261 - Manufacture of glass and glass products; 262 - Manufacture of non-refractory ceramic goods other than for construction purposes; manufacture of refractory ceramic products; 263 - Manufacture of ceramic tiles and flags; 264 - Manufacture of bricks, tiles and construction products; 315 - Manufacture of lighting equipment and electric lamps; 332 - Manufacture of instruments and appliances for measuring, checking, testing, navigating and other purposes, except industrial process control equipment; 364 - Manufacture of sports goods; 365 - Manufacture of games and toys; 366 Miscellaneous manufacturing n.e.c.; 372 - Recycling of non-metal waste and scrap. Second, we interact the indicator variables with the percentage share of each affected industry in total manufacturing employment in each country (average over 1985-1987). Source: Buigues et al. (1990), Table 26 of statistical Annex, p. XVI.

Financial Development Country-level Measures

PCDMBANKOFINSTGDP Private credit by deposit money banks and other financial institutions to GDP. Average over the period 1990-1994. Source: The World Bank Financial Structure and Economic Development Database.

STMCAPGDP Stock market capitalization to GDP. Average over the period 1990-1994. Source: The World Bank Financial Structure and Economic Development Database.

STMTVTGDP Stock market total value traded to GDP. Average over the period 1990-1994. Source: The World Bank Financial Structure and Economic Development Database.

ACCOUNT Index created by examining and rating companies' 1990 annual reports on their inclusion or omission of 90 items in balance sheets and income statements and published by the Center for International Financial Analysis \& Research, Inc. The maximum is 90 while the minimum is 0. Source: The Center for International Financial Analysis \& Research, Inc.

FD High

$0 / 1$ variable, equal to 1 if a country has above-median value of financial development among the 10 countries that participated in the EU's 'Single Market Programme' at its inception in 1993. 'FD High' is constructed separately for each financial development measure listed above. Source: The World Bank Financial Structure and Economic Development Database.

FD Low

0/1 variable, equal to 1 if a country has below-median value of financial development among the 10 countries that participated in the EU's 'Single Market Programme' at its inception in 1993. 'FD Low' is constructed separately for each financial development measure listed above. Source: The World Bank Financial Structure and Economic Development Database. 